\title{
Leg symptoms after deep vein thrombosis : the complexity of a simple syndrome
}

Citation for published version (APA):

Kolbach, D. N. (2003). Leg symptoms after deep vein thrombosis : the complexity of a simple syndrome. [Doctoral Thesis, Maastricht University]. Universiteit Maastricht. https://doi.org/10.26481/dis.20031120dk

Document status and date:

Published: 01/01/2003

DOI:

$10.26481 / \mathrm{dis} .20031120 \mathrm{dk}$

Document Version:

Publisher's PDF, also known as Version of record

\section{Please check the document version of this publication:}

- A submitted manuscript is the version of the article upon submission and before peer-review. There can be important differences between the submitted version and the official published version of record.

People interested in the research are advised to contact the author for the final version of the publication, or visit the DOI to the publisher's website.

- The final author version and the galley proof are versions of the publication after peer review.

- The final published version features the final layout of the paper including the volume, issue and page numbers.

Link to publication

\footnotetext{
General rights rights.

- You may freely distribute the URL identifying the publication in the public portal. please follow below link for the End User Agreement:

www.umlib.nl/taverne-license

Take down policy

If you believe that this document breaches copyright please contact us at:

repository@maastrichtuniversity.nl

providing details and we will investigate your claim.
}

Copyright and moral rights for the publications made accessible in the public portal are retained by the authors and/or other copyright owners and it is a condition of accessing publications that users recognise and abide by the legal requirements associated with these

- Users may download and print one copy of any publication from the public portal for the purpose of private study or research.

- You may not further distribute the material or use it for any profit-making activity or commercial gain

If the publication is distributed under the terms of Article $25 \mathrm{fa}$ of the Dutch Copyright Act, indicated by the "Taverne" license above, 
Leg symptoms after deep vein thrombosis 


\section{ISBN 90-9017434-6}

O Dinanda N. Kolbach. Mastricht 2003

Vormgeving en druk: Datawyse / Universitaire Pers Mastricht Omslagontwerp: Geertjan van Zonneveld 


\title{
Leg symptoms after deep vein thrombosis
}

\author{
The complexity of a simple syndrome
}

\section{PROEFSCHRIFT}

ter verkrijging van de graad van doctor aan de Universiteit Maastricht, op gezag van de Rector Magnificus,

Prof.dr. A.C. Nieuwenhuijzen Kruseman volgens het besluit van het College van Decanen, in het openbaar te verdedigen op donderdag 20 november 2003 om 14.00 uur

door

Dinanda Nicolina Kolbach

geboren te Rijswijk (NBr) op 10 januari 1964 
Promotores

Prof.dr. M.H. Prins

Prof.dr. H.A.M. Neumann

Co-promotor

Dr. K. Hamulyák

Beoordelingscommissie

Prof.dr. P.M. Steijlen

Prof.dr. H.R. Büller (Universiteit van Amsterdam)

Prof.dr. H. ten Cate

Prof.dr. H. Partsch (Wilhelminen Hospital, Vienna, Austria)

Dr. J.S.G. Schouten 
"mamma's boekje" voor mijn mannen 



\section{Contents}

\section{Chapter 1}

General introduction and outline of this thesis

\section{PART ONE}

Diagnosis of the post-thrombotic syndrome

\section{Chapter 2}

A comprehensive guide to clinical diagnosis of venous leg symptoms

\section{Chapter 3}

Interobserver variation in reading ambulant venous pressure from invasive venous pressure curves. The need for clear guidelines

\section{Chapter 4}

Definitions of the post-thrombotic syndrome: $A$ comparison with invasive venous pressure measurement

\section{PART TWO}

Prevention and treatment of the post-thrombotic syndrome

\section{Chapter 5}

Therapy of acute deep vein thrombosis and prevention of the postthrombotic syndrome: A survey among dermatologists in the Netherlands

\section{Chapter 6}

Identifying inappropriate hospital stay in patients with venous

thromboembolism

\section{Chapter 7}

Cochrane review: Non-pharmaceutical measures for prevention of post-thrombotic syndrome

\section{Chapter 8}

Cochrane review: Compression therapy for treating stage I and II

(Widmer) post-thrombotic syndrome 


\section{PART THREE}

Pathophysiology of the post-thrombotic syndrome

\section{Chapter 9}

Recurrent leg ulcers in a young man with hyperhomocysteinemia,

factor V Leiden and impaired fibrinolysis

\section{Chapter 10}

Local endothelial function and leg symptoms after deep vein thrombosis

\section{Chapter 11}

Severity of venous insufficiency is related to the density of microvascular deposition of PAI-1, uPA and von Willebrand factor

\section{Chapter 12}

Epilogue and future research

Summary

Samenvatting

Dankwoord

Curriculum Vitae

List of publications 


\section{Chapter 1}

General introduction and outline of this thesis 


\section{GENERAL INTRODUCTION}

Venous thromboembolism is a frequent disorder in general medical practice, since it affects 1 to 2 out of every 1000 persons per year in the population. Considerable progress has been achieved over the last two decades in the diagnosis and management of deep vein thrombosis. The introduction of home treatment with low molecular weight heparin has changed the management of venous thromboembolism dramatically ${ }^{1}$. However, the tendency to treat the majority of patients with deep vein thrombosis at home carries an increasing risk for the neglect of the importance of the disease and its impact mediated by long-term sequelae such as the post-thrombotic syndrome. Residual damage inflicted to the deep veins might, together with other mechanisms, including hypercoagulable states, predispose patients to a high risk of recurrent deep vein thrombosis, as well as to a substantial risk of the clinical manifestation of the post-thrombotic syndrome. The clinical presentation of the post-thrombotic syndrome may vary from minor signs, including discomfort, pain, venous ectasia, skin discoloration, leg swelling and skin indurations to severe manifestations including venous leg ulceration. These signs and symptoms are clinically also known as chronic venous insufficiency. It is usually manifest within one year after the index deep vein thrombosis ${ }^{2,3}$. In the best studies on the risk of subsequent post-thrombotic syndrome, it became apparent that, based on the population incidence of deep vein thrombosis of the lower extremities of 1 in 1000 per year and a $20-50 \%$ risk, approximately 3000 to 8000 patients in the Netherlands will develop a post-thrombotic syndrome, annually. Ideally, patients who experience a deep vein thrombosis and are at risk of developing a (severe) post-thrombotic syndrome could be recognized and optimal measures could be taken to prevent this happening. Currently, we are far from this objective. Firstly, the definition of the post-thrombotic syndrome is unclear, and many proposed clinical scales are currently used, that have largely unknown measurement characteristics. Secondly and more importantly, a better understanding of the pathophysiological mechanisms underlying post-thrombotic complaints is important. Venous thrombus resolves itself naturally by a slow process of thrombolysis, organization and recanalization ${ }^{4,5}$. Accelerating this process may prevent the development of the post-thrombotic syndrome by reducing valvular damage and residual obstruction ${ }^{6}$. In this thesis about the post-thrombotic syndrome, various studies on the post-thrombotic syndrome are described that highlight the complexity of this syndrome which may seem quite simple at first glance. These studies are dedicated to the diagnosis, prevention, and treatment as well as to the pathophysiological mechanisms of this syndrome. 


\section{PART I}

\section{Diagnosis of post-thrombotic syndrome}

An overall definition of the post-thrombotic syndrome is lacking; the clinical diagnosis is based on the findings during physical examination and the patients' complaints, which together with the history of deep vein thrombosis, establishes the presence of the disorder. During the physical examination the clinical signs as described by Widmer remain the classical components of the post-thrombotic syndrome. All of the objective signs of chronic venous insufficiency that mark leg symptoms as due to this condition are located in the skin. Hence, it is important to have a good pictorial knowledge of the clinical features. Only clinical signs of chronic venous insufficiency are classified by Widmer, which makes it difficule to assess the actual clinical status of the patients and to describe the potentially beneficial effects of interventions.

Eventually, the need for a new definition became apparent. Therefore, a consensus meeting held in the early 1990 's led to the CEAP classification. The consensus meeting and broad implementation of the CEAP classification in the literature notwithstanding, different definitions are still used in practice. In all these definitions, clinical symptoms as well as objective signs are used.

Since the diagnosis of chronic insufficiency and thus that of the post-thrombotic syndrome are based on clinical phenomena alone, other disorders of anatomical structures in the leg can also give rise to those complaints. Symptoms such as leg swelling, pain and signs of inflammation are found in twisting injury, primary lymph-edema, cellulitis, erysipelas and miscellaneous other conditions of the skin, fascia and muscles. Those conditions can mimic venous disease, in which also pain, redness and leg swelling is found, i.e. hypodermitis, this accounts for an acute stage of lipodermatosclerosis, or secundary lymphedema due to longstanding venous insufficiency with dermal backflow. In chapter 2 , a comprehensive guide for diagnosis of clinical signs is given, to get a better impression of definitions.

In chapter 3, we focus on at which point the ambulant venous pressure, (i.e. the gold standard) should be read according to different sources. In chapter 4, clinical definitions of post-thrombotic syndrome are compared to each other and to the gold standard. Their accuracy in allowing for discrimination between deep vein thrombosis and control legs, as well as the observed prevalence of the post-thrombotic syndrome is discussed. 


\section{GENERAL INTRODUCTION}

Venous thromboembolism is a frequent disorder in general medical practice, since it affects 1 to 2 out of every 1000 persons per year in the population. Considerable progress has been achieved over the last two decades in the diagnosis and management of deep vein thrombosis. The introduction of home treatment with low molecular weight heparin has changed the management of venous thromboembolism dramatically'. However, the tendency to treat the majority of patients with deep vein thrombosis at home carries an increasing risk for the neglect of the importance of the disease and its impact mediated by long-term sequelae such as the post-thrombotic syndrome. Residual damage inflicted to the deep veins might, together with other mechanisms, including hypercoagulable states, predispose patients to a high risk of recurrent deep vein thrombosis, as well as to a substantial risk of the clinical manifestation of the post-thrombotic syndrome. The clinical presentation of the post-thrombotic syndrome may vary from minor signs, including discomfort, pain, venous ectasia, skin discoloration, leg swelling and skin indurations to severe manifestations including venous leg ulceration. These signs and symptoms are clinically also known as chronic venous insufficiency, It is usually manifest within one year after the index deep vein thrombosis ${ }^{2.3}$. In the best studies on the risk of subsequent post-thrombotic syndrome, it became apparent that, based on the population incidence of deep vein thrombosis of the lower extremities of 1 in 1000 per year and a $20-50 \%$ risk, approximately 3000 to 8000 patients in the Netherlands will develop a post-thrombotic syndrome, annually. Ideally, patients who experience a deep vein thrombosis and are at risk of developing a (severe) post-thrombotic syndrome could be recognized and optimal measures could be taken to prevent this happening. Currently, we are far from this objective. Firstly, the definition of the post-thrombotic syndrome is unclear, and many proposed clinical scales are currently used, that have largely unknown measurement characteristics. Secondly and more importantly, a better understanding of the pathophysiological mechanisms underlying post-thrombotic complaints is important. Venous thrombus resolves itself naturally by a slow process of thrombolysis, organization and recanalization ${ }^{4.5}$. Accelerating this process may prevent the development of the post-thrombotic syndrome by reducing valvular damage and residual obstruction ${ }^{6}$. In this thesis about the post-thrombotic syndrome, various studies on the post-thrombotic syndrome are described that highlight the complexity of this syndrome which may seem quite simple at first glance. These studies are dedicated to the diagnosis, prevention, and treatment as well as to the pathophysiological mechanisms of this syndrome. 


\section{PART I}

\section{Diagnosis of post-thrombotic syndrome}

An overall definition of the post-thrombotic syndrome is lacking; the clinical diagnosis is based on the findings during physical examination and the patients' complaints, which together with the history of deep vein thrombosis, establishes the presence of the disorder. During the physical examination the clinical signs as described by Widmer remain the classical components of the post-thrombotic syndrome. All of the objective signs of chronic venous insufficiency that mark leg symptoms as due to this condition are located in the skin. Hence, it is important to have a good pictorial knowledge of the clinical features. Only clinical signs of chronic venous insufficiency are classified by Widmer, which makes it difficult to assess the actual clinical status of the patients and to describe the potentially beneficial effects of interventions.

Eventually, the need for a new definition became apparent. Therefore, a consensus meeting held in the early 1990 's led to the CEAP classification. The consensus meeting and broad implementation of the CEAP classification in the literature notwithstanding, different definitions are still used in practice. In all these definitions, clinical symptoms as well as objective signs are used.

Since the diagnosis of chronic insufficiency and thus that of the post-thrombotic syndrome are based on clinical phenomena alone, other disorders of anatomical structures in the leg can also give rise to those complaints. Symptoms such as leg swelling, pain and signs of inflammation are found in twisting injury, primary lymph-edema, cellulitis, erysipelas and miscellaneous other conditions of the skin, fascia and muscles. Those conditions can mimic venous disease, in which also pain, redness and leg swelling is found, i.e. hypodermitis, this accounts for an acute stage of lipodermatosclerosis, or secundary lymphedema due to longstanding venous insufficiency with dermal backflow. In chapter 2 , a comprehensive guide for diagnosis of clinical signs is given, to get a better impression of definitions.

In chapter 3, we focus on at which point the ambulant venous pressure, (i.e. the gold standard) should be read according to different sources. In chapter 4 , clinical definitions of post-thrombotic syndrome are compared to each other and to the gold standard. Their accuracy in allowing for discrimination between deep vein thrombosis and control legs, as well as the observed prevalence of the post-thrombotic syndrome is discussed. 


\section{PART II}

\section{Prevention and treatment of the post-thrombotic syndrome}

The aim of treatment of patients with venous thromboembolism is not just to prevent (fatal) pulmonary embolism, recurrent deep vein thrombosis, but also the development of the post-thrombotic syndrome. In this part we focused on the prevention of the post-thrombotic syndrome. In chapter 5 the results of a survey are described that evaluated the involvement of dermatologists in the treatment of deep vein thrombosis and post-thrombotic syndrome. In this survey, advice about bed rest for one or more days was still given. In addition, in chapter 6 , we evaluated inappropriate hospital stay in the past for patients with venous thromboembolism. The Dutch Appropriateness Evaluation Protocol criterion takes into account several factors involved in decisions about bed rest in order to provide guidelines to improve the efficiency of the hospital stay. In chapter 7 and 8 , systematic reviews are described to assess the efficacy of physical measurements in the prevention and treatment of the post-thrombotic syndrome.

\section{PART III}

\section{Pathophysiology of the post-thrombotic syndrome}

Deep vein thrombosis is an important cause of venous leg ulcers. In patients with venous leg ulcers a prevalence rate for thrombophilia of $41 \%$ was found, similar to the rate reported in deep vein thrombosis? ${ }^{7}$. The case report with combined thrombophilia, presented in chapter 9, made it plausible to hypothesize that post-thrombotic changes are more severe because the thrombosis was recurrent, more extensive, and possibly more resistant to endogenous fibrinolysis and recanalization. Adequate compression therapy alone was insufficient and tended to fail due to thrombophilia. It has been suggested that microthrombi play an important role in the pathogenesis of progressive venous insufficiency. The influence of venous hypertension on the vascular endothelial wall in patients with previous deep vein thrombosis as compared to age and gender matched subjects is presented in chapter 10.

During, the last two decades increasing progress has been made in delineating the pro- and anticoagulant properties of the vascular endothelial wall ${ }^{8}$. A simplified schematic representation of the coagulation system is shown in figure 1. Inhibition of thrombus formation of the endothelium is achieved by continuous production of prostacyclin and nitrous oxide, which inhibit platelet activation and lead to vasodilatation, as well as the heparin like molecule coating which enhances the inhibition of coagulation. In addition, the vascular endothelial wall produces pro-fibrinolytic factors and facilitates protein $\mathrm{C}$ activation by its surface bound thrombomodulin. Thrombin can bind to thrombomodulin, thereby losing its 


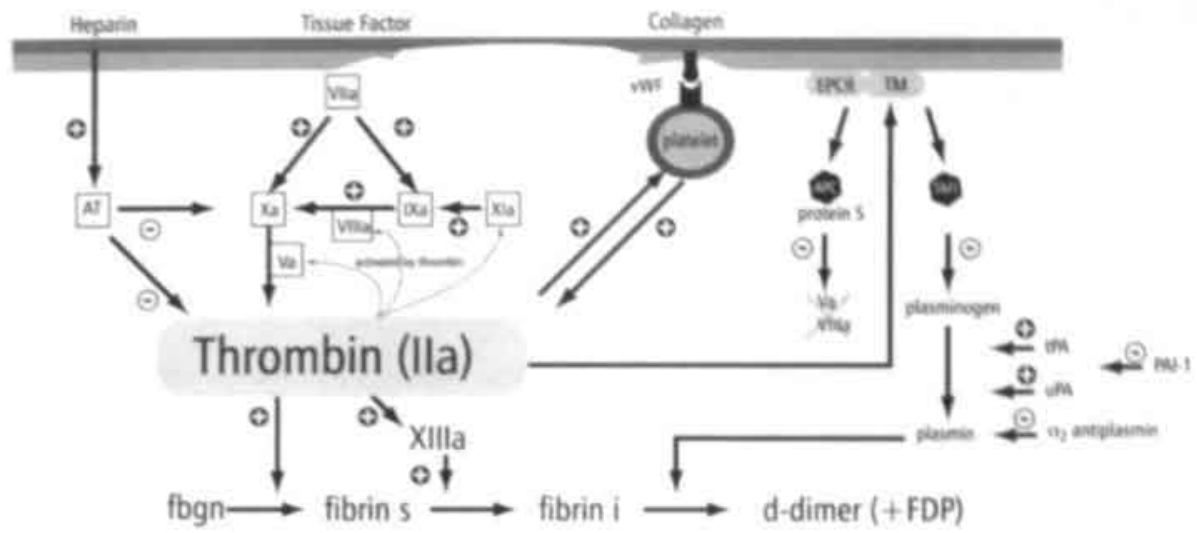

Figure 1 Vascular endothelial wall with a schematic representation of the coagulation system and fibrinolysis.

$\begin{array}{ll}\text { AT } & \begin{array}{l}\text { antithrombin } \\ \text { Fbgn }\end{array} \\ \text { fibrinogen } \\ \text { Fibrin i } & \text { insoluble fibrin } \\ \text { Fibrin s } & \text { soluble fibrin } \\ \text { FDP } & \text { fibrin and/or fibrinogen degradation products } \\ \text { vWF } & \text { von Willebrand factor } \\ \text { TM } & \text { thrombomodulin } \\ \text { EPCR } & \text { endothelial protein C receptor } \\ \text { TAFI } & \text { thrombin activated fibrinolysis inhibitor } \\ \text { PAI-1 } & \text { plasminogen activator inhibitor type 1 } \\ \text { uPA } & \text { urokinase type plasminogen activator } \\ \text { tPA } & \text { tissue type plasminogen activator } \\ \text { APC } & \text { activated protein C }\end{array}$

procoagulant properties and activating protein $\mathrm{C}$. This activated protein C (APC) forms a complex with its cofactor protein $\mathrm{S}$. This complex neutralizes factors $\mathrm{Va}$ and VIIIa, downregulating the thrombin formation. The fibrin deposit will be broken down by the fibrinolytic system shown in detail in figure 1 . The central enzyme is plasmin, formed from plasminogen by the action of tissue-type plasminogen activator (tPA) and urokinase-type plasminogen activator (uPA). Fibrinolysis is regulated by plasminogen activator inhibitors (PAl's), $\alpha_{2}$-antiplasmin, and by the thrombin activated inhibitor of fibrinolysis (TAFI).

In chapter 11 skin biopsies of different stages of venous insufficiency, immunostained with $\mathrm{vWF}, \mathrm{PAI}-1, \mathrm{uPA}$ and $\mathrm{PA}$ to get a better understanding of procoagulant and fibrinolytic response, are discussed. 


\section{REFERENCES}

1. Koopman MM, Prandoni P, Piovella F, Ockelford PA, Brandjes DP, van der Meer J, et al. Treatment of venous thrombosis with intravenous unfractionated heparin administered in the hospital as compared with subcutaneous low-molecular-weight heparin administered at home. The Tasman Study Group. N Engl J Med 1996;334:682-7.

2. Brandjes DP, Buller HR, Heijboer H, Huisman MV, de Rijk M, Jagt H, et al. Randomised trial of effect of compression stockings in patients with symptomatic proximal-vein thrombosis. Lancet 1997;349:759-62.

3. Prandoni P. Below-knee compression stockings for prevention of post-thrombotic syndrome in patients with proximal-vein thrombosis. In: ISTH 2003; Birmingham.

4. Sevitt S. The mechanisms of canalisation in deep vein thrombosis. J Pathol 1972;110:153-65.

5. Wakefield T, Linn M, Henke P, Kadell A, Wilke C. Wrobleski S, et al. Neovascularization during venous thrombosis organization: A preliminary study. Journal of Vascular Surgery 1999;30:885-893.

6. Meissner MH, Manzo RA, Bergelin RO, Markel A, Strandness DE, Jr. Deep venous insufficiency: the relationship between lysis and subsequent reflux. J Vasc Surg 1993;18:596-605; discussion 606-8.

7. Mackenzic RK, Ludlam CA, Ruckley CV, Allan PL, Burns P, Bradbury AW. The prevalence of thrombophilia in patients with chronic venous leg ulceration. J Vasc Surg 2002;35:718-22.

8. Colman RW. Hirsch J. Marder VJ. Clowes AW. Overview of Coagulation, Fibrinolysis, and Their Regulation. Chapter 2 In: Colman RW, Hirsch J, Marder VJ, Clowes AW. George JN ed. Hemostasis and Thrombosis. Basic Principles and Clinical Practice. 4th edition. 2001, Lippincott, Williams \& Wilkins. Philadelphia. 


\section{Chapter 2}

A comprehensive guide to clinical diagnosis of venous leg symptoms 


\section{DIAGNOSIS OF THE POST-THROMBOTIC SYNDROME}

The overall diagnosis of venous signs and symptoms is chronic venous insufficiency. Chronic venous insufficiency is either the result of deep and/or superficial valvular reflux, obstruction of the deep venous system or the combination of both aforementioned mechanisms. Either of these mechanisms alone can lead to sustained high venous pressure while walking.

The diagnosis of post-thrombotic syndrome is based on the findings made during physical examination and from the patients' complaints, which, together with the history of deep vein thrombosis, establishes the presence of the disorder.

To provide a better understanding of the post-thrombotic syndrome, we describe below the skin changes and present pictures of skin signs observed during physical examination of patients with venous complaints.

\section{Veins}

Venous circulation of the lower extremities consists of superficial and deep veins, which are connected by communicating veins. Communicating veins (perforantes) transport blood from the superficial to the deep venous system by means of valves. The superficial system originates from the dorsal venous arch of the foot. Changes observed comprise a wide spectrum of clinical severity varying from asymptomatic venous incompetence, telangiectases, reticular veins, varicose veins, stasis skin changes to the most severe presentation with leg ulceration.

Telangiectases (photo 1) are confluences of permanently dilated intradermal venules of less than $1 \mathrm{~mm}$ in caliber. Synonyms include spider veins, hyphen webs, thread veins and "besenreiser varices"

Reticular veins are permanently dilated; tortuous bluish intradermal veins with a diameter from $1 \mathrm{~mm}$ to less than $3 \mathrm{~mm}$. Synonyms include blue veins, intradermal varicose veins and venulectases.

Varicose veins (photo 2) are subcutaneous permanently dilated, tortuous veins equal to or more than $3 \mathrm{~mm}$ in diameter in the standing position. Synonyms include varix, varices and varicosities.

\section{Early signs in venous insufficiency}

A special form of teleangiectases can be seen in early stages of venous insufficiency. It is known among dermatologists and phlebologists as corona phlebectatica 


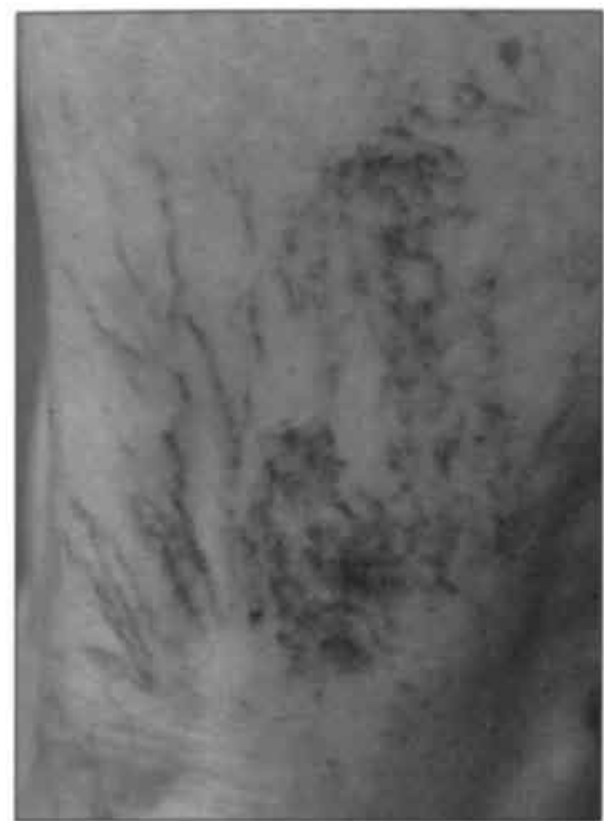

Photo 1 Telangiectases.

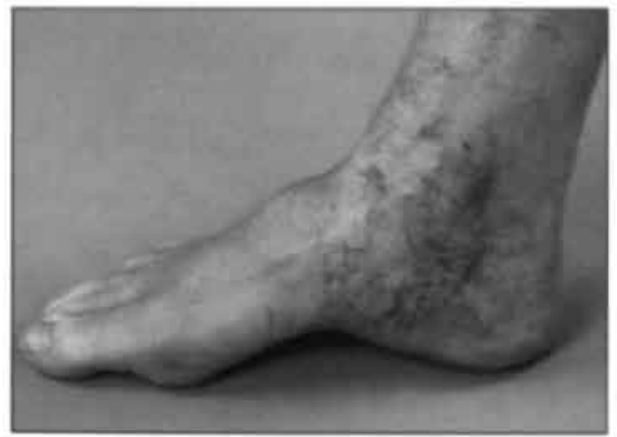

Photo 3 Corona phlebectatica paraplantaris.

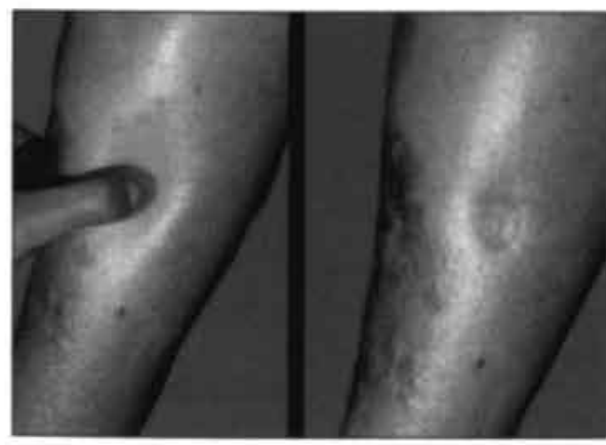

Photo 4 Pitting edema.

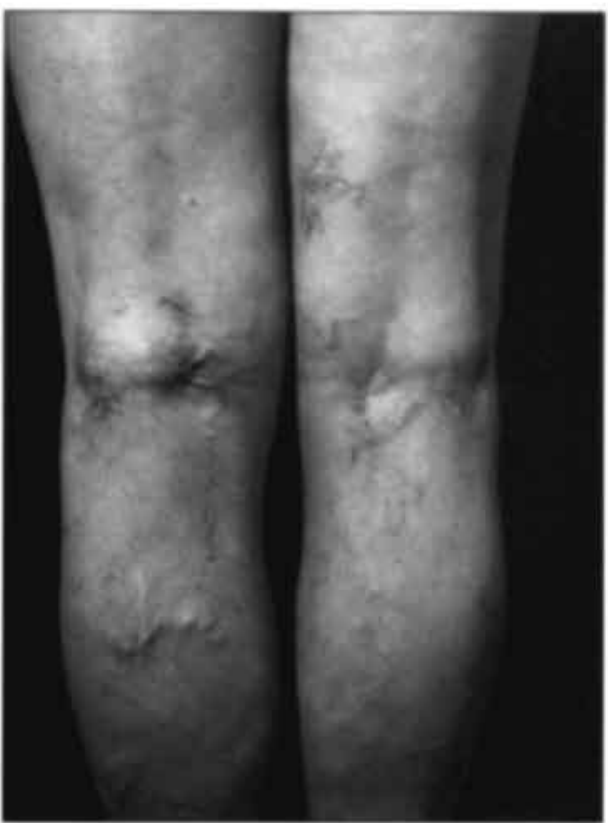

Photo 2 Varicose veins

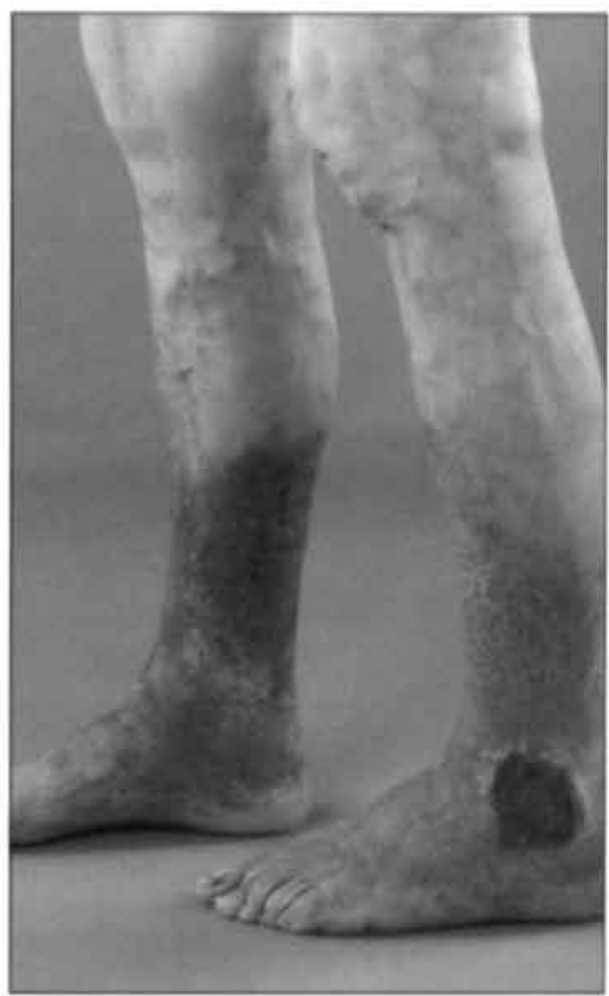

Photo 7 Lipodermatosclerous, leg uleer 


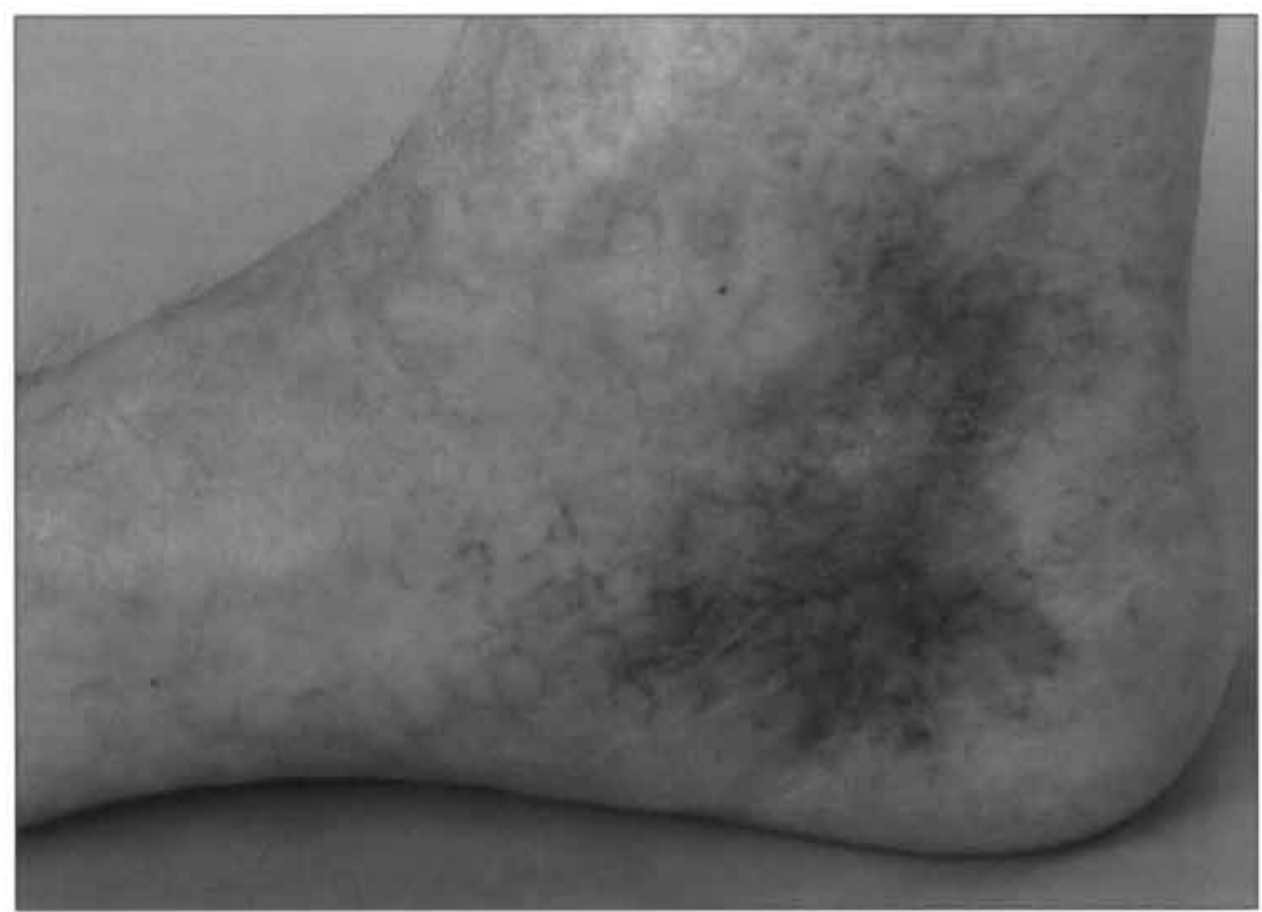

Photo 5 Dermatite jaune d'ocre.

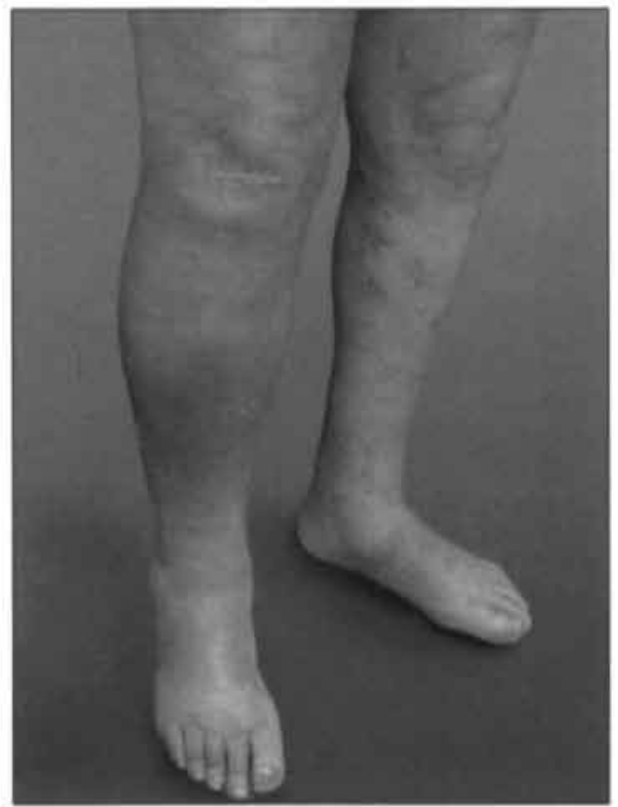

Photo 8 Hypodermitis, edema.

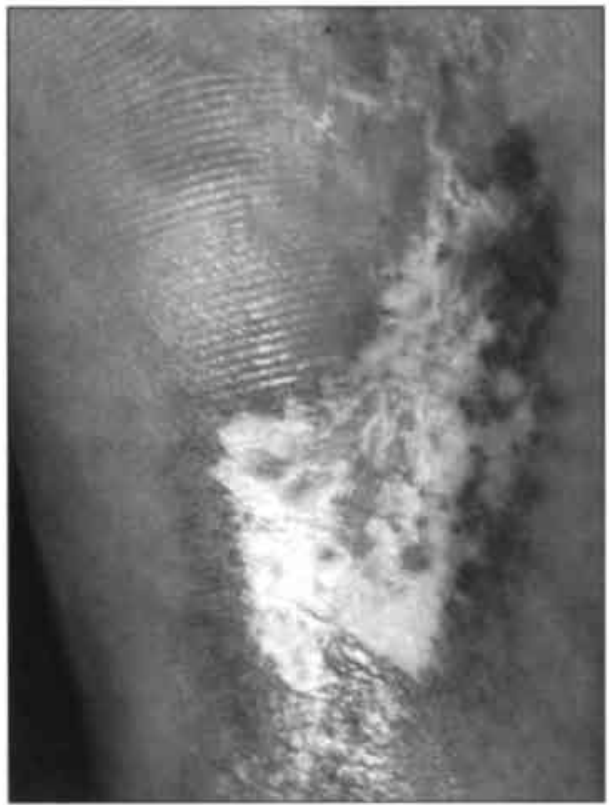

Photo 9 Atrophic blanche. 


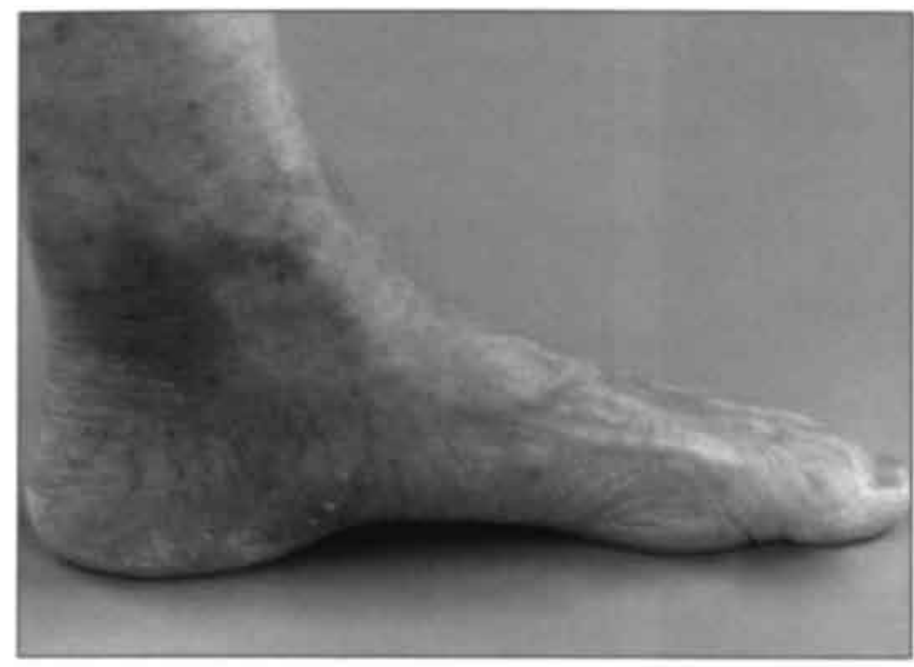

Photo 6

Eczema cruris.

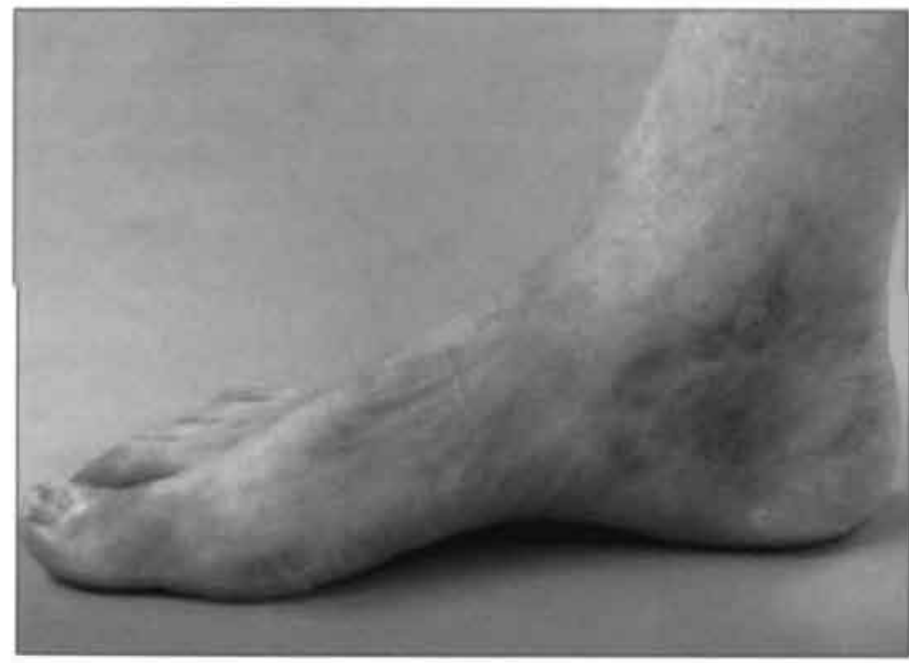

Photo 10

Healed venous leg uleer (scar).

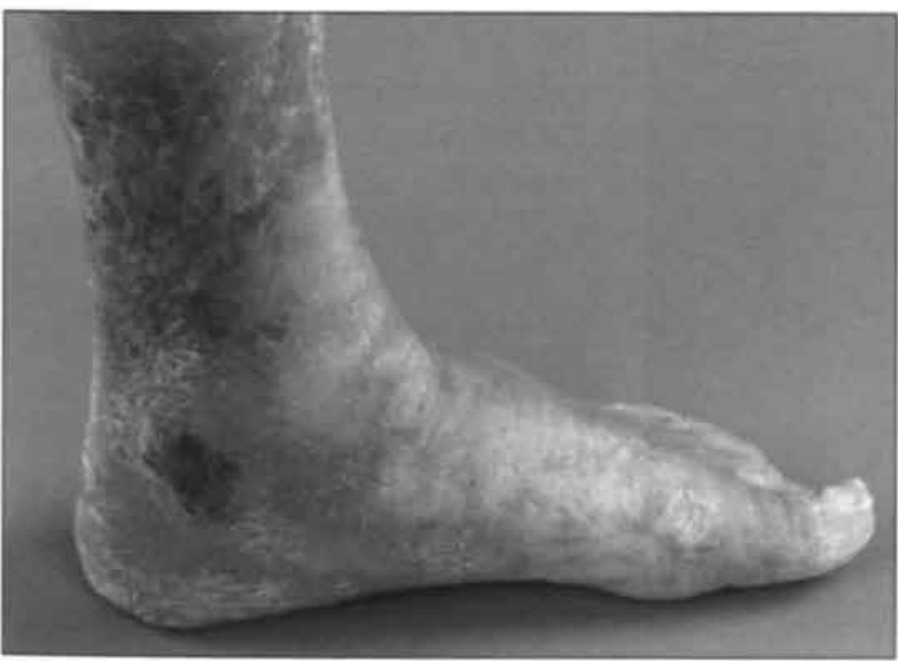

Photo 11

Venous leg ulcer, marked desquamation. 


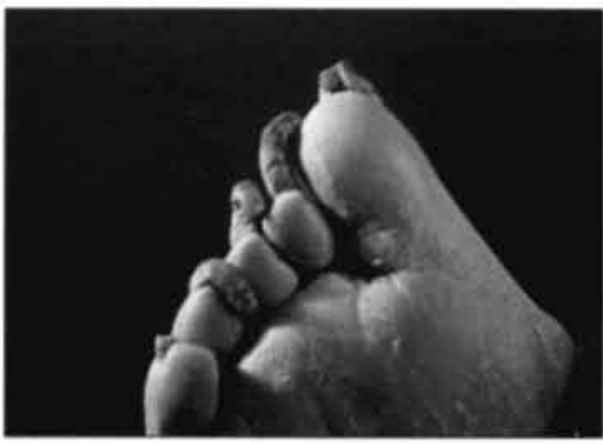

Photo 12 Onychogryphosis.

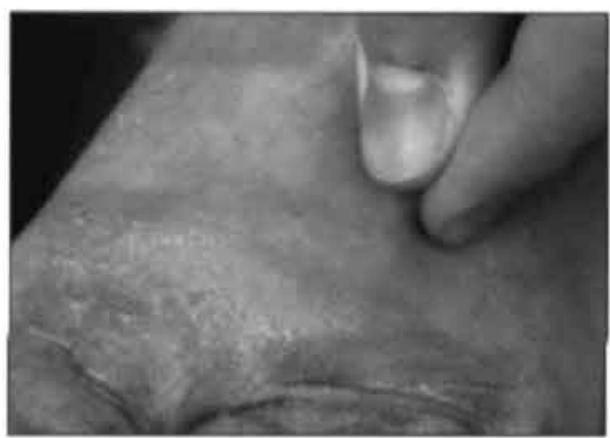

Photo 14 Lymph-edema, skin sign according to Stemmer.

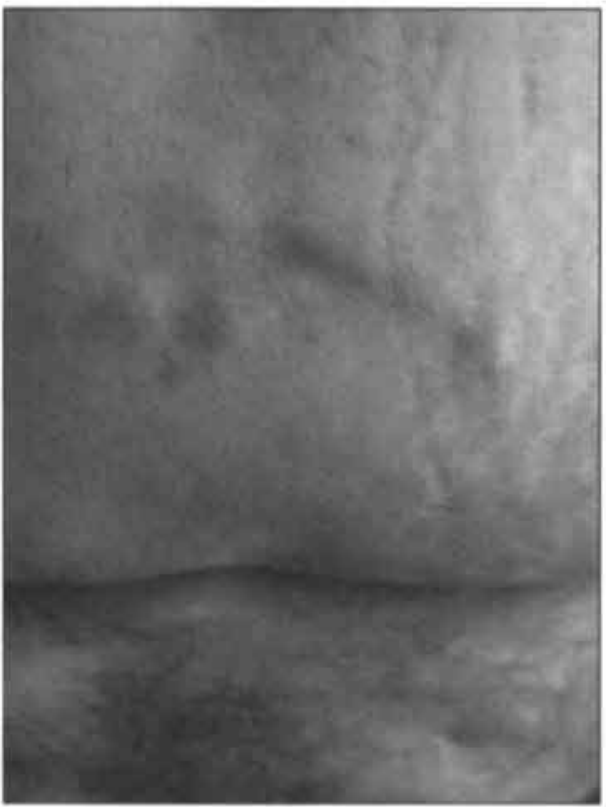

Photo 15 Suprapubre vances

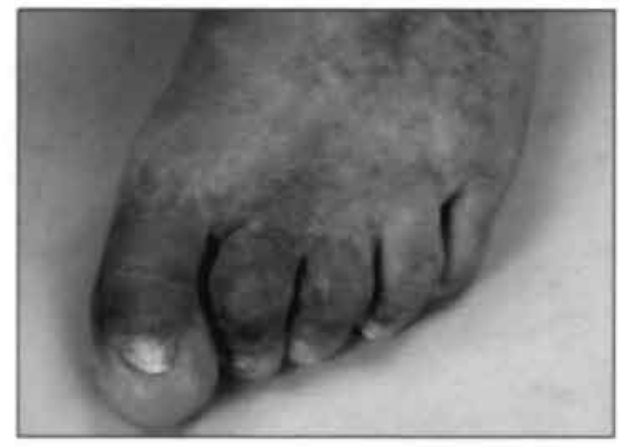

Photo 13 Acroangiodermatitis.

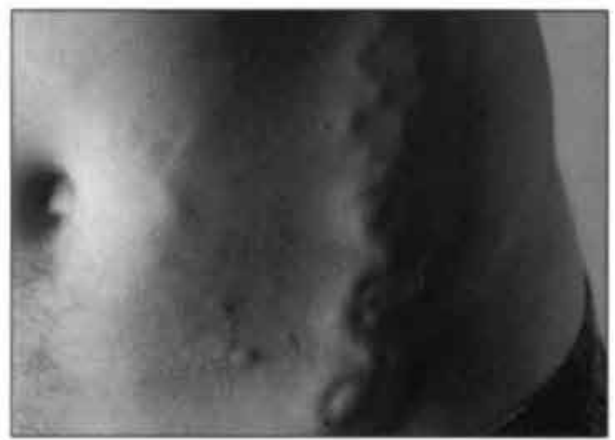

Photo 16 Superficial abdominal varices. 
paraplantaris (photo 3). Synonyms include malleolar flare and ankle flare, Corona phlebectatica paraplantaris are fan-shaped intradermal telangiectases found on the medial or lateral sides of the foot. This sign can be seen in combination with erythema. These two skin changes are seen in early stages of venous insufficiency. They are often accompanied by subclinical edema.

\section{Edema}

Edema is an increase in the volume of fluid in subcutaneous tissue characterized by indentation with pressure (photo 4 ). Venous edema usually occurs in the ankle region, but it may extend to the leg and foot.

\section{Pigmentation}

By pigmentation is generally meant a brownish pigment, a darkening of the skin, usually in the ankle region. Dermatite jaune docre (photo 5) is a yellow-brown colored pigmentation that appears before more extended pigmentation occurs.

\section{Eczema}

Eczema cruris (photo 6) is defined as erythematic, blistering, weeping, or scaling eruption of the skin of the leg often located near varicose veins. It mostly appears in more advanced stages of venous insufficiency, synonyms include stasis dermatitis.

\section{ADVANCED CHRONIC VENOUS INSUFFICIENCY}

\section{Lipodermatosclerosis}

Lipodermatosclerosis (photo 7) is a localized chronic induration of the skin, characterized by fibrosis and chronic inflammation of the skin, subcutaneous tissues and sometimes the fascia. Hypodermitis (photo 8) is an acute stage of lipodermatosclerosis, characterized by diffuse reddening and tenderness of the skin. Confusion with erysipelas or cellulitis can occur, but lymphadenitis and fever accompany these conditions. Sometimes even recurrence of deep vein thrombosis is diagnosed because of tenderness, pain, redness and edema. Compression echography can be interpreted wrongly, because an old thrombus can be seen in patients with prior deep vein thrombosis. Nothing is known about laboratory measurements such as d-dimer in these cases; it might be increased because of the acute phase reaction in the skin. 


\section{Atrophie blanche}

Atrophie blanche (photo 9) or white atrophy are circumscribed, whitish and atrophic skin areas surrounded by dilated capillary spots and some hyperpigmentation. Also scars of healed ulcers (photo 10) can give the same impression, but must be excluded in this definition.

\section{Venous ulcer}

Venous ulcer (photo 7,11) is a chronic defect of the skin that fails to heal spontaneously and which is caused by chronic venous insufficiency.

\section{Accompanying signs of chronic venous insufficiency}

In advanced chronic venous insufficiency, other changes in skin and skin appendices are also found, such as marked desquamation (photo 10), nail changes (photo 12), acroangiodermatitis (photo 13) and secondary lymph-edema (photo 14).

\section{Collateral formation}

Extensive deep vein thrombosis and subsequently persistant obstruction of major veins give rise to collateral formation. This can be seen as suprapubic varices (photo 15) usually one large vessel along the superior margin of the pubic bone, which crosses to the opposite site. In this way de Palma reconstructed a new venous route to relieve a deep vein insufficiency, so another name for it is spontaneous De Palma. Other collaterals are found as extensive superficial abdominal varices (photo 16). The presence of extensive collateral formation in the vertebral and the paravertebral venous system in aplasia of the inferior vena cava can be shown by Magnetic Resonance Imaging 


\section{Chapter 3}

\section{Interobserver variation in reading ambulant venous pressure from invasive venous pressure curves} The need for clear guidelines 


\section{ABSTRACT}

Objective To assess the inter-observer variation between 3 experts by reading AVP from graphs of intravenous pressure measurements.

Methods Invasive venous pressure measurement in a dorsal foot vein was performed in 38 legs with and 50 legs without a history of objectively diagnosed proximal deep vein thrombosis during a standardized exercise. Three experts independently estimated AVP from the pressure curves. Presence of post-thrombotic syndrome was determined for each leg according to the criteria of Prandoni.

Results For each observer the association between the presence of post-thrombotic syndrome and the level of AVP readings was statistically significant $(\mathrm{p}<0.001)$. Median AVP readings by the 3 experts for all graphs were $51.4,43.0$ and $32.2 \mathrm{mmHg}$, showing systematic differences in the way AVP was estimated. The random interobserver variation was expressed as the standard deviation of the differences in readings by a pair of experts. For the 3 pairs these standard deviations were 13,10 and $10 \mathrm{mmHg}$, respectively.

Conclusion Even though AVP readings from the 3 experts in this study seemed as correct as those reported in the literature, there is proof of large systematic and random errors in estimating AVP from intravenous pressure measurement graphs. It is likely that other phlebologists would show at least similarly large measurement error. In order to improve the situation, clear reading instructions should be devised, based on consensus between experts in the field of intravenous pressure measurements.

\section{INTRODUCTION}

Chronic venous insufficiency is characterized by symptoms or signs produced by venous hypertension. Sustained high venous pressure is the result of failure of the calf and foot muscle pump to adequately empty the veins of the lower extremity. This can be caused by valvular incompetence or destruction, venous obstruction, calf or foot muscle dysfunction or any combination of these factors.

Anatomical and functional information can be obtained by Duplex ultrasonography, which however, does not provide a quantitative measure of the calf and foot muscle pump function. Invasive ambulatory pressure measurement is therefore considered the 'gold standard' for the evaluation of other techniques to quantify the muscle pump function'.

In a study about prognostic factors for the development of the post-thrombotic syndrome we used a plethysmographic technique ${ }^{2}$ that was reported to have been validated against the 'gold standard ${ }^{3}$. When we tried to replicate this validation, it became apparent that reading the ambulant venous pressure (AVP) from the graphs was not as clear-cut as is suggested in textbooks ${ }^{4-11}$. To evaluate the importance of the consequent measurement error, we assessed the interobserver variations between 3 experts in determining the ambulant venous pressure in venous pressure curves. 


\section{METHODS}

In order to have a wide range of ambulant venous pressures, measurements were done in one or both legs of patients with a history of deep vein thrombosis (DVT) and in healthy volunteers. The patients who entered into the study had experienced their DVT more than one year before and the diagnosis of a proximal DVT had been confirmed by compression ultrasonography or ascending venography. Volunteers did not have any symptoms and/or signs of DVT or chronic venous insufficiency. Only mobile subjects were included. This study is part of a larger project that was approved by the institutional ethical review board of the Academic Hospital Maastricht. All subjects gave informed consent.

\section{Invasive venous pressure measurement}

Venous pressure was measured continuously using a 21 gauge $(0.8 \mathrm{~mm})$ butterfly needle (VYGON microflex ref 246.08) which was inserted into a vein on the dorsum of the foot ${ }^{6,12}$. The needle was connected to a computer via a pressure monitoring set (Edwards life sciences ref T100200A) and an amplifier. Pressure readings were taken every $2 \mathrm{msec}$ and stored in the computer. Pressure versus time graphs were visible on the computer screen and were printed out. Recordings of about 60 sec were made, starting with the subject in standing position while holding onto a frame. After stabilization of the pressure the subject was asked to make 10 tiptoe movements at the rate of 1 per 1.5 seconds, synchronously with a metronome. Then the subject had to stand still again until venous pressure had stabilized. If possible, the exercise was repeated once or twice. Some subjects participated in more than one measurement session.

\section{Ambulant venous pressure reading}

Printed graphs of the invasive venous pressure measurements were sent to three experts ( $\mathrm{MN}, \mathrm{JK}$ and $\mathrm{HP}$ ). These experts are phlebologists and they have ample experience with the measurement of intravenous pressure. They independently estimated AVP from the graphs.

\section{Post-thrombotic syndrome}

Patients after objectively documented DVT were scored concerning the severity of post thrombotic syndrome (PTS) according to the critera of Prandoni ${ }^{13.14}$. Symptoms (pain, cramps, heaviness, pruritus, and paraesthesia) and signs (pretibial edema, induration of the skin, hyperpigmentation, new venulectasies, redness and pain during calf compression) were graded as absent ( 0$)$, mild (1), moderate (2), or severe (3). A total score of more than 5 on two consecutive visits and/or the pres- 
ence of venous ulcer were considered as indicative of PTS. None of the volunteers had any symptoms or signs of PTS or chronic venous insufficiency and they were therefore classified as not having PTS.

\section{Statistical analyses}

AVP estimates based on all graphs from both the same and from different measurement sessions were considered as independent observations for the purpose of measuring inter-observer variation. For comparison of the distributions of AVP values for legs with and without symptoms of PTS the lowest of all available AVP readings on the leg involved was chosen.

Because the distributions of AVP estimates were clearly not normal, the median and inter-quartile ranges are reported. Wilcoxon's $U$ test was used for statistical testing of differences between subgroups. Bland -Altman plots ${ }^{15}$ including least squares regression lines are made to show the relationship of the difference in AVP measurements between 2 experts as a function of the level of AVP.

SPSS 11.0 was used for statistical data analyses.

\section{RESULTS}

A total of 108 sheets were printed with 187 interpretable graphs from 87 legs. In 127 of these curves, AVP was estimated by all 3 experts; in 46 graphs by 2 experts; and in 14 , by only one expert. For the purpose of another analysis for which the same intravenous pressure measurements were used, a tourniquet was applied in 11 measurement sessions to eliminate the influence of refilling from superficial veins.

\section{Association of $A V P$ and post-thrombotic syndrome}

Of the 87 legs, 31 were diagnosed with PTS. According to the readings by the 3 experts $(\exp 1, \exp 2, \exp 3)$, legs without the post-thrombotic syndrome had a median AVP (inter-quartile range) of $39.7 \mathrm{mmHg}(23.6 ; 54.6)$, versus $29.1 \mathrm{mmHg}$ $(18.0 ; 45.6)$ and $23.6 \mathrm{mmHg}(11.2 ; 36.0)$. For the legs with PTS, these values were $64.5 \mathrm{mmHg}(51.5 ; 81.8), 60.8 \mathrm{mmHg}(40.9 ; 70.7)$ and $45.9 \mathrm{mmHg}(34.1 ; 64.5)$. respectively. For all experts the difference in AVP readings between PTS legs and non-PTS legs was highly statistically significant $(\mathrm{p}<0.001)$. 

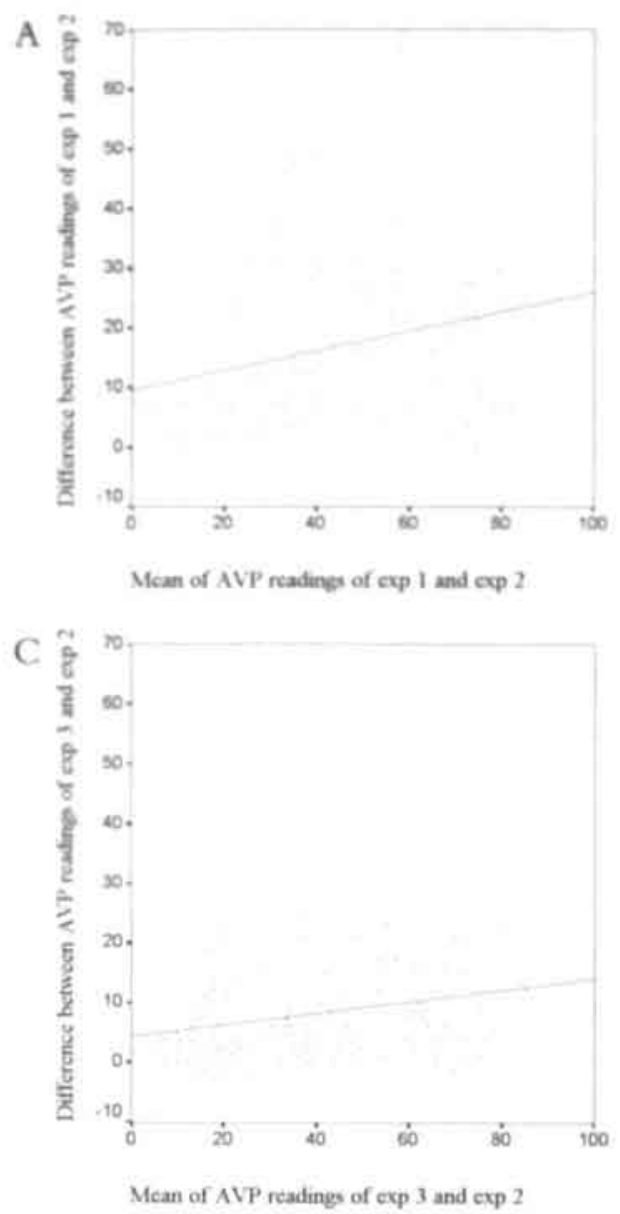

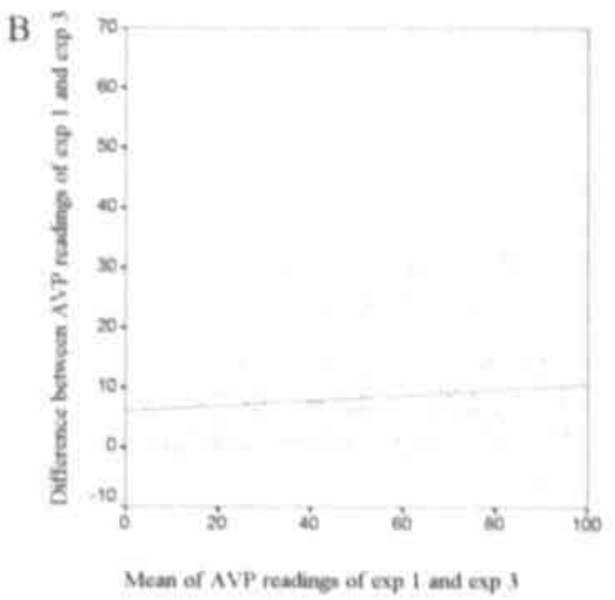

Figure 1 a-c Bland-Altman plots of the differences between two experts in reading AVP.

\section{Interobserver variation}

The medians of the AVP (inter-quartile range) in the 127 graphs that were scored by all three experts were $51.4 \mathrm{mmHg}(33.5 ; 70.7), 43.0 \mathrm{mmHg}^{(23.6 ; 63.2)}$ and $32.2 \mathrm{mmHg}(16.1 ; 48.4)$ respectively. In figures 1a to 1c Bland Altman plots are shown for each of the three combinations of observers. The level of the regression line above the $\mathrm{x}$-axis is a measure for the systematic difference in readings. The regression lines also show that the difference between the readings of the observers tended to be larger for higher values of AVP, i.e. an increase in the difference between readings of exp1 and exp3 of $0.05 \mathrm{mmHg}^{2} 95 \%$ confidence interval: $-0.02: 0.11)$ per $\mathrm{mmHg}$ AVP. For the other comparisons the slope of the regression line is $0.16(\exp 1$ vs $\exp 2 ; 95 \% \mathrm{Cl}: 0.05 ; 0.28)$ and $0.10(\exp 3$ vs $\exp 2 ; 95 \%$ CI: $0.02 ; 0.18$ ). The vertical scatter of the dots indicates the degree to which the error is non-systematic (random) which can be expressed as the standard deviations: 13,10 and $10 \mathrm{mmHg}$, respectively. 
Exclusion of the graphs in which a tourniquet was used gave virtually the same results (data not shown).

\section{Pictorial analysis}

We did not do a formal analysis of the characteristics of graphs that were associated with the level of inter-observer variation. Based on a subjective impression, we selected 4 graphs in which there was quite small or quite large disagreement between the experts. In figure 2, AVP readings from the three experts were almost equal: $23.6,19.8$ and $18.6 \mathrm{mmHg}$, respectively (figure $2 \mathrm{a}$ ) and $74.4,74.4$ and 75.6 $\mathrm{mmHg}$, respectively (figure $2 \mathrm{~b}$ ). In figure 3 , AVP values were quite different: $\mathbf{5 5 . 8}$, 9.9 and $16.1 \mathrm{mmHg}$, respectively (figure $3 \mathrm{a}$ ) and $91.8,24.8$, and $89.3 \mathrm{mmHg}$, respectively (figure $3 \mathrm{~b}$ ). From these pictures it seems that variation tends to be smaller when the amplitude of the pressure spikes is small. When curves with large and small amplitudes were sorted by estimation, only in about one quarter of the graphs was the amplitude judged to be 'small'.

\section{DISCUSSION}

In this study we determined the interobserver variation in reading the ambulant venous pressure (AVP) from graphs of intravenous pressure measurement in the legs of subjects with and without a history of deep vein thrombosis. The AVP as estimated by three experts seemed as correct as reported in the literature regarding the associated PTS ${ }^{16-18}$. This supports the fact that the assessors in our study have the same level of expertise as other authors in the field of intravenous pressure measurement.

However, when comparing the readings of the 3 experts, there turned out to be systematic differences of about 10 and $20 \mathrm{mmHg}$. These systematic differences become larger with increasing intravenous pressure. In addition to these systematic differences, there was a large random variation. As there is no information about the 'true' intravenous pressure and there is no clear indication that any one of the experts is better than the others, it is likely that these differences reflect systematic and random measurement errors of all 3 observers.

These results merely reflect the differences in reading AVP from the graphs of intravenous pressure measurement. However, there are many more sources of systematic and/or random error, such as problems with proper insertion of the needle and incomplete compliance of the subject with the instructions given during the measurement session ${ }^{19}$. Therefore the measured interobserver variation is likely to be an underestimate of the total variation. when including all sources of error. 

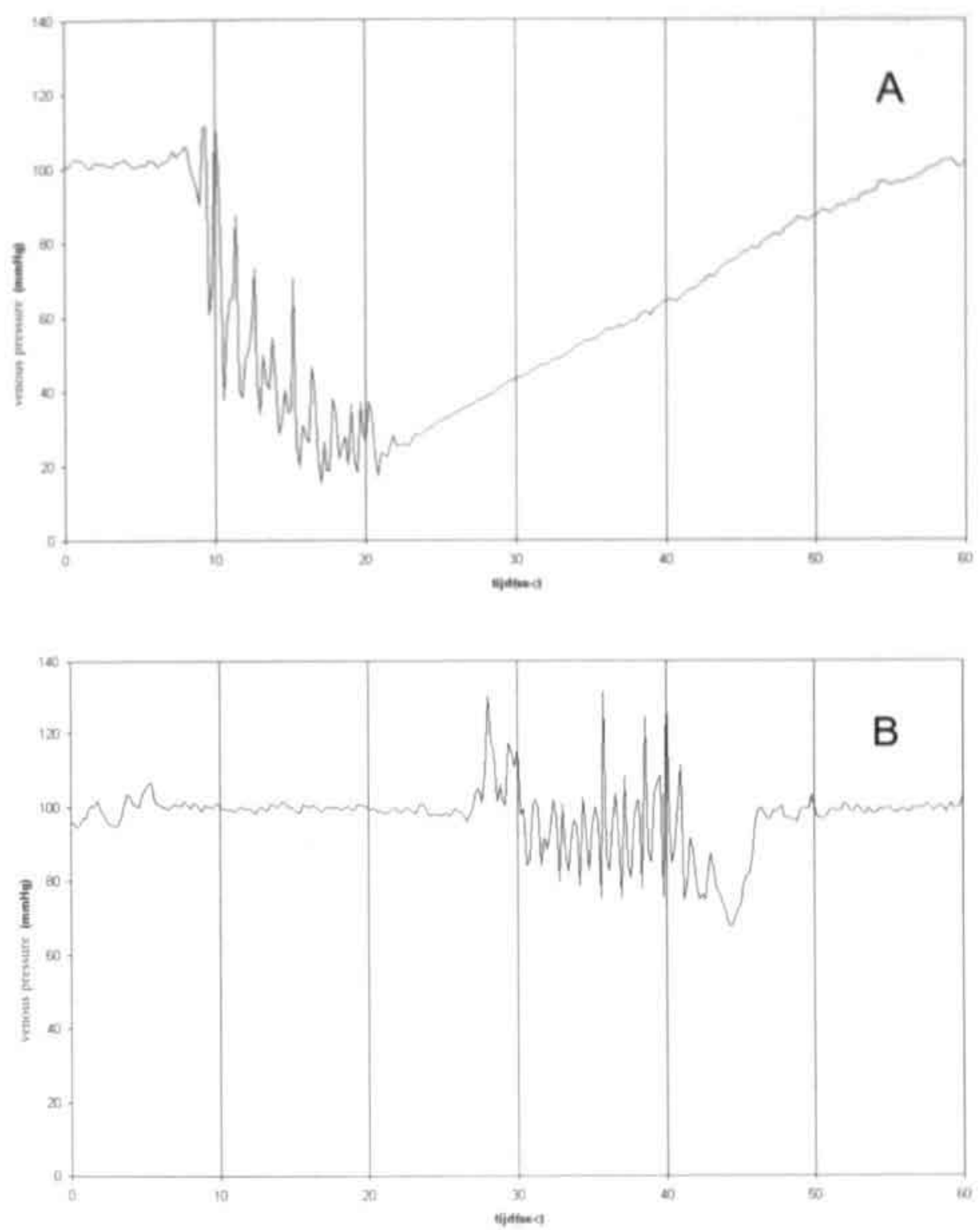

Figure 2 a-b Ambulant venous pressure measurement graphs in which all expert gave a small disagreement of the reading of AVP. 

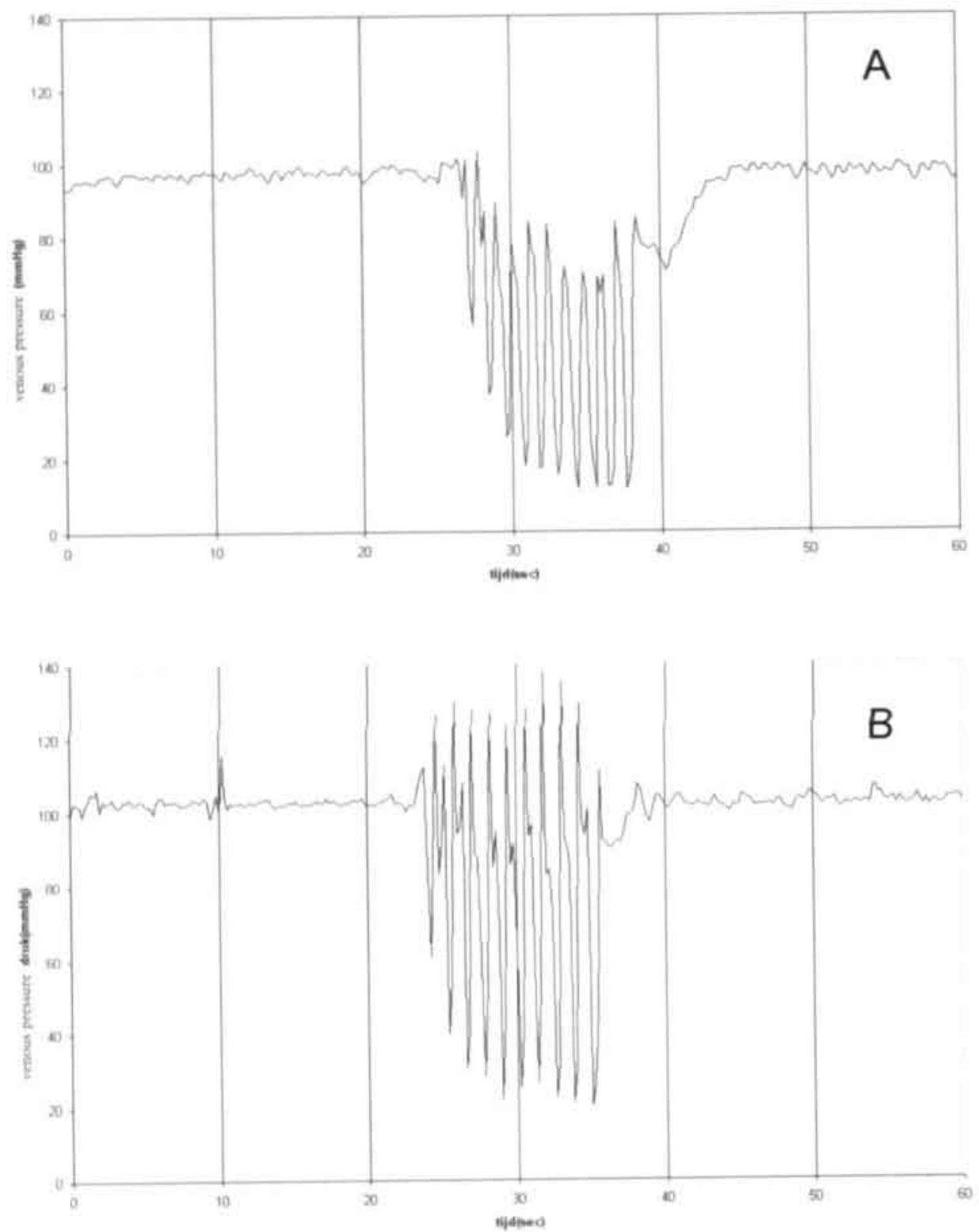

Figure 3 a-b. Ambulant venous pressure measurement graphs in which the experts had a quite large disagreement of the reading of AVP. 


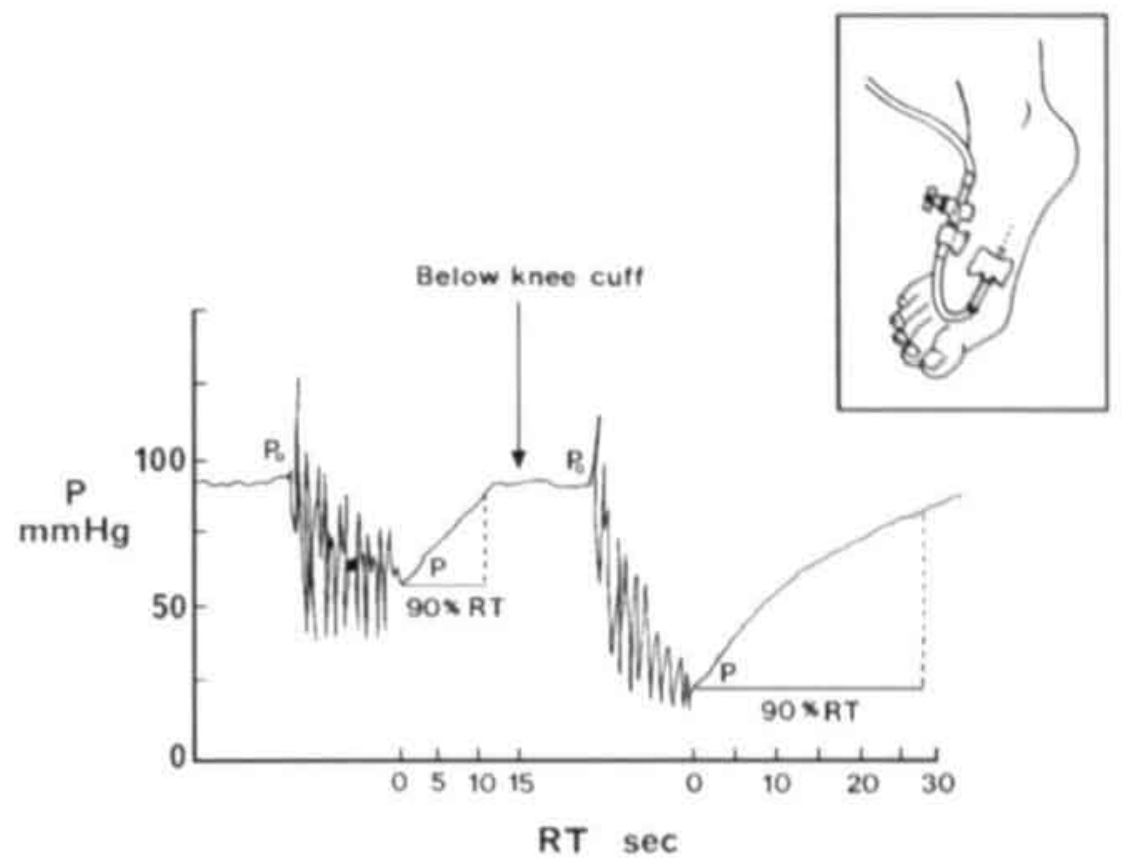

Figure 4 Example of ambulant venous pressure measurement. Reprinted figure with permission from G. Belcaro et al. J Cardiovasc Surg (Torino) 1993:34:3-11

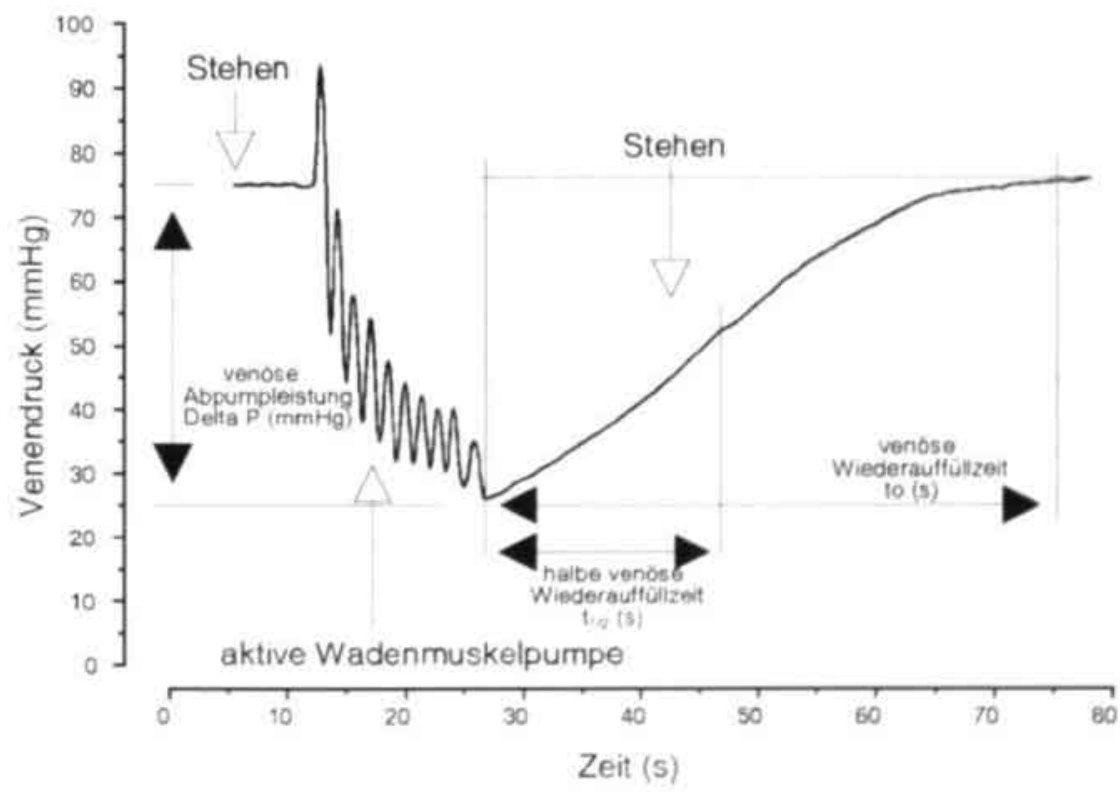

Figure 5 Example of ambulant venous pressure measurement. Reprinted figure with permission from A. Steins et al. Phlebologie 2002;31:86 
For any measurement, correct test results are needed for proper communication between colleagues, both in daily patient care and through the medical literature. Also, when using intravenous pressure measurement as the gold standard for validation of non-invasive techniques, such measurement should be as free from systematic and random error as possible. A first step in that direction would be the standardization of the method for reading the graphs.

When searching through phlebological textbooks and the relevant medical literature, we found no clear instructions for estimating AVP from graphs. Belcaro and co-workers do state that the AVP should be read as the lowest value of the pressure curve 4 . However, as shown in figure 4 , they themselves mark the AVP somewhat above the lowest point. The graphs presented in the literature are almost exclusively based on measurements in healthy subjects where the amplitude of the pressure spikes is relatively small ${ }^{20}$. An example of these graphs is shown in figure 5 ; these graphs are much easier to interpret than those from most patients with a muscle pump function problem. Therefore the lack of clarity in the reading instructions will lead to much larger inter-observer variation in estimating AVP in daily patient management.

Because there is no 'true' value of intravenous pressure available, improved reading instructions should come from a task force of experts in the field of intravenous pressure measurement. Proposed instructions should be evaluated for clarity and strength of association with the clinical severity of the venous insufficiency. Moreover, such instructions should pertain to all the pressure curves that will be encountered in daily practice and not only to the easy to interpret graphs from healthy volunteers. Among the issues that need to be taken into account are criteria for judging the adequacy of the curves for valid reading of AVP and the interpretation of the pressure spikes in relation to the relevant level of intra-venous pressure for diagnosis of existing or development of new chronic venous insufficiency.

\section{CONCLUSION}

Even though the individual AVP readings from the 3 experts in this study seemed as correct as those reported in the literature, there is also proof of large systematic and random errors in estimating AVP from intravenous pressure measurement graphs. It is likely that other phlebologists would show at least similarly large measurement error. In order to improve the situation, clear reading instructions should be devised. These should then be evaluated for intra- and interobserver variability and strength of association with the clinical syndrome. Then a justifiable, data driven, consensus between experts in the field of intravenous pressure measurements could be reached. 


\section{REFERENCES}

1. Nicolaides AN. Investigation of chronic venous insufficiency: A consensus statement (France, March 5-9, 1997). Circulation 2000;102:E126-63.

2. Gerwen van H. Brakkee AJ. Kuiper JP. Non-invasive measurement of venous muscle pump function in the supine possition. Phlebology 1992;7:146-149.

3. Janssen MC, Claassen JA, van Asten WN, Wollersheim H. de Rooy MJ. Thien T. Validation of the supine venous pump function test: a new non-invasive tool in the assessment of deep venous insufficiency. Clin Sci (Lond) 1996:91:483-8

4. Belcaro G, Labropoulos N. Christopoulos D, Vasdekis S, Laurora G. Cesarone MR, et al. Noninvasive tests in venous insufficiency. J Cardiovase Surg (Torino) 1993:34:3-11.

5. Belcaro G. Christopoulos D. Nicolades A. Venous insufficiency: non-invasive teating. In: Bergan J. Kirstner R. eds. Atlas of venous surgery. Philadelphia: Saunders; 1992. 9-24.

6. Criado E. Laboratory evaluation of the patient with chronic venous insufficiency (chapter 133). In: Rutherford RB, ed. Vascular surgery, 4th ed. Philadelphia: W. B. Saunders company; 1995. $1771-1785$

7. Kuiper JP. Perifere veneuze drukmeting. |thess]: Katholieke Universiteit Numegen; 1966.

8. Kuiper JP, Brakkee AJM. Bemerkung zur Standardsserung der Venendruckmessung. In: May R, Knessmann A, editors. Periphere Venendruckmessung: 1978; 1978, 98-102.

9. Knessmann A [Penpheral phlebodynamometry, Basis, technics, capabilities]. Vasa Suppl 1975:4:1-35.

10. Partsch H. Venedruckmessung in der Phlebologie. Der Hautarzt 1981:32:53-58

11. Kuiper JP. Venous pressure determination (direct method). Dermatologica 1966:132:206-217.

12. Nicolaides AN, Zukowski AJ. The value of dynamic venous pressure measurements. World J Surg 1986;10:919-24.

13. Kahn SR. Hirsch A, Shrier I. Effect of postthrombotic syndrome on health-related quality of life after deep venous thrombosis. Arch Intern Med 2002:162:1144-8.

14. Villalta S, Bagatella P. Piccioli A. Lensing AW. Prins MH. Prandoni P. Assessment of validity and reproducibility of a clinical scale for the post-thrombotic syndrome. Haemostasis 1994:24:158A.

15. Bland JM. Altman DG. Statistical methods for assessing agreement between two methods of clinical measurement. Lancet 1986;1:307-10.

16. Dix FP, McCollum CN. Role of ambulatory venous pressure measurement in the assessment of venous disease. Phlebology 2003:18:23-29.

17. Nicolaides AN, Hussein MK, Szendro G, Christopoulos D), Vasdekis S, Clarke H. The relation of venous ulceration with ambulatory venous pressure measurements. J Vase Surg 1993:17:414-9.

18. Payne SP. London NJ. Newland CJ. Thrush AJ, Barrie WW, Bell PR. Ambulatory venous pressure: correlation with skin condition and role in identifying surgically correctible disease, Eur J Vase Endovasc Surg 1996;11:195-200.

19. Kugler C. Strunk M, Rudofsky G. Venous pressure dynamics of the healthy human leg. Role of muscle activity, joint mobility and anthropometne factors. J Vasc Res 2001;38:20-9.

20. Steins A, Hafner HM, Bablich H. Rassner G. Junger M. Dynamische Venenfunktionstests auf dem Prüstand. (Functional venous tests under scrutiny). Phlebologie 2002;31:85-90. 


\section{Chapter 4}

\section{Definitions of the post-thrombotic syndrome}

A comparison with invasive venous pressure measurement 


\section{ABSTRACT}

Background For the diagnosis of deep vein thrombosis (DVT) accepted diagnostic criteria exist. However, no uniform definition for the diagnosis and treatment of the post-thrombotic syndrome (PTS) exists. We examined the various definitions of PTS that are used and their relationships with invasive venous pressure measurement.

Methods Patients with ultrasound documented DVT underwent a clinical evaluation of both lower extremities, in which five clinical definitions to grade PTS were used. Evaluated were the definition of Widmer, the CEAP classification, the Venous Clinical Severity score (also without compression therapy), and the definitions according to Prandoni and Brandjes. Comparison of none, mild-to moderate and severe scoring was done with invasive ambulant venous pressure measurement.

Results In total 124 patients were enrolled, of whom both legs were evaluated. Thirteen patients had bilateral DVT and 9 patients had an ipsilateral recurrent DVT. In the DVT legs, 10 (7\%) to 29 (21\%) were defined as severe PTS, compared to 0 to $4(4 \%)$ in the control legs. Mild-to-moderate PTS in the DVT legs ranged from 23-49\%, compared to $13-34 \%$ in the control legs. Overall, the presence of any PTS in the DVT legs varied from $30 \%$ (VCS without compression) to $66 \%$ (Brandjes). The scoring systems of Brandjes and VCS showed a tendency towards more legs to be defined as severe PTS. Absolute frequencies of PTS in DVT legs were highest for the classifications according to Widmer. Prandon and Brandjes. Differences in proportions of any PTS calculated between DVT and control legs varied from 18 to $39 \%$, while odds ratios varied between 2.2 and 5.2 for the different definitions.

The CEAP classification and definition of Brandjes show a moderate relation to Widmer, $K=0.53$ and $K=0.52$, respectively. The VCS shows in all comparisons a poor correlation $(\kappa 0.22-0.41)$. Prandon has a moderate correlation with most definitions $(\kappa 0.40-0,44)$.

Condusion Although all clinical definitions of PTS were highly statistically significantly associated with the gold standard, invasively determined ambulant venous pressure, their ability to discriminate between DVT and control legs as well as the observed prevalence of PTS differed substantially. The definition that combined good discriminatory power with a plausible correlation to the gold standard was the definition of PTS according to Prandoni. Since this definition has known measurement properties, it seems to be the definition of choice for future studies, especially if criteria for the grading of individual elements of the scorings systems were to be made explicit.

\section{BACKGROUND}

For the diagnosis of deep vein thrombosis (DVT) accepted diagnostic criteria exist $^{1,2}$. However, the definition, and thus the identification of the post-thrombotic syndrome (PTS) remains a challenge. Several means of measuring and classifying chronic venous disease exist, most of which are based on clinical signs and symptoms ${ }^{3-7}$. Only a few definitions exist specifically for the post-thrombotic syndrome, a term coined for the long-term local complications after an episode of deep vein thrombosis. For the evaluation of methods to prevent and treat PTS, it is crucial that the outcome of the disease be objectively documented. 
The fundamental pathophysiologic disturbance found in patients with severe leg symptoms or signs after deep vein thrombosis is sustained venous hypertension, which results from valvular incompetence, outflow obstruction, calf muscle dysfunction, or a combination of these ${ }^{\gamma}$. Sustained venous hypertension can be measured with invasive venous pressure measurement, which can be regarded as the gold standard, since it directly measures the pressure in the venous system of the lower extremity. However, this technique requires special equipment, is invasive, time-consuming and cumbersome. On the other hand non-invasive equivalents are insufficiently validated. In order to shed some light on the similarities and differences between the various definitions of PTS that can be used and their relationship with invasive venous pressure measurement, this study was conducted on a group of patients who had previously experienced a deep vein thrombosis.

\section{METHODS}

\section{Participants}

Patients with a documented deep vein thrombosis diagnosed by compression ultrasonography or phlebography between 1991 and 2001 were asked by letter to participate in our study of PTS. Exclusion criteria for participation in the clinical evaluation were diabetes mellitus, coexistent arterial disease and immobility. The current evaluation is part of a larger study that was approved by the institutional review board. Written informed consent was obtained from all patients prior to study entry. Included patients underwent a physical examination of the lower extremities by the clinician. For this purpose a standardized form was used that included items as defined in the various scores for PTS as well as a thorough dermatologic description of the legs.

\section{Scoring system of the post-thrombotic syndrome}

At the baseline visit the physician examined the patient's legs and classified the clinical categories and severity of PTS using the different scoring systems. The five different scoring systems: Widmer classification, the CEAP classification, the venous clinical severity (VCS), classification according to Prandoni and Brandjes, are presented in tables 1a-1e. The scoring according to Widmer was meant to classify chronic venous insufficiency and took only objective signs into account, these were graded classes I, II and $\mathrm{III}^{5}$. Another system of scoring venous diseases is the CEAP classification devised in 1994 by the committee of the American Venous Forum, the North American Society of Phlebology in co-operation with the European Societies of Phlebology and published widely in many languages ${ }^{6}$. CEAP classification was developed to obtain comparison of diagnosis and treat- 
Table 1a Classification of Chronic Venous Insufficiency according to Widmer

\begin{tabular}{ll} 
& Symptom \\
\hline Class I & $\begin{array}{l}\text { Ankle flare } \\
\text { Subclinical edema }\end{array}$ \\
Class II & $\begin{array}{l}\text { Edema } \\
\text { Pigmentation } \\
\text { Lipodermatosclerosis } \\
\text { White (skin) atrophy }\end{array}$ \\
Class III & $\begin{array}{l}\text { Leg ulcer } \\
\text { Leg ulcer in the past }\end{array}$ \\
\hline
\end{tabular}

Table 1b CEAP-classification as developed by the American Venous Forum and North American Society of Phlebology in co-operation with the European Societies on Phlebology.

\begin{tabular}{ll} 
Clinical signs & Class 0 No visible or palpable signs of venous disease \\
Class 1 Teleangiectases or reticular veins \\
Class 2 Vancose vems \\
Class 3 Edema \\
Class 4 Skin changes ascribed to venous disease \\
Class 5 Skin changes as defined above with healed ulceration \\
Class 6 Leg ulceration, skin changes as defined above \\
Etiologic classification & Congenital, primary, secondary \\
Anatomic distribution & Superficial, deep, or perforator, alone or in combination \\
Pathophysiologic dysfunction & Reflux or obstruction, alone or in combination \\
\hline
\end{tabular}

ment in patients with venous diseases; the scoring of clinical symptoms represented a progressive gradation of disease severity $(\mathrm{CO}-6)$. Based on the best usable elements of the CEAP system, the Venous Clinical Severity score (VCS) has been developed to form a quantifiable system with gradable elements that could change in response to treatment ${ }^{7}$. It consists of nine clinical characteristics of chronic venous disease graded from 0 to 3 (absent, mild, moderate, severe) with specific criteria to avoid overlap or arbitrary scoring. Zero to three points is added for differences in background conservative therapy (compression and elevation) to produce a 30 point-maximum flat scale. Threshold values for the VCS were validated ${ }^{6}$. Absence of disease was defined by scores of 3 or less and presence of severe disease defined by scores 8 or more. The scoring system of Prandoni assessed five symptoms and six signs, in which each item could be scored from 0 to $3^{3}$. For each item, the investigators assigned a score of 0 (not present or minimal) to 3 (severe). A total score of more than 14 or the presence of a venous ulcer indicated severe post-thrombotic syndrome. Five to 15 indicated mild post-thrombotic syndrome. The scoring according to Brandjes had an equivalent system of objective symptoms and subjective signs, but these were graded as absent or present ${ }^{4}$. Brandjes scoring 
Table 1c Venous Clinical Severity (VCS) score

\begin{tabular}{|c|c|c|c|c|}
\hline Attribute & Absent $=0$ & Mild $=1$ & Moderate $=2$ & Severe $=3$ \\
\hline Pain & None & $\begin{array}{l}\text { Occasional, not restricting activity } \\
\text { or requining analgesics }\end{array}$ & $\begin{array}{l}\text { Dally, moderate activiry limicanon. } \\
\text { occasional analgesics }\end{array}$ & $\begin{array}{l}\text { Dasly, severe lamiting activities or } \\
\text { requiring regular use of analgesios }\end{array}$ \\
\hline Varicose veins* & None & Few, scattered branch VV: & $\begin{array}{l}\text { Multuple: GS varicose veins confined } \\
\text { to calf or thight }\end{array}$ & $\begin{array}{l}\text { Extensive: Thigh and alf or GS and } \\
\text { LS distribution }\end{array}$ \\
\hline Venous edema† & None & Evening ankle edema only & Aftemoon edema, above ankle & $\begin{array}{l}\text { Morning edema above ankle and } \\
\text { requiring activity change, elevation }\end{array}$ \\
\hline Skin pignientationf & $\begin{array}{l}\text { None or focal, fow } \\
\text { intensity (tan) }\end{array}$ & $\begin{array}{l}\text { Diffuse, but limited in area and old } \\
\text { (brown) }\end{array}$ & $\begin{array}{l}\text { Diffuse over most of paiter } \\
\text { distribution (lower } 1 / 3 \text { ) or } \\
\text { recent pigmentation (purple) }\end{array}$ & $\begin{array}{l}\text { Wider distribution (above lower } \\
1 / 3 \text {, and recent pigmentation }\end{array}$ \\
\hline Intlanmution & None & $\begin{array}{l}\text { Mild cellulitis, limited to marginal } \\
\text { area around ulcer }\end{array}$ & $\begin{array}{l}\text { Moderate cellulitis, involves most } \\
\text { of gaiter area (lower } 1 / 3 \text { ) }\end{array}$ & $\begin{array}{l}\text { Severe cellulints (lower } 1 / 3 \text { and } \\
\text { above) or significant venous eczema }\end{array}$ \\
\hline Induration & None & Focal. circummalleolar $(<5 \mathrm{~cm})$ & $\begin{array}{l}\text { Medial or lateral, less than lower } \\
\text { thurd of leg }\end{array}$ & Enture lower third of leg ot more \\
\hline No of artive ulcers & 0 & 1 & 2 & $>2$ \\
\hline $\begin{array}{l}\text { Active ulecration. } \\
\text { duration }\end{array}$ & None & $<3$ mo & $>3 \mathrm{mo}_{\mathrm{s}}<1 \mathrm{y}$ & Nor bealed $>1$ y \\
\hline Actuve ulcer, sizes & None & $<2-\mathrm{cm}$ diameter & 2- to 6-cm diameter & $>6-\mathrm{cm}$ diameter \\
\hline Compresave therapy I & $\begin{array}{l}\text { Not used or not } \\
\text { compliant }\end{array}$ & Intetmittent use of stockmgs & W cars elastic stockings most days & $\begin{array}{l}\text { Full compliance: stocking + } \\
\text { clevatooni }\end{array}$ \\
\hline
\end{tabular}

- "Varicose" vems must be > 4-mm diameter to qualify wo that diferentation is ensured between $\mathrm{Cl}$ and $\mathrm{C} 2$ venous pathology.

† Presumes venous ongm by characteristaes (eg. Brawny [not pittung or spongy] edena), with sganficant effect of standing/limb elevation and/or other chinical madence of venous enology (ic, varicose veins, history of DVT). Edema muse be regular finding (eg, dajly occurrence). Occasonal or mild edema does not qualify.

¥ Focal pigmentation over vancose veins does not quulify.

S. Langest dimenston/diancter of largest ulcer.

1) Shdung wale to adjust for background differences un use of compressve therapy

G.S. Greater suphenous; LS, lesser sphenous. 
Table 1d Scoring system of PTS according to Prandoni

\begin{tabular}{ll}
\hline Symptoms & Signs \\
\hline Pain & Pretibial edema \\
Cramps & Induration of the skin, \\
Heaviness & Hyperpigmentation \\
Pruritus & New venous ectasia \\
Paraesthesia & Redness \\
& Pain during calf compression \\
& Leg ulceration \\
\hline
\end{tabular}

For each item a score of 0 (= no or minimal) to 3 (severe) is assigned. A total score 5-14 is a mild-to moderate PTS, a score of $\geq 15$ or a leg ulcer is always severe PTS

Table 1e Scoring system according to Brandjes for mild-to-moderate and severe post-thrombotic syndrome.

Mild-to-moderate PTS (score $\geq 3$ including one objective criterion)

\begin{tabular}{|c|c|c|c|}
\hline \multicolumn{2}{|l|}{ Subjective criteria } & \multicolumn{2}{|l|}{ Objective criteria } \\
\hline Symptoms & score & Signs & score \\
\hline Spontaneous pain in calf & 1 & Calf circumference increased by $1 \mathrm{~cm}$ & 1 \\
\hline Spontaneous pain in thigh & 1 & Ankle circumference increased by $1 \mathrm{~cm}$ & 1 \\
\hline Pain in calf on standing/walking & 1 & Pigmentation & 1 \\
\hline Pain in dagh on scantuig watking & , & venentente & 1 \\
\hline Edema of foot/calf & 1 & Newly formed varicosis & 1 \\
\hline "Heaviness" of leg & 1 & Phlebitis & 1 \\
\hline
\end{tabular}

Severe PTS (score 24 )

\begin{tabular}{|c|c|c|c|}
\hline $\begin{array}{l}\text { Subjective criteria } \\
\text { Symptoms }\end{array}$ & score & $\begin{array}{l}\text { Objective criteria } \\
\text { Signs }\end{array}$ & score \\
\hline $\begin{array}{l}\text { Spontancous pain and pain on } \\
\text { standing/walking }\end{array}$ & 1 & Calf circumference increased by $1 \mathrm{~cm}$ & 1 \\
\hline Edema of calf & 1 & Pigmentation, discolouration, and venectasia & 1 \\
\hline Impainnent of daily activities & 1 & Venous ulcer & 4 \\
\hline
\end{tabular}

is done with separate scales for mild-to-moderate and severe post-thrombotic syndrome. Mild-to-moderate PTS was defined as score 3 or more including one objective criterion. Severe post-thrombotic syndrome consisted of a score of 4 or more.

\section{Invasive venous pressure measurement ${ }^{10-1}$}

A 21-gauge butterfly needle was inserted into a vein on the dorsum of the foot and connected through a pressure transducer and an amplifier to a computer system. The pressure transducer was stabilized at the same height as the inserted needle on a flexible standard. The patient stood while holding to a frame in order to avoid con- 
tractions of the calf muscles. The ambulant venous pressure (AVP) was recorded after a short, standardized exercise regimen (10 tiptoe movements performed at the rate of one per 1.5 second). At the end of the exercise the patient remained still, until stable recovery of the standing venous pressure. Then the exercise was repeated once again. The lower of the two repeated measurements of AVP was recorded.

\section{Thresholds of no, mild-to-moderate and severe PTS}

To evaluate the relationship between the different scoring systems, thresholds for scoring of no, mild-to-moderate and severe PTS are given. In definition of thresholds for PTS severity, Widmer class 0 represents no disease, Widmer classes I and II are considered mild-to-moderate PTS and Widmer class III severe PTS. In definition of thresholds for PTS severity of the CEAP clinical classification, CEAP classes 0 and 1 are considered no PTS, CEAP classes 2 and 3 are considered to represent mild-to-moderate PTS and CEAP classes 4 through 6 severe PTS ${ }^{2}$. Thresholds for venous disease of the VCS score are used similarly for PTS. Absence of disease defined by scores of 3 or less is considered no PTS, score 4 through 7 represents mild-to-moderate PTS and a threshold of 8 or more is considered severe PTS. Since stockings are routinely described in our patients with DVT, the use of stockings would be a measure of compliance rather than disease. Therefor, we made a second group of VCS scores in which we excluded compression therapy from the scoring. The thresholds were the same as for VCS, only the total score after exclusion of therapy produced a 27 point-maximum flat scale. Prandoni and Brandjes had already graded in their classification system for no, mild-to-moderate and severe PTS.

\section{Statistical analysis}

Descriptive statistics were calculated for the separate groups. Differences in proportions of any PTS between DVT and control legs were calculated and both expressed as absolute differences and odds ratio with a $95 \%$ confidence interval. Inter-observer agreement, differences between scorings systems and invasive venous pressure measurement were assessed by the weighted kappa test $(\kappa)$ for the classification of the severity of the PTS. Values for $\kappa$ of more than 0.75 usually represent excellent agreement beyond chance, $\kappa$ values between 0.40 and 0.75 fair to good agreement and $\kappa$ values less than 0.40 poor agreement ${ }^{13}$. One-way ANOVA was performed, with the ambulant venous pressure measurement as variable of outcome and the different scoring systems as experimental variable. All data analyses were performed using the SPSS-PC software package, version 11.5. 
Table 2 Ptoportion of legs defined as post-thrombotic syndrome according to the different definitions.

\begin{tabular}{|c|c|c|c|c|c|c|c|c|}
\hline & \multicolumn{3}{|c|}{$\begin{array}{l}\text { DVT legs }(\mathrm{n}=137) \\
\text { Post-thrombotic syndrome }\end{array}$} & \multicolumn{3}{|c|}{$\begin{array}{l}\text { Control legs }(n=111) \\
\text { Post-thrombotic syndrome }\end{array}$} & \multirow{2}{*}{$\begin{array}{l}\text { Absolute Differences } \\
\text { in proportion of } \\
\text { any PTS } \\
5 .(95 \% \text { CI })\end{array}$} & \multirow{2}{*}{$\begin{array}{l}\text { Odds Ratio for } \\
\text { any PTS } \\
\text { (DVT vi, control) } \\
\text { OR }(95 \% \text { Cl) }\end{array}$} \\
\hline & $\begin{array}{l}\text { No } \\
\mathrm{n}(\%)\end{array}$ & $\begin{array}{l}\text { Mild-to- } \\
\text { moderate } \\
\mathrm{n}(\%)\end{array}$ & $\begin{array}{l}\text { Severe } \\
\mathrm{n}(\%)\end{array}$ & $\begin{array}{l}\text { No } \\
\mathrm{n}(\%)\end{array}$ & $\begin{array}{l}\text { Mild-to- } \\
\text { moderate: } \\
\mathrm{n}(\mathrm{x})\end{array}$ & $\begin{array}{l}\text { Severe } \\
n(\%)\end{array}$ & & \\
\hline Widmet 0, I-1I", III & $57(42)$ & $67(49)$ & $13(10)$ & $71(64)$ & $38(34)$ & $2(2)$ & $22 \%(9-35 \%)$ & $2.5(1.4-4.3)$ \\
\hline CEAP $0-1,2-3 \cdots, 4-6 \cdots$ & $71(52)$ & $48(35)$ & $18(13)$ & $78(70)$ & $29(26)$ & $+(4)$ & $18 \%(5-31 \%)$ & $2.2(1.3-3.9)$ \\
\hline $\begin{array}{l}\text { VCS } 0-3,4-7, \geq 8 \\
\text { VCS without therapy }\end{array}$ & $63(46)$ & $53(39)$ & $21(15)$ & $90(81)$ & $20(18)$ & $1(1)$ & $35 \%(23-46 \%)$ & $5.0(2.7-9.4)$ \\
\hline $0-3,4-7,28$ & $95(69)$ & $32(23)$ & $10(7)$ & $97(87)$ & $14(13)$ & 0 & $18 \%(7-27 \%)$ & $3.1(1.5-6.3)$ \\
\hline Prandom & $54(39)$ & $67(49)$ & $16(12)$ & $85(77)$ & $23(21)$ & $3(3)$ & $37 \%(24-48 \%)$ & $5.0(2.8-9.1)$ \\
\hline & $47(34)$ & $61(45)$ & $29(21)$ & $81(73)$ & $25(23)$ & $5(5)$ & $39 \%(26-50 \%)$ & $5.2(2.9-9.3)$ \\
\hline
\end{tabular}

Brandjes $\quad 47(34) \quad 61(45)$. 29 (21)

*Widmer class I: 25 control. 37 DVT: *CEAP class 0: 52 control. 37 DVT, class 2: 22 control, 33 DVT: * * class 4: 2 control, 5 DVT: class 5: 1 control, 9 DVT.

Table 3 Companson of agreement between all used scoring systems for $137 \mathrm{legs}$ with documented DVT in the past.

\begin{tabular}{|c|c|c|c|c|c|}
\hline $\operatorname{DVT}(n=137)$ & $\begin{array}{l}\text { Widmer } \\
\text { Kappa }(95 \% \mathrm{Cl})\end{array}$ & $\begin{array}{l}\text { CEAP } \\
\text { Kappa }\left(95^{*}, \mathrm{Cl}\right)\end{array}$ & $\begin{array}{l}\text { VCS } \\
\text { Kappa }(95 \% \text { CI })\end{array}$ & $\begin{array}{l}\text { VCS (without therapy) } \\
\text { Kappa }(95 \% \mathrm{CI})\end{array}$ & $\begin{array}{l}\text { Prandoni } \\
\text { Kappa }(95 \% \text { CI) }\end{array}$ \\
\hline Brandjes & $0.52(0.40-10.64)$ & $0.54(0.43-0.66)$ & $0.22(0.09-0.36)$ & $0.23(0.11-0.34)$ & $0.40(0.27-0.53)$ \\
\hline Prandoni & $0.44(0.29-0.58)$ & $0.42(0.29-0.56)$ & $0 .+1(0.28-0.55)$ & $0.31(0.19-0.43)$ & \\
\hline VCS without therapy & $0.33(0.21-0.46)$ & $0.39(0.25-0.53)$ & & & \\
\hline VCS & $\begin{array}{l}0.24(0.10-0.38) \\
0.53(0.40-0.65)\end{array}$ & $0.27(0.12-0.41)$ & & & \\
\hline
\end{tabular}


Table 1 Mean ambulant venous pressure (AVP) measured in 76 legs compared with the defintions for post-thrombotic syndrome.

\begin{tabular}{|c|c|c|c|c|c|c|c|}
\hline & $\mathrm{n}$ & Mean AVP ( \pm sd) & $\begin{array}{l}\text { Normal AVP } \\
\begin{array}{l}0-29.9 \mathrm{mmHg} \\
\mathrm{n}=36\end{array}\end{array}$ & $\begin{array}{l}\text { Mild increased AVP, } \\
\text { i.e. } 30 \text { thru } 40 \mathrm{~mm} \mathrm{Hg} \\
n=15\end{array}$ & $\begin{array}{l}\text { Increased AVP, Le. } \\
40 \text { mum } \mathrm{Hg}_{\mathrm{g}} \text { thru higher } \\
\mathrm{n}=25\end{array}$ & $\begin{array}{l}\text { One way } \\
\text { ANOVA } \\
\text { p-value: }\end{array}$ & $\begin{array}{l}\text { Comparison of } \\
\text { agreement } \\
\text { Kappa (95\% CI) }\end{array}$ \\
\hline Widmer 0 & 38 & $28.1( \pm 17.4)$ & 25 & 6 & 7 & $<0.001$ & $0.30(0.11$ to 0.49$)$ \\
\hline Widmer I-II & 34 & $40.4( \pm 20.4)$ & 11 & 9 & 14 & & \\
\hline Widmer III & 4 & $66.4( \pm 17.0)$ & 0 & 0 & 4 & & \\
\hline Ceap 0-1 & 47 & $31.2( \pm 16.7)$ & 26 & 10 & 11 & $<0,001$ & $0.22(0.10000 .41)$ \\
\hline Ceap 2-3 & 24 & $37.5( \pm 23.4)$ & 10 & 5 & 9 & & \\
\hline Ceap +-6 & 5 & $67.9( \pm 15.1)$ & 0 & 0 & 5 & & \\
\hline $\operatorname{VCS}(0-3$ & +0 & $27.5( \pm 16.1)$ & 25 & 8 & 7 & 0.001 & $0.21(0.20$ to 0.41$)$ \\
\hline VCS $4-7$ & 27 & $44.4( \pm 20.1)$ & 7 & 6 & 14 & & \\
\hline VCS \& thru higher & 9 & $45.4( \pm 28.5)$ & 4 & 1 & 4 & & \\
\hline \multicolumn{8}{|l|}{ VCS without theraps } \\
\hline $0-3$ & 57 & $32.2( \pm 18.5)$ & 30 & [I & 16 & 0.001 & $0.13(-4.07$ to 0.35$)$ \\
\hline $4-7$ & 17 & $41.5( \pm 21.9)$ & 6 & 4 & 7 & & \\
\hline 8 thru higher & 2 & $81.8( \pm 11.4)$ & ") & 0 & 2 & & \\
\hline Prandoni 0 & +2 & $29.0( \pm 17.3)$ & 26 & 8 & 8 & $<0,001$ & $0.27(0.07$ to 0.46$)$ \\
\hline Prandoni I & 30 & $40.8( \pm 21.1)$ & 10 & 7 & 13 & & \\
\hline Prandon 2 & 4 & $66.4( \pm 17.0)$ & 0 & 0 & 4 & & \\
\hline Brandjes 0 & 39 & $26.3( \pm 14.7)$ & 27 & 8 & 4 & $<0.001$ & $0.35(0.16$ to 0.55$)$ \\
\hline Brandjes 1 & 26 & $43.6 \cdot( \pm 20.9)$ & 7 & 5 & 14 & & \\
\hline Brandjex 2 & 11 & $49.8( \pm 24.8)$ & 2 & 2 & 7 & & \\
\hline
\end{tabular}



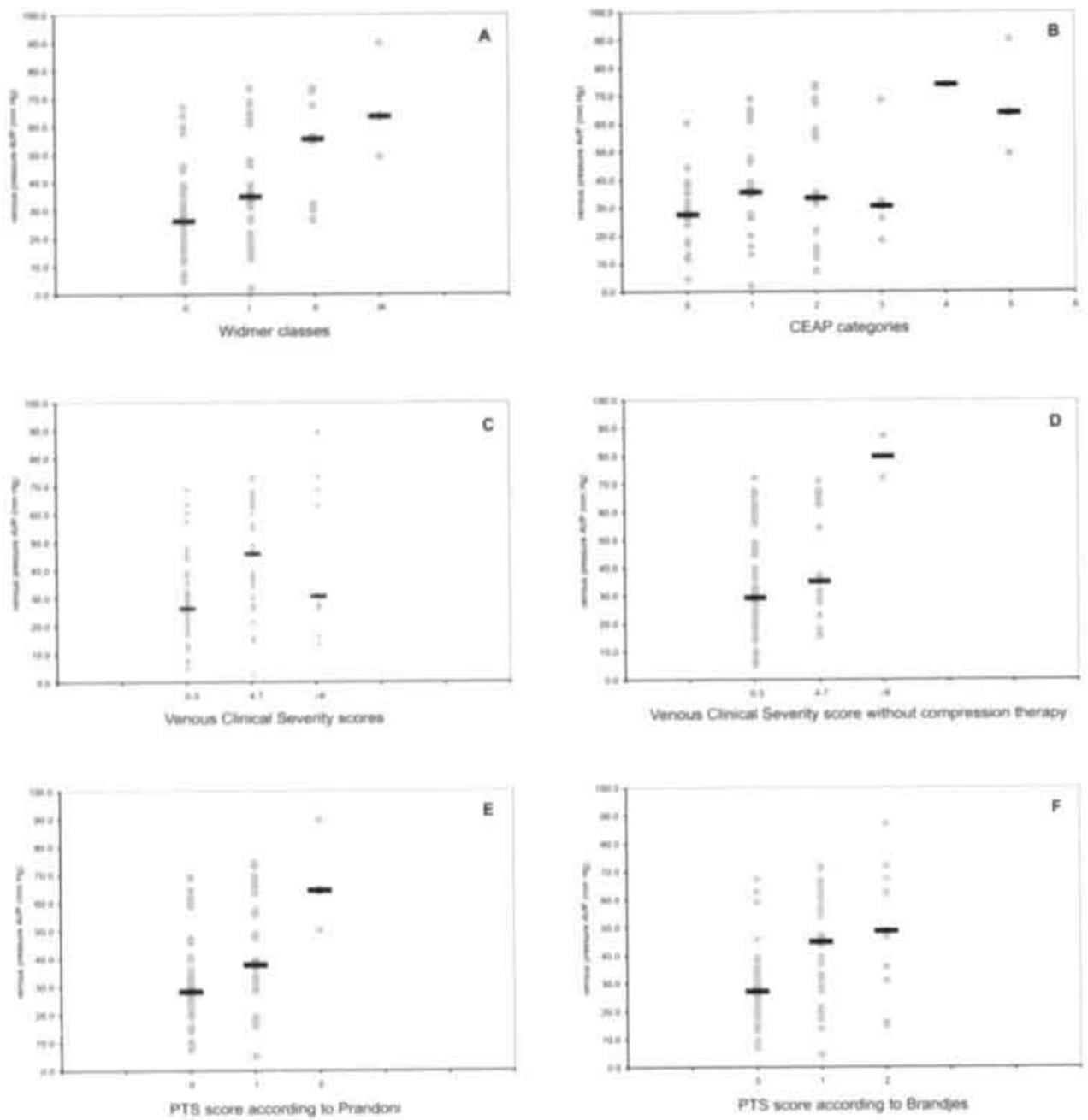

Figure 1 a-f Ambulant venous pressure $\left(\mathrm{mmHg}_{\mathrm{g}}\right)$ in legs classified for the different definitions. $\mathrm{AVP}=\bullet:$ mean $=-$ 


\section{RESULTS}

\section{Population}

In total 124 patients were enrolled, 54 men (mean age: $57 \pm 13$ years) and 70 women (mean age: $47 \pm 13$ years). Thirteen patients had bilateral DVT and 9 patients had had an ipsilateral recurrent DVT. The median time elapsed since the first DVT was 6 years, interquartile range 3 to 9 years.

\section{Clinical definitions}

The classification of the leg status according to the clinical definitions is given in table 2. In the DVT group, $10(7 \%)$ to $29(21 \%)$ legs were defined as severe PTS, compared to 0 to $4(4 \%)$ in the control legs. Mild-to-moderate PTS in the DVT group ranged from $23 \%$ to $49 \%$, compared to $13 \%$ to $34 \%$ in the control group. Overall the presence of any PTS in the DVT group varied from $30 \%$ (VCS without compression) to $66 \%$ (Brandjes). The scoring systems of Brandjes and VCS showed a tendency towards more legs being defined as severe PTS. Absolute frequencies of PTS in DVT legs were highest for the classifications according to Widmer, Prandoni and Brandjes. Differences in proportions of any PTS calculated between DVT and control legs varied from $18 \%$ to $39 \%$, while odds ratios varied between 2.2 and 5.2 for the different definitions.

Table 3 shows the measurement of agreement between the different scoring systems for the 137 legs with documented DVT. The CEAP classification and definition of Brandjes show a moderate relation to Widmer, $\kappa 0.53$ and $\kappa 0.52$, respectively. The VCS shows a poor correlation in all comparisons ( $\kappa 0.22-0.41$ ). Prandoni has a moderate correlation with most definitions $(\kappa(0.40-0.44)$; only with VCS without compression therapy was a poor relationship ( $\kappa 0.31)$ shown.

\section{Invasive venous pressure measurement}

Invasive venous pressure measurement was done in 46 patients. In thirty patients both legs were measured and in sixteen patients only one leg. Of the legs, 43 had been affected by DVT and 33 were control. The mean AVP values, measured in DVT and control legs, were $41( \pm 21) \mathrm{mmHg}$ and $28( \pm 18) \mathrm{mmHg}(\mathrm{p}=0.005)$, respectively.

In figure 1a-f results of the different PTS scorings systems and their relation to the AVP are presented. Table 4 shows the comparison of the scoring systems to the invasive venous pressure measurement. The mean AVP for legs without PTS according to the various definitions varied between 26.3 and $32.2 \mathrm{mmHg}$. Also the 
difference in mean AVP for mild-to-moderate PTS was limited for the different definitions, 37.5 to $44.4 \mathrm{mmHg}$. A larger difference occurred in the severe PTS group, with a mean AVP of $49.8 \mathrm{mmHg}$ for the definition of Brandjes compared to $81.8 \mathrm{mmHg}$ for the VCS score without compression therapy. All classification systems showed a tendency for higher AVP values among legs with PTS. It is noteworthy that 2 of $11 \mathrm{legs}$ and 4 of $9 \mathrm{legs}$ classified as severe PTS according to the scoring systems of Brandjes and VCS, respectively, had normal AVP values. While more severe PTS in all classification systems was associated with a higher mean AVP (all p values $<0.001$, ANOVA), the association was strongest in the Widmer, Brandjes and Prandoni classification systems.

\section{DISCUSSION}

In general, all PTS classification systems showed a reasonable correlation with the AVP. However, the clinical classification systems varied strongly in the number of legs that were classified as having PTS, as well as in their ability to discriminate between DVT and control legs.

Ideally, a clinical classification system would be easy to obtain, have a good association with the pathophysiological mechanism as well as the ability to discriminate between affected and non-affected legs. Additionally, good reproducibility and clinical meaningfulness are required. Moreover, for leg symptoms after deep vein thrombosis, an ideal outcome measure would be sensitive enough to identify the post-thrombotic syndrome and allow for detection of stabilization, improvement or deterioration of this disorder.

The clinical component of the CEAP classification system has been widely implemented as a descriptive means of categorizing patients with venous diseases. In our evaluation the discriminatory power was limited in comparison to other definitions, and many patients with increased AVP were classified as no PTS. In addition, many components of the CEAP clinical classification are static over time and subtle changes can't be classified. Hence, possibilities to describe changes over time in leg symptoms after deep vein thrombosis are limited.

The VCS was designed to include only those manifestations of chronic venous disease that can potentially change over time and has been shown to have a moderate to good inter-observer variability ${ }^{9}$. It showed a high discriminatory power between DVT and control legs. However, when the compression therapy was left out of the score, this power decreased. In addition, many patients with normal venous pressure were scored as severe PTS when stockings were taken into account. Moreover, the VCS score showed a poor correlation with all other defi- 
nitions of PTS and when compression therapy was excluded, the relation with other definitions diminished even more. The VCS score showed only a limited difference in mean AVP between legs classified as mild-to-moderate and severe PTS. A problem with the VCS score is that it takes into account the use of compression therapy. Three points are added for the compliance with compression therapy and with a total score of 4, mild-to-moderate disease is classified. Consequently, non-compliant patients are graded as less severe disease and patients who wear stockings to prevent development of PTS after DVT have, by definition with only one minor symptom present, already mild-to-moderate disease. The VCS without compression therapy showed a larger difference in mean AVP between mild-to-moderate and severe PTS, but the discriminatory power decreased.

The Widmer classification is based on objective signs, which rarely improve over time. Thus, only detection of deterioration is possible. Hence, it can be used to measure prevalence of PTS after previous DVT, but is not useful as an outcome for treatment after DVT or of treatment of PTS. We observed a low discriminatory power between DVT and control legs for the Widmer classification in comparison to other definitions. However, a moderate to good association with the Brandjes, Prandoni and CEAP scores, and a fair correlation with the AVP were observed.

The definition of Brandjes includes subjective complaints and objective clinical signs. It had a good discriminatory power, but patients with normal or only mildly increased AVP were also classified as severe disease. Potentially this can be explained by the use of the binary classification of the presence of signs and symptoms rather than an ordinal scale, which is generally recommended for scoring of signs and symptoms.

Finally, the score of Prandoni, also based on subjective complaints and objective clinical signs, combined a good discriminatory power with a reasonable relation with AVP. Moreover, this score has been shown to have good reproducibility, and to correlate well with the patient's perception of the interference with daily life ${ }^{14}$ and generic quality of life measures ${ }^{15}$. The only disadvantage is the absence of specific criteria for grading of the individual elements of the score.

Another definition of PTS used by Ginsberg et al. included the measurement of valvular reflux and was not included in our evaluation. This definition requires the combination of pain and swelling, that are of at least 1 month duration and typical in character ${ }^{16}$. Hence, this definition is likely to be less sensitive. In addition, the measurement characteristics have not been assessed.

Some methodological aspects of our evaluation merit attention. The different scoring systems were all separately scored on the same day, by the same observer. 
Hence, differences between the different classifications cannot be due to interobserver variation of fluctuation of signs and symptoms ${ }^{17}$. However, this classification was made by an observer who was unaware of AVP results. The AVP measurements were made blind from scores on PTS on a later occasion using a software algorithm to define the AVP. Of all patients included, both legs were clinically scored and analyzed separately, without taking into account the correlated data-structure. For the development of tests, however, this was regarded as acceptable. In addition, the presence of patients with bilateral DVT in the current study would have made such a case control type of analysis difficult.

\section{CONCLUSION}

Although all clinical definitions of PTS were highly statistically significantly associated with the gold standard, invasively determined ambulant venous pressure, their ability to discriminate between DVT and control legs as well as the observed prevalence of PTS differed substantially. The definition that combines good discriminatory power with a plausible correlation to the gold standard was the definition of PTS according to Prandoni. Since this definition has known measurement properties it seems to be the definition of choice for future studies, especially if criteria for the grading of individual elements of the scoring system were to be made explicit.

\section{REFERENCES}

1. Lensing AW, Prandoni P, Brandjes D, Huisman PM, Vigo M, Tomasella G, et al. Detection of deep-vein thrombosis by real-time B-mode ultrasonography. N Engl J Med 1989:320:342-5.

2. Prandoni P, Lensing AW, Bernardi E, Villalta S, Bagatella P, Girolami A. The diagnostic value of compression ultrasonography in patients with suspected recurrent deep vein thrombosis. Thromb Haemost 2002;88:402-6.

3. Prandoni P, Lensing AW, Cogo A, Cuppini S, Villalta S, Carta M, et al. The long-term clinical course of acute deep venous thrombosis. Ann Intern Med 1996;125:1-7.

4. Brandjes DP, Buller HR, Heijboer H, Huisman MV, de Rijk M, Jagt H, et al. Randomised trial of effect of compression stockings in patients with symptomatic proximal-vein thrombosis. Lancet 1997:349:759-62.

5. Widmer LK. Stathelin HB. Nissen C. A. Sd. Venen-, Arterien-, Krankheiten, koronaire Herzkrankhei bei berufstatigen. In. Bern: Verlag Hans Huber; 1981. 66-82.

6. Porter JM, Moneta GL. Reporting standards in venous disease: an update. International Consensus Committec on Chronic Venous Disease. J Vase Surg 1995;21:635-45.

7. Rutherford RB. Padberg FT. Jr., Comerota AJ. Kistner RL, Meissner MH, Moneta GL. Venous severity scoring: An adjunct to venous outcome assessment. J Vase Surg $2000: 31: 1307-12$

8. Criado E. L.aboratory evaluation of the patient with chronic venous insufficiency (chapter 133). In: Rutherford RB, ed. Vascular surgery. 4th ed. Philadelphia: W. B Saunders company: 1995. $1771-1785$. 
9. Meissner MH, Natiello C, Nicholls SC. Performance characteristics of the venous clinical severity score. J Vasc Surg 2002;36:889-95.

10. Nicolaides AN, Zukowski A]. The value of dynamic venous pressure measurements. World J Surg 1986;10:919-24.

11. Belcaro G, Christopoulos D, Nicolaides A. Venous insufficiency: non-invasive testing. In: Bergan Jl. Kintner R, eds. Atlas of venous surgery. Philadelphia: Saunden; 1992. 9-24.

12. Kriessmann A. [Peripheral phlebodynamometry. Basis, technics, capabilities]. Vasa Suppl 1975; 4:1-35.

13. Fleiss J. Statistical methods for rates and proportions. New York: Wiley: 1981.

14. Villalta S, Bagatella P. Piccioh A. Lensing AW, Prins MH, Prandoni P. Assessment of validity and reproducibility of a clinical scale for the post-thrombotic syndrome. Haemostasis 1994;24:158A.

15. Kahn SR, Hirsch A. Shrier I. Effect of postthrombotic syndrome on health-related quality of life after deep venous thrombosis. Arch Intern Med 2002:162:1144-8.

16. Ginsberg JS, Hirsh J. Julian J, Vander LaandeVries M, Magier D, MacKinnon B, et al. Prevention and treatment of postphlebitic syndrome; results of a 3-part study. Arch Intern Med 2001: 161:2105-9.

17. Uhl JF, Cornu-Thenard A. Carpentier P, Schadeck M, Parpex P, Chleir F, Reproducibility of the " $\mathrm{C}$ " classes of the CEAP classification. J. Phlebology 2001;1:39-48. 


\section{Chapter 5}

Therapy of acute deep vein thrombosis and prevention of the post-thrombotic syndrome A survey among dermatologists in the Netherlands 


\section{RESULTS}

\section{Study population}

Of the 324 questionnaires sent to all of the dermatologists in the Netherlands, 203 $(63 \%)$ were returned at first mailing. The 121 reminders resulted in the return of an additional 58 questionnaires. Thus a total response rate of $81 \%(261 / 324)$ was achieved. Of the respondents, $191(73 \%)$ were involved in phlebology. Their responses were used for further analyses. Of the other 70 respondents, 11 had recently retired, and 59 were not or only rarely involved in phlebology.

\section{Diagnostic approach}

Of the 191 dermatologists, 93 referred patients to other specialists upon suspicion of deep vein thrombosis (radiologists, internists, and surgeons), and 98 performed diagnostic procedures themselves. Of these, a small group of $7(7 \%)$ dermatologists were doing the diagnostic procedure for deep vein thrombosis for the entire hospital, whereas the other 91 did the diagnostic procedure only for their own patients. In a great majority of cases (94/98) duplex ultrasound was used for diagnostic purposes. Before they sent the patient for further diagnostic procedures to the radiologist or vascular laboratory, $32(33 \%)$ dermatologists used bidirectional doppler and $9(9 \%)$ performed impedance plethysmography.

\section{Therapeutic approach}

The majority $174 / 191(91 \%)$ indicated that treatment of deep vein thrombosis in the acute phase was initiated by internists, while $40 / 191$ (21\%) of the dermatologists also initiated treatment for deep vein thrombosis in referred patients.

Of the 191 dermatologists, $114(60 \%)$ indicated that a standardised protocol for treatment of deep vein thrombosis was available in their hospital, $55(29 \%)$ indicated that no such protocol existed, while $22(12 \%)$ were not aware of its presence or absence. Involvement of the general practitioner in at-home administration of subcutaneous low-molecular-weight heparin was indicated by $95(50 \%)$ dermatologists. Of these dermatologists, $56(59 \%)$ were involved in the development of the protocol for out-patient treatment.

\section{Acute phase compression therapy}

In table I compression therapy in the acute phase was related to the use of diagnostic measures for deep vein thrombosis. A clear association was found between the command of diagnostic measures for deep vein thrombosis and compression ther- 
Table 1 Compression therapy given by dermatologests in the acute phase of decp vein thrombosis against initiating diagnostic procedures for suspected deep vein thrombosis. (Chi square test: $p<$ $0.001)$.

\begin{tabular}{lcccc}
\hline & \multicolumn{2}{c}{ Compression therapy in the acute phase } & \multirow{2}{*}{ Total } \\
\cline { 2 - 4 } & & Yes & No & \\
\cline { 2 - 5 } & Yes & 78 & 15 & 93 \\
Dagnostic procedures initiated by & No & 56 & 42 & 98 \\
dermutologists involved in phlebology & & 134 & 57 & 191 \\
Total & & &
\end{tabular}

apy in the acute phase $(\mathrm{p}<0.001)$. It is noteworthy that not all patients with deep vein thrombosis received compression therapy. Compression therapy in the acute phase mostly consisted of compression bandages. The majority of dermatologists preferred early mobilisation. As indications for bed rest, deep vein thrombosis of the pelvic region, common femoral vein and pulmonary embolism were mentioned.

\section{Maintenance compression therapy}

Before installing compression therapy, an ankle-brachial index was done on indication to detect arterial insufficiency by $48 / 189(26 \%)$ dermatologists. In the maintenance phase, elastic compression stockings were prescribed. Information about the length of the elastic compression stockings was received from 179 dermatologists. Knee-length elastic compression stockings were prescribed by 69 (39\%), 6 dermatologists $(3 \%)$ always gave thigh-length elastic compression stockings and $104 / 179(58 \%)$ prescribed both lengths. Of these last 104 dermatologists, $45(43 \%)$ indicated that extension of the thrombus mass was a reason to use thigh-length elastic compression stockings, $8(8 \%)$ indicated leg swelling, and $14(14 \%)$ always started with thigh-length elastic compression stockings. Table 2 shows that most dermatologists $(54 \%)$ gave class III elastic compression stocking as final therapy. The brand of the elastic compression stockings to be used in the maintenance phase was decided by dermatologists alone in $97 / 185(53 \%)$ cases, in $31(17 \%)$ cases the decision was made in deliberation with the bandager, while in $57(31 \%)$ cases the bandager alone decided on the brand generally. The bandager took measurements of individual leg size. Only $27(15 \%)$ dermatologists indicated that they measured stockings themselves in patients with abnormal leg sizes. Advice about the duration of use of elastic compression stockings varied as shown in table 3. Lifelong elastic compression stockings were prescribed when signs of post-thrombotic syndrome appeared. Estimation of the compliance with elastic compression stockings ranged from $12-100 \%$, average $71 \%$ (SD $18 \%$ ).

$143 / 184(78 \%)$ of the dermatologists indicated that after the prescription of elastic compression stockings, the patient was seen at least once at the outpatient depart- 
Table 2 Elastic compression stockings prescribed by dermatologists in the maintenance phase of deep vein thrombosis.

\begin{tabular}{|c|c|c|c|}
\hline \multirow{2}{*}{$\begin{array}{l}\text { Different compression classes according } \\
\text { to the CEN (European Committee for } \\
\text { Standardization) }\end{array}$} & \multicolumn{2}{|c|}{ Pressure at the ankle level in } & \multirow{2}{*}{$\begin{array}{l}\text { Prescription by } \\
\text { Dermatologists } \\
(\%)\end{array}$} \\
\hline & $\mathrm{hPa}_{\mathrm{a}}$ & $\mathrm{mmHg}_{\mathrm{H}}$ & \\
\hline Flat-knitted class II & $31-43$ & $23-32$ & $27(15 \%)$ \\
\hline Circular-knitted class II & & & $21(11 \%)$ \\
\hline Flat-knitted class III & $45-61$ & $34-46$ & $99(54 \%)$ \\
\hline Circular-knitted class III & & & $33(18 \%)$ \\
\hline Miscellaneous & & & $4(2 \%)$ \\
\hline Total & & & $184(100 \%)$ \\
\hline
\end{tabular}

Table 3 Advise which period after deep vein thrombosis patients have to wear elastic compression stockings given by Dutch dermatologists involved in phleboiogy.

\begin{tabular}{lcc}
\hline & Dermatologists & $\%$ \\
\hline No advise & $4 / 181$ & 2 \\
3 months & $4 / 181$ & 2 \\
$3-6$ months & $12 / 181$ & 7 \\
$6-12$ months & $39 / 181$ & 22 \\
$12-24$ months & $73 / 181$ & 40 \\
More than 24 months & $49 / 181$ & 27 \\
\hline
\end{tabular}

ment. 173/185 (94\%) of the dermatologists indicated that other specialists consulted them for a second opinion for patients with post-thrombotic syndrome.

\section{DISCUSSION}

Our survey indicates that dermatologists in the Netherlands are interested in the prevention of the post-thrombotic syndrome of patients with acute deep vein thrombosis. However, their involvement in the actual management of these patients as well as the development of standardised treatment protocols for these patients is limited. For referred patients, compression bandages are usually applied in the acute phase, while class III elastic compression stockings are used in the maintenance phase. There seems to be a great uncertainty about the strategy of mobilisation in the acute phase, which can be linked to the absence of clear evidence.

Compression therapy reduces the edema of the leg in acute deep vein thrombosis. Although the precise mechanism of compression therapy is unknown, it is hypothesised that in dilated veins the function of valves is improved by moving these venous valves closer together through reduction of the venous capacity. In addition, constriction of the veins increases the flow velocity, reduces transcapillary fil- 
tration and decreases the venous hypertension in the leg vein system ${ }^{13-15}$. In spite of the available evidence for the efficacy of compression therapy with elastic compression stockings to reduce the incidence of the post-thrombotic syndrome in patients with deep vein thrombosis ${ }^{2}$, our survey indicates that this non-pharmaceutical treatment is not used for all patients. In a recent survey of the management of deep vein thrombosis in general practice in the Netherlands, compression therapy was not even mentioned as part of the treatment strategy ${ }^{16}$. Since $60 \%$ of general practitioners indicate that they treat patients with deep leg vein thrombosis at home, sufficient attention to the use of compression therapy in treatment protocols involving the general physician and hospital based care is needed. Otherwise, the beneficial effects of compression therapy may be withheld from the majority of patients with deep vein thrombosis. In view of the experience of dermatologists in the use of compression therapy, both acute and long-term, it would be optimal to involve this group of specialists in the development of shared care management models for patients with deep vein thrombosis, to avoid sub-optimal care for these patients.

In general, compression bandages with short-stretch materials should be given in the acute phase; as they exert moderate compression at rest but high pressure during walking because of poor elasticity. Therefore, they are well tolerated and can be left on the leg at night. When care has been taken about arterial circulation as in patients with diabetes mellitus and arterial insufficiency (ankle-brachial index below 0.8 ), compression therapy will give relief from pain and restore the ability to walk freely within a short period of time ${ }^{17}$.

Compliance with compression therapy was estimated at $70 \%$ in this survey, whereas, in the Tübingen study only $47 \%$ of the patients actually wore their elastic compression stockings ${ }^{18}$. Only well-informed patients understand the necessity for treatment and agree to wear elastic compression stockings. Learning simple skills like putting on elastic compression stockings is also important. The prescribing physician needs to be acquainted with the manufacturer's product range in order to combine individual requirements in terms of compression class, fit and ease of putting on elastic compression stockings.

Outpatient treatment of acute deep vein thrombosis is effective, safe and practicable. Mobile patients treated with LMWH and ambulant compression therapy have no increased risk of pulmonary embolism regardless of the size or location of the thrombi ${ }^{8}$. In our questionnaire, dermatologists indicated that bed rest was given to avoid clots from breaking off and causing pulmonary embolism of patients with extensive ileofemoral thromboses. In contrast with this, the study of Partsch ${ }^{17}$ showed that the progression of thrombi in the femoral vein was greater and occurred more frequently in the bed rest group than in ambulant groups. Throm- 
bus propagation depends on the level of anticoagulation and is influenced by the amount of stasis. Therefore mobilisation of patients with deep vein thrombosis directly after diagnosis and application of LMWH is essential. Guidelines about ambulant compression therapy were not clearly given in the consensus meeting of the Dutch organisation for quality care because no literature was available at that time. However, clear guidelines concerning selection of patients for hospital or home treatment are needed.

The use of surveys to review current practice has pitfalls. We believe that our results represent the Dutch practice, since we achieved a favourably high response rate of $81 \%$. However, willingness to provide the 'correct' answer, rather than the true reflection of current practice could have resulted in an overly optimistic view of the current state of affairs. Still, our results indicate that considerable improvements are required in the use of compression therapy. For other areas of our survey, such as duration of compression therapy and mobilisation in the acute phase no hard evidence is available, and it is likely that these answers truly reflect current practice.

We conclude from this survey that internists are mainly in charge of treating deep vein thrombosis with anticoagulants. Compression therapy is mostly done by dermatologists.

\section{RECOMMENDATIONS}

Dermatologists are willing to treat and capable of management of deep vein thrombosis with ambulant compression therapy. Shared care type management models should be developed to ensure optimal care of patients with deep vein thrombosis. All professionals involved in the care of these patients should participate in this development.

\section{REFERENCES}

1. Prandom P, Lensing AW, Cogo A, Cuppini S, Villalta S, Carta M, et al. The long-term clinical course of acute deep venous thrombosis. Ann Intern Med 1996;125:1-7.

2. Brandjes DP, Buller HR. Hejboer H. Huisman MV, de Rijk M, Jagt H, et al. Randomised trial of effect of compression stockings in patients with symptomatic proximal-vein thrombosis. Lancet 1997;349:759-62.

3. Eichlisberger R, Frauchiger B, Widmer T, LK W, Jager KA. Spatfolgen der tiefen venenthrombose: ein 13-jahres follow-up von 223 Patienten. Vasa 1994:23:235-243.

4. Franzeck UK. Schalch I, Jager KA, Schneider E, Grimm J. Bollinger A. Prospective 12-year follow-up study of clinical and hemodyname sequelae after deep vein thrombosis in low-risk patients (Zunch study). Circulation 1996;93:74-9. 
5. Callam MJ. Ruckley CV, Harper DR, Dale IJ. Chronic ulceration of the leg: extent of the problem and provision of care. Br Med J (Clin Res Ed) 1985;290:1855-6.

6. Margolis DJ, Bilker W, Santanna J, Baumgarten M. Venous leg uleer: incidence and prevalence in the elderly. J Am Acad Dermatol 2002;46:381-6.

7. Bosanquet N, Franks P, Moffatt C, Connolly M, Oldroyd M, Brown P, et al. Community leg ulcer clinics: cost-effectiveness. Health-Trends 1993;25:146-8.

8. Schellong SM, Schwarz T, Kropp J. Prescher Y, Beuthien-Baumann B, Daniel WG. Bed rest in deep vein thrombosis and the incidence of scintigraphic pulmonary embolism. Thromb Hacmost 1999;82 Suppl 1:127-9.

9. Prandomi P, Lensing AW, Prins MH, Bagatella P, Scudeller A, Girolami A. Which is the outcome of the post-thrombotic syndrome? Thromb Haemost 1999,82:1196-7.

10. Partsch H. Compression therapy of the legs. A review. J Dermatol Surg Oncol 1991:17:799-805.

11. Koopman MM, Prandoni P, Piovella F, Ockelford PA, Brandjes DP, van der Meer J, et al. Treatment of venous thrombosis with intravenous unfractionated hepanin administered in the hospital as compared with subcutaneous low-molecular-weight heparin administered at home. The Tasman Study Group. N Engl J Med 1996;334;682-7.

12. Blattler W, Kreis N, Blattler IK. Practicability and quality of outpatient management of acute deep venous thrombosis. J Vasc Surg 2000;32:855-60,

13. Brakkee AJM, Kuiper JP. The influence of compressive stockings on the haemodynamics in the lower extremities. Phlebology 1988;3:147-153.

14. Partsch H. Do we need firm compression stockings exerting high pressure? Vasa 1984;13:52-7.

15. Rogers LQ. Lutcher CL. Streptokinase therapy for deep vein thrombosis: a comprehensive review of the English literature. Am J Med 1990;88:389-95.

16. van der Velde EF, Kraijenhagen RA, van Weert HC. Turkstra F, Buller HR. Survey of the management of deep vein thrombosis in general practice in the Netherlands. Neth J Med 2000;57:135-41.

17. Partsch $\mathrm{H}$, Blattler W. Compression and walking versus bed rest in the treatment of proximal deep venous thrombosis with low molecular weight heparin. J Vasc Surg 2000;32:861-9.

18. Fischer H. Venenleiden: Eine repräsentative Untersuchung in der Bundesrepublik Deutschland. Munich, Vienna, Baltimore: Urban u. Schwarzenberg: 1981. 


\section{Chapter 6}

\section{Identifying inappropriate hospital stay in patients} with venous thromboembolism 


\section{ABSTRACT}

Background Traditionally, venous thromboembolism was treated in a hospital setting. Nowadays, low molecular weight heparin preparations allow most deep vein thrombosis patients to have home therapy. The objective of this study was to evaluate if in the past the treatment of deep vein thrombosis in a hospital setting was appropriate, in the context of modern opinion, using the Dutch Appropriateness Evaluation Protocol. If so, the Dutch Appropriateness Evaluation Protocol could be used to assess the appropriateness of the present hospital stay of other patient groups.

Methods A retrospective research of patients treated during 1995- 1998 for deep vein thrombosis or pulmonary embolism was conducted; assessing the appropriateness of the patient's hospital stay using the Dutch Appropriateness Protocol.

Results Only $27.1 \%$ of the treatment for deep vein thrombosis was found to be appropriate in a hospital setting and related to specific hospital care. Inappropriate stay was mostly caused by delays in hospital and discharge procedures. Of the patients with pulmonary embolism, $50.2 \%$ needed hospital stay. This proportion was statistically significantly higher than in deep vein thrombosis patients $(p<0.001)$. The extent of the deep vein thrombosis was not related to the length of bed rest prescribed or mortality.

Condusions The Dutch Appropriateness Evaluation Protocol was sensitive enough to identify inappropriate hospital stay in the past within venous thromboembolism patients. Additional research into other patient groups is indicated to provide guidelines to improve the efficiency of the hospital stay of every patient group.

\section{INTRODUCTION}

The annual incidence of deep vein thrombosis (DVT) and / or pulmonary embolism (PE) is 2-3 per 1000 inhabitants. Traditionally, patients with venous thromboembolism (VTE) were treated with intravenous heparin and strict bed rest, followed by oral anticoagulants. Hospital admission was recommended to facilitate treatment with intravenous (IV) heparin for at least five days and was frequently associated with bed rest. The approval of low molecular weight heparin preparations ( $\mathrm{LMWH}$ ) for the treatment of DVT has revolutionized the management of this disease. Several meta-analyses involving randomized controlled studies have shown that LMWH administered subcutaneously is as effective and safe as unfractionated heparin given intravenously ${ }^{1}$. Laboratory monitoring is not necessary and body weight adjusted doses of LMWH can be injected subcutaneously which allows a majority of patients suffering form DVT to have home therapy ${ }^{2,3}$.

Nowadays, there is a tendency to reduce the length of hospital stay or even avoid hospital admissions, mostly due to budget restrictions and for efficiency reasons. This tendency has led to the development of several tools to assess the appropriateness of hospital admissions and / or stay and to provide management information to control these processes ${ }^{4}$. Appropriate stay is considered to be: up to standard, effective, efficient and tailored to the patients' actual needs 5 . In other words: inap- 
propriate patient stay is neither effective (it serves no clinical purpose) nor efficient (resources cannot be used optimally). Tools to assess appropriateness of hospital stay could also be used in order to systematically search for patient groups for whom hospital stay could be avoided.

Since the management of DVT has been proven as effective and safe in an ambulatory setting as in a hospital setting, the hospital stay of most DVT patients in the past can be considered inappropriate in the context of modern opinion. If the past 'inappropriate' hospital stay could be identified by the use of a 'modern' tool, this would be an indication that this tool could indeed be used to assess the appropriateness of present hospital stay of other patient groups. Hence, the objective of this study was to evaluate if in the past the treatment of deep vein thrombosis in a hospital setting was appropriate in the context of modern opinion, using the Dutch Appropriateness Evaluation Protocol (DAEP). Therefore, in this study, patients admitted for PE were included as comparative group.

\section{METHODS}

\section{Setting}

This study was conducted at the university hospital of Maastricht. This 715-bed teaching hospital is located in the south-eastern part of the Netherlands. In 2001 this hospital admitted about 22,000 patients and generated about 200,000 days of stay with an average length of stay of 9 days. The treatment protocol of both DVT and PE consisted until 1996 of intravenous unfractionated heparin. Subsequently the DVT treatment protocol changed to $\mathrm{LMWH}$, one-day bed rest, and ambulant compression therapy. PE continued to be treated intravenously with unfractionated heparin and bed rest. At-home treatment of deep vein thrombosis was introduced during 1999.

\section{Assessment of the appropriateness of bed rest in the treatment of DVT}

We used the Dutch Appropriateness Protocol (DAEP) as the initial tool to assess the appropriateness of bed rest in the treatment of DVT. This tool is a criteria-based decision support tool for determining the necessity of hospital stay based on sets of generic (diagnosis-independent) and explicit (care-related) criteria ${ }^{6}$. It consists of 19 criteria for appropriate stay, related to medical and nursing services and a list of reasons for inappropriate patient stay (appendix 1). If none of the criteria can be met the day of stay is considered to be "inappropriate" in an in-patient setting and the list of reasons has to be filled out, specifying the reason for inappropriate stay. In this study the IV administration of heparin was not scored for as a cri- 
terion for appropriate stay. Appropriate hospital stay was defined as: "Inpatient stay, requiring continuous and active medical, nursing or paramedical treatment, which could not be provided through extramural care, day care or outpatient care with regard to existing legislation." Bed rest was defined as "compulsory stay in bed all day, with permission to go to the bathroom".

\section{Study sampling and data collection}

The study was set up as a retrospective cohort study. The written and electronic medical charts from patients admitted for venous thromboembolism (VTE) during the period from January 1995 to January 1999 were reviewed. If a patient was admitted several times during this period, each hospital stay of this patient was assessed separately. Periods of hospital stay that concerned VTE other than in leg and/or lung were excluded from further review. The following data were extracted from the hospital information system and patient charts: age, gender, date of admission and discharge, date of death, existence and date of occurrence of malignancy and data on objective tests for DVT and PE. In addition, it was assessed whether VTE was the main reason for hospital admission (primary diagnosis) or not (secondary diagnosis). Thereafter, all days of hospital stay during treatment of VTE were evaluated using the DAEP to assess the appropriateness of the patient's stay for treatment of VTE in a hospital setting. All deaths and occurrence of malignancy were recorded until May 2002.

\section{Statistical analysis}

The analysis was restricted to patients with objectively documented diagnosis of DVT or PE. Periods of stay were considered to be related to DVT or PE with or without DVT. Based on the available medical data, patients were divided in four groups; DVT and PE positive or negative. Descriptive statistics were calculated for the separate groups. We used the Student's t-test to test the difference in means between groups if data were normally distributed, while the Mann Whitney U-test was used if data were not normally distributed. The Pearson Chi-square test was used to test the significance of differences in frequencies between groups. All data analyses were performed using the SPSS-PC software package, version 10,0.

\section{RESULTS}

\section{Patient population}

Between January 1995 and January 1999 a total of 639 admissions (596 patients) coded as venous thromboembolism (VTE) occurred. Data on 29 admissions (27 
Table 1 Climcal charactenstacs

\begin{tabular}{|c|c|c|c|}
\hline & $\begin{array}{l}\text { DVT patients } \\
\mathrm{n}=262\end{array}$ & $\begin{array}{l}\text { PE patients }(+1-\text { DVT }) \\
n=249\end{array}$ & ) \\
\hline \multicolumn{4}{|l|}{$\operatorname{Sex}(\theta)$} \\
\hline - male & $135(51.5)$ & $108(43.4)$ & 0.054 \\
\hline - female & $127(48.5)$ & $141(56.6)$ & \\
\hline$A_{g e}(S D)$ & $60.1(18.4)$ & $64.5(16.9)$ & 0.005 \\
\hline Primary diagnosis (\%) & $163(6.2 .2)$ & $144(57.8)$ & 0.481 \\
\hline secondury diagnosis & $98(37.4)$ & $104(41.8)$ & \\
\hline Mahgnancy (\%6) & $83(31.7)$ & $60(24.1)$ & 0.045 \\
\hline - in the past & $23(8.8)$ & $23(9.2)$ & \\
\hline present on admission & $22(8.4)$ & $32(12.9)$ & \\
\hline occurring during follow-up* & $38(14.5)$ & $5(2.0)$ & $<0.001$ \\
\hline Deceased (until May 2002) & $90(34.4)$ & $104(41.8)$ & 0.084 \\
\hline Months after admission (median / iqr ${ }^{* \star *}$ ) & $9 \longdiv { 2 1 . 2 5 }$ & $1 / 19.5$ & \\
\hline Within 1 month after admission (86) & $22(8.4)$ & $56(22.5)$ & $<0.001$ \\
\hline Length of stay (median / $25-75$ percentile) & $9 / 7-20$ & $12 / 8-18$ & 0.268 \\
\hline
\end{tabular}

* until may 2002, **iqri interquartile range

patients) were not available and 51 admissions ( 50 patients) for other than leg vein thrombosis or pulmonary embolism were not assessed. Hence, information on 559 admissions (519 patients) for DVT and/or PE was available for analysis. The diagnosis of VTE was objectively documented by ultrasonography and / or perfusion ventilation lung scanning in 511 admissions.

The clinical characteristics of these patients are shown in table 1. Data showed the mean age to be statistically significantly higher in PE patients. There was no difference found in gender. Overall, in $60 \%$ of the patients DVT and/or PE was the primary diagnosis. In both DVT and PE groups the occurrence of malignancy in the past or during admission showed no differences $(8.4$ to $12.9 \%)(p=0.354)$, while the occurrence of malignancy during follow up was found to be higher among patients with DVT $(14.5 \%)$ than with PE $(2.0 \%)(\mathrm{p}<0.001)$. The median length of hospital stay was rather high in both groups (DVT: 9 days, PE: 12 days). This length of stay was mainly due to patients with secondary DVT or PE (median: 19 days, iqr 25 days), while in all patients with a primary diagnosis the median length of stay was only 9 days (iqr 6 days).

Since co-morbidities can influence the length of hospital stay and bed rest, only data on the group with a primary diagnosis were used for further analysis. The median length of stay of the patients with a primary DVT or PE diagnosis was 8 10 days (table 2). During this stay the patients were actively treated for DVT and/or PE for 4 or 7 days. Data collected at the height of the DVT did not show 
Table 2 Treatment of primary DVT / PE

\begin{tabular}{|c|c|c|c|c|c|c|}
\hline & \multicolumn{3}{|c|}{ Primary DVT } & \multicolumn{3}{|c|}{ Primary PE } \\
\hline & median & $\begin{array}{l}25-75 \\
\text { percentile }\end{array}$ & $\mathbf{n}$ & median & $\begin{array}{l}25-75 \\
\text { percentile }\end{array}$ & $\mathbf{n}$ \\
\hline Overall length of hospital stay in days & 8 & $7-10$ & 163 & 10 & $8-14$ & 144 \\
\hline $\begin{array}{l}\text { Length of anticoagulant therapy during } \\
\text { hospital stay in days }\end{array}$ & 4 & $3-6$ & 156 & 7 & $6-9$ & 141 \\
\hline $\begin{array}{l}\text { Length of combination bed rest with } \\
\text { intravenous Heparin }\end{array}$ & 5 & $3-7$ & 7 & 7 & $5-10$ & 24 \\
\hline - subcutaneous LMWH & 5 & $4-7$ & 132 & 5 & $3-7$ & 3 \\
\hline $\begin{array}{l}\text { No bed rest prescribed, only } \\
. \text { intravenous Heparin } \\
\text {. subcutaneous LMWH }\end{array}$ & $\begin{array}{l}3 \\
0\end{array}$ & $\begin{array}{l}2-4 \\
0\end{array}$ & $\begin{array}{l}9 \\
9\end{array}$ & $\begin{array}{l}7 \\
0\end{array}$ & $\begin{array}{l}5-8 \\
0\end{array}$ & $\begin{array}{r}108 \\
7\end{array}$ \\
\hline
\end{tabular}

Table 3 Reasons for appropnate hospital stay during treatment primary DVT / PE

\begin{tabular}{lcc}
\hline & DVT positive & PE positive \\
\hline Patients mecting DAEP criteria during tratment of DVT / PE* & $\mathrm{n}=44(27.1 \%)$ & $\mathrm{n}=73(50.2 \%)$ \\
Reasons for appropriate stay in percentages & & \\
threatening stuations, requiring acute clinical care & 7.8 & 23.2 \\
care, requinng clinical control or observation & 48.3 & 42.0 \\
montoring & 5.8 & 10.1 \\
infusion and / or medication & 36.6 & 23.2 \\
nursing care & - & 1.4 \\
\hline
\end{tabular}

- Intravenous administration is a criterion for hospital admission, excluded as criterion in this study was intravenous Heparin

any difference between levels of thrombosis, mortality, and the length of bed rest prescribed. Mortality in the first month after admission within the DVT group was $8.4 \%(n=22)$ while it was in PE patients $22.5 \%(n=56)(p<0.001)$. During further follow up another 116 patients died, leading to a total mortality in the DVT group of $34.4 \%(n=90)$ and $41.8 \%$ in the PE group $(n=104)$.

\section{Appropriateness of stay}

As said before, only data on patients with a primary diagnosis were assessed. The length of stay and the type and duration of the treatment for DVT and PE are given in table 2. The treatment consisted of intravenous (IV) heparin. IV heparin combined with bed rest, subcutaneous low molecular weighted heparin (LMWH) and bed rest or only LMWH.

As shown in table 3 , of the 163 patients with a primary DVT, only $27.1 \%(n=44)$ met one or more of the DAEP criteria during the period of treatment, indicating this stay to be 'appropriate'. In PE patients $(n=144)$, the proportion of 'appropriate 
Table 4 Reasons for inappropriate hospital stay

\begin{tabular}{|c|c|c|}
\hline & DVT postive & PE positive \\
\hline Median time of overall inapproprate hospital stay in days & 4 & 3 \\
\hline \multicolumn{3}{|l|}{ Reasons for inappropriate stay in percentages } \\
\hline - delay in hospital procedures & 59.3 & 44.4 \\
\hline application not in time & $(25.9)$ & $(22.1)$ \\
\hline $\begin{array}{l}\text { not dear defined medical policy due to procedures, } \\
\text { products or refusal patient }\end{array}$ & $(14.9)$ & $(-)$ \\
\hline - delay in discharge procedures & 29.6 & 38.8 \\
\hline - unavailability of other health care facilities & 7.4 & 5.6 \\
\hline unavalability of test results & - & 11.1 \\
\hline other & 3.7 & - \\
\hline
\end{tabular}

stay' was $50.2 \%$. This proportion was statistically significantly higher than in patients admitted for DVT ( $p<0.001)$. In 73 patients with PE, the frequency of (imminent) threatening situations was higher than in the 44 DVT-patients $(23.2 \%$ vs. $7.8 \%)$.

Table 4 shows that this stay was mainly related to care, requiring specific observation (48.3\%) or the administration of medication / infusion (36.6\%) excluding the IV administration of heparin. Inappropriate stay in both groups was mainly related to delays in internal hospital and discharge procedures $(88.9 \%$ vs. $83.2 \%)$. About one quarter of this inappropriate stay was related to delays in the application or the logistics of diagnostic test performance. Within the DVT group not clear defined medical policy caused about $15 \%$ of the inappropriate stay. The unavailability of other care facilities (e.g. homes for the elderly, rehabilitation homes, primary and/or home care) resulted in only a small proportion of inappropriate stay (7.4 vs. $5.6 \%)$ in both groups.

\section{DISCUSSION}

This study showed that the DAEP can be used to assess the appropriateness of hospital stay for DVT and PE patients and can provide reasons why patients need specific hospital care or why patients remain hospitalized inappropriately. The instrument is sensitive enough to differentiate between different patient groups. This study also showed that bed rest is not appropriate in the treatment of DVT. The idea of a higher risk for PE in patients with extensive DVT in not supported by the data found on co-morbidity in this and other studies?. If bed rest was indicated it was mainly due to co-morbidity. There was no relation found between the location of DVT and the prescription of bed rest. Except for frequent APTT monitoring and specific infusions, there is no indication for hospital stay. So, the appropriateness of hospital stay is mostly determined by reasons not directly related to the 
treatment of DVT / PE. This study confirms previous research reporting that in most cases hospital stay is inappropriate in treating DVT ${ }^{1-3,8}$. Yet, regarding the data in this study, there is reason to believe that there are possibilities for improvement measures for PE patients. Approximately half of these patients could possibly be treated outside a hospital setting. Further research on this matter is indicated. Although it was not the scope of this study, the incidence of malignancy during the follow up was remarkably higher in DVT patients. This finding is confirmed by other studies ${ }^{9.10}$. Therefore, DVT as a possible predictor of malignancy needs further research

The retrospective use of an AEP-based instrument depends on accurate record keeping. Due to deficient record keeping data can be missed. This is already demonstrated in the literature ${ }^{11,12}$. By using the DAEP concurrently, these disadvantages would disappear and more and better data could be collected.

Previous studies at the university hospital of Mastricht ${ }^{6}$ showed, that over $20 \%$ of the total hospital stays are inappropriate and almost half of these inappropriate stays are related to delays in hospital procedures (e.g. not clear defined medical policy, delay in diagnostics, therapy or discharge). Other international studies ${ }^{13}$ showed an even higher proportion of inappropriate hospital stay. If inappropriate stay can be reduced, considerable profits in terms of quality, efficiency and costs are possible. Even if medical record keeping (patient files) is not always as perfect as it should be, this kind of study can provide useful data to analyze specific patient processes or treatment and the operational management of an organization. The data can also provide additional information leading to agreement on medical policy (hospital admission vs. out patient treatment).

\section{CONCLUSION}

We demonstrated that the DAEP was sensitive enough to identify inappropriate hospital stay in the past within a specific patient group for which it has been proven that it can be treated in an outpatient setting. Therefore, it is plausible to use this tool to systematically assess the current hospital stays of other patient groups to reduce or even avoid hospital stays in order to increase hospital efficiency and decrease health care costs. Even so, additional research into other patient groups is indicated to provide guidelines so the treatment or hospital stay can be as efficient as possible for every patient group. 


\section{REFERENCES}

1. Schraibman IG, Milne AA, Royle EM. Home versus in-patient treatment for deep vein thrombosis. Cochrane Database Syst Rev 2001:CD003076.

2. Koopman MM, Prandoni P, Piovella F, Ockelford PA, Brandjes DP, van der Meer J, et al. Treatment of venous thrombosis with intravenous unfractionated heparin administered in the hospital as compared with subcutaneous low-molecular-weight hepann adminustered at home. The Tasman Study Group. N Engl J Med 1996;334:682-7.

3. van Den Belt AG. Prins MH, Lensang AW, Castro AA, Clark OA, Atallah AN, et al. Fixed dose subcutaneous low molecular weight heparins versus adjusted dose unfractionated heparin for venous thromboembolism. Cochrane Database Syst Rev 2000;CD001100.

4. Strumwasser 1. Paranjpe NV, Ronis DL, Share D, Sell LJ. Reliability and validity of utilization review criteria. Appropriateness Evaluation Protocol, Standardized Medreview Instrument, and Intensity-Severity-Discharge criteria. Med Care 1990;28:95-111.

5. Act on quality of Care Facilities (in Dutch). Dutch Law Gazette 1996:341.

6. Panis JGG, Verheggen FWSM. Pop P. To stay or not to stay. The assessment of appropriate hospital stay, a Dutch report. Int. Journal of Quality in Health Care 2002;13:1-13.

7. Partsch H. Blattler W. Compression and walking versus bed rest in the treatment of proximal deep venous thrombosis with low molecular weight heparin. J Vase Surg 2000;32:861-9.

8. van der Velde EF, Kraajenhagen RA, van Weert HC. Turkstra F, Buller HR. Survey of the management of deep vein thrombosis in general practice in the Netherlands. Neth J Med $2000 ; 57 ; 135-41$.

9. Monreal M, Lafoz E, Casals A, Inaraja L. Montserrat E, Callejas JM. et al. Oecult cancer in patients with deep venous thrombosis. A systematic approach. Cancer 1991;67:541-5.

10. Hettiarachchi RJ. Lok J, Prins MH, Buller HR, Prandoni P. Undiagnosed malignancy in patients with deep vein thrombosis: incidence, risk indicators, and diagnosis. Cancer 1998;83:180-5.

11. Ramos-Cuadra A, Marion-Buen J, Garcia-Martin M, Fernandez-Gracia J, Morata-Cespedes MC. Martin-Moreno L, et al. The effect of completeness of medical records on the determination of appropriateness of hospital days. Int J Qual Health Care 1995;7:267-75.

12. Santos-Eggimann B, Sidler M, Schopfer D, Blanc T. Comparing results of concurrent and retrospective designs in a hospital utilization review. Int J Qual Health Care 1997:9:115-20.

13. Lang T, Liberati A, Tampieri A, Fellin G, Gonsalves Mda L, Lorenzo S, et al. A European version of the Appropriateness Evaluation Protocol. Goals and presentation. The BIOMED I Group on Appropriateness of Hospital Use. Int J Technol Assess Health Care 1999;15:185-97. 


\section{APPENDIX}

\section{DAEP LIST of CRITERIA,}

Criteria for appropriate clinical stay

1. Threatening situations, requiring acute clinical
care
(Imminent) carculatory disordens
(Imminent) respiratory disorden
(Imminent) CVA / spinal cord lesion
Inability to void or move bowel
Other critena, (to be specified):

3. Momitonng

Close medical monutonng by a nurse $(>3$ times a day) under physucsan's orders, or according to existing procedure

U. Intake and output measurements

5. Nursing care

Care according to existing procedure/ protocol

Isolation of the patient

Endotracheal suction
2. Care, requiring clinical control or observation: Scheduled for procedure the next day Surgical procedure in operating room Diagnostic procedures

Adjustment of medication

Adjustment of hematological disorders

Wound and drainage care

Patient instruction in nursing techniques

4. Infusions and/or medication

IV administration of tluids and/or nutrition

IV or epidural administration of medication

6 Assessment of appropriate stay is not possible Reasons, (to be specified):

\section{DAEP LIST Of REASONS}

Reasons for inappropriate clinical stay

7. Delay in hospital procedures (diagnostics and / or therapy)

1) Specify:

Due to patient

Panent refusal

Due to peronnel

Application not in time

Incomplete admunstration

Not clear defined medical policy

Due to procedures

Inefficient scheduling

Insufficient out patient work up

Waiting lests

Admesson for urgent dapnostics

Due to products

Products not avalable

9. Unavalability of (test) results Specify: ........................................

11. Prumary care facilties not (yet) available Specify:
8. Delay due to discharge procedures

Due to patient

Patient refusal

Difficulties in home situation

Due to personnel

Discharge procedure not stated in time

Incomplete administration

not clear defined medical planning

Due to procedures

Discharge planning not performed

No consultanion with other care facilities

Therapy diagnostics not completed in time

Due to products

Products not available

10. Pataent is waiting for transfer to other care facility Specify: 


\section{Chapter 7}

\section{Cochrane review}

Non-pharmaceutical measures for prevention of post-thrombotic syndrome 


\section{ABSTRACT}

Background Post-thrombotic syndrome (PTS) is a long-term complication of deep vein thrombosis characterized by chronic complaints, swelling, and skin changes in the affected limb. One in every three patients with deep vein thrombosis develops post-thrombotic sequelae within five years.

Objectives The objective of this review is to determine the relative effectiveness of, and the rate of complications in using non-pharmaceutical interventions in patients with deep vein thrombosis in prevention of the post-thrombotic syndrome.

Search strategy All published reports of non-pharmaceutical interventions in patients with deep vein thrombosis were traced through MEDLINE, and EMBASE (up to and including March 2003) using the search strategy described by the Cochrane Peripheral vascular diseases group. Additional searches included the Cochrane CCTR/Central database, handsearching non-listed journals, and personal communications with researchers.

Selection criteria Randomised controlled trials of non-pharmaceutical interventions of clinically confirmed deep vein thrombosis were selected. Primary outcome consisted of the extent to which they prevented development of the post-thrombotic syndrome. There was no restriction on date or language.

Data collection E analysis Detasls of eligible studies were extracted and summarised using a data extraction sheet. Data extraction was verified by three reviewers independently.

Main results. Three randomised controlled trials on the development of the post-thrombotic syndrome were identified. Two studies compared elastic compression stockings with a pressure of $30-40 \mathrm{mmHg}$ at the ankle with no intervention applied directly after the deep vein thrombosis. The other small study compared elastic compression stockings (pressure $20-30 \mathrm{mmHg}$ ) with one to two sizes too large stockings in patients one year after the deep vein thrombosis. In the treatment group, the overall use of elastic compression stockings was associated with a highly statically significant reduction in the incidence of any post-thrombotic syndrome with OR 0.31 (95\% Cl 0.20-0.48). Also the incidence of severe PTS was reduced with OR $0.39(95 \% \mathrm{CI} 0.20)-0.76)$. In another randomised controlled trial regarding the first nine days after deep vein thrombosis, no difference in pulmonary embolism and extent of thrombus in the femoral vein was found. A statistically significant reduction $(p<0.05)$ of pain, swelling and clinical scores was found, favoring the compression group.

Revieuers' andusions. There is substantial evidence that elastic compression stockings reduced the occurrence of the post-thrombotic syndrome after deep vein thrombosis. No serious adverse effects were mentioned in the studies. Hence, elastic compression stockings should be added to the treatment of deep vein thrombosis to prevent the development of the post-thrombotic syndrome.

\section{BACKGROUND}

Details of eligible studies were extracted and summarized using a data extraction sheet, Data extraction was verified by three reviewers independently.

One out of every three patients with deep vein thrombosis will develop post-thrombotic sequelae within five years ${ }^{1,2}$. Although there is no consensus on 
the definition in the literature, several scoring systems are used to define post-thrombotic syndrome $e^{2.3}$. The main item in all definitions is a (documented) deep vein thrombosis preceding chronic complaints of the leg(s). Complaints may include subjective symptoms of the legs e.g. pain, cramps, heaviness, pruritus (itching), and paresthesia (numbness and tingling sensation), signs of stasis (pre-tibial edema, redness, induration (hardening) of the skin, hyperpigmentation, new venous ectasia (dilatation) and pain during calf compression and venous leg ulceration. All of these complaints have an impact on the quality of life ${ }^{4}$.

The pathophysiology of the post-thrombotic syndrome is not entirely understood. Contributing factors are thought to be deep vein obstruction, venous reflux, and calf muscle pump dysfunction ${ }^{5}$. In the acute phase of deep vein thrombosis, a fresh thrombus in the deep vein produces an obstruction. In the first few months following deep vein thrombosis, recanalisation, a complex process involving fibrinolysis, thrombus organization, and neovascularization (proliferation of blood vessels), occurs $^{6}$. This process can result in valve destruction. Damaged valves, insufficient closure and/or occlusion of the veins increase pressure in the veins (venous hypertension). It is postulated that this venous hypertension disturbs the normal flow in small capillaries, resulting in increased capillary filtration leading to ankle flare, edema in the lower leg, and a number of skin changes which include dermatitis. lipodermatosclerosis and white skin atrophy. (Lipodermatosclerosis is the term given to a hardening of the skin, which may gain a red/brown pigmentation, and is accompanied by wasting of the subcutaneous fat. White skin atrophy consists of small depressions of ivory-coloured hard skin with stippled red spots). Finally, this disturbed microcirculation may lead to a decrease of cutaneous oxygen concentration $\left(\mathrm{TcPO}_{2}\right)$, contributing to delayed healing after cutaneous injury or leading to spontaneous breakdown of the skin (venous leg ulceration) ${ }^{7.8}$. These changes are called chronic venous insufficiency, and when deep vein thrombosis is the source of this insufficiency, it is called the post-thrombotic syndrome,

A number of non-pharmaceutical measures are used for the prevention of post-thrombotic syndrome in the acute phase of deep vein thrombosis. These include elevation of the legs and compression therapy. Compression therapy may consist of circular pressure on the leg with either removable bandages or permanent bandages such as adherent bandage and Unna's paste boot, medical elastic compression stockings, anti-thrombosis stockings or an external intermittent pneumatic device ${ }^{9-12}$. Medical elastic compression stockings are classified according to the pressure they exert, although unfortunately, grading systems are not internationally standardised ${ }^{13}$. This difference complicates analyses. The European Economic Community is working on a European standard for medical compression stockings, the so called CEN (Comité Européen de Normalisation) classification $^{14}$. 
The mechanism of action of compression therapy of the legs is reduction of edema, acceleration of venous blood flow, and improvement of the venous pump function $^{15}$. Very tight non-elastic bandages are used in an attempt to reverse the venous hypertension $^{16}$. Although compression therapy is potentially harmless at first sight, it can lead to complications. Pressure sores may develop if pressure is given at an extremely high level, because it will reduce blood supply to the skin ${ }^{17}$. Similarly, the application of moderate pressures to patients with impaired arterial blood supply to the legs may result in exacerbation of the arterial insufficiency ${ }^{18,19}$.

Since the opinions of clinicians as well as the guidelines of their professional organisations differ in the assessment of the utility of compression therapy for treatment of deep vein thrombosis, there is a need for review of the literature ${ }^{20,21}$.

\section{Objectives}

The objective of this review was to determine the relative effectiveness of, and the rate of complications in using non-pharmaceutical interventions in patients with deep vein thrombosis. Interventions of interest included compression therapy and bed rest. These were compared with no intervention and with each other.

The primary outcome was the extent to which they, nrevented the develqnueno af post-thrombotic syndrome. Secondary outcome measures included reduction of pain, recurrence of deep vein thrombosis, pulmonary embolism, patient satisfaction, quality of life, compliance with compression therapy and costs.

\section{CRITERIA FOR CONSIDERING STUDIES FOR THIS REVIEW}

\section{Types of studies}

Randomised controlled trials (RCTs), or controlled clinical trials (CCTs) evaluating compression therapy and other non-pharmaceutical measures in the treatment of deep vein thrombosis were selected. Trials which used allocation processes which are transparent before assignment such as open list of random numbers, case record, day of the week, surname and so forth, were classified as CCT.

\section{Types of participants}

Men and women of any age with a deep vein thrombosis objectively diagnosed. Methods considered acceptable for diagnosis of deep vein thrombosis included ultrasound, venography and impedance plethysmography. 


\section{Types of intenentions}

The primary intervention was compression therapy. We compared with medical elastic stockings, compression bandages, bed rest and no intervention. Comparison against mechanical devices such as intermittent pneumatic compression was not available. We will include such comparisons should they become available in future.

Anticoagulant therapy and/or surgical intervention for deep vein thrombosis was equal in the patient groups in the trials.

\section{Types of outcome measures}

1) The primary outcome was the occurrence of post-thrombotic syndrome over time. The definitions used in each trial paper for post-thrombotic syndrome were accepted, provided they included a systematic clinical history and scoring of physical examinations.

2) Secondary outcomes included intervention-related complaints and/or complications. The most important of these was pulmonary embolism occurring in the first two weeks after initiation of the treatment. Adverse effects, after initiation of the compression therapy, were of particular importance, as some treatments riave thie potential to affêct tie patient adversely. Common complications were identified and compared between interventions. These included discomfort, pain, pressure sores, and recurrence of thrombosis.

3) Patient satisfaction and quality of life data.

Generic or specific measures of quality of life.

4) Economic analysis.

Cost-effectiveness or cost-benefit analysis.

\section{Search strategy for identification of studies}

This review will draw on the search strategy developed for the Cochrane Peripheral Vascular Diseases Group as a whole, All publications describing (or which might describe) randomised controlled trials (RCTs) and controlled clinical trials (CCTs) of non-pharmaceutical measures of deep vein thrombosis were sought through electronic searches of the Cochrane Peripheral Vascular Diseases Specialised Trials Register (latest date searched 31" March 2003). This Specialised Trials Register has been constructed from regular electronic searches of MEDLINE (1966 onwards), EMBASE (1980 onwards), and The Cochrane Central Register of Controlled Trials (CENTRAL). The full list of journals that have been handsearched, as well as the search strategies for the electronic databases, are described in the 'Search strategies for the identification of studies' section within 
the editorial information about the Cochrane Peripheral Vascular Diseases Group in the Cochrane Library.

In addition we handsearched the following journals: Scripta Phlebologica (1993-2000). Journal of Thrombosis and Haemostasis (2003) and Conference Proceedings of the International society of Thrombosis and Haemostasis $(2001,2002)$ and the International Union of Phlebology (Rome 2001). We also handsearched Compression Bulletin and Scope on Phlebology, both contain abstracts and comments on articles in the field of phlebology. Citations within identified studies were searched. In addition, we wrote to specialists known to be involved in phlebology and interested in post-thrombotic syndrome for details of unpublished and ongoing trials. The relevant data provided were included in this review.

\section{METHODS OF THE REVIEW}

\section{Trial assessment}

One reviewer (DNK) assessed titles and abstracts of studies identified in terms of their relevance and design, according to the selection criteria. Full versions of articles were obtained if, from the initial assessment, they satisfied the inclusion criteria. Another reviewer (MHP or HAMN) checked those rejected. Full papers were checked to identify those that fitted the criteria. Another reviewer (RS) repeated this independently, for verification. Any disagreements were resolved by discussion.

\section{Data extraction}

Details of the studies were extracted and summarised using a data extraction sheet. If data were missing from reports then attempts were made to contact the authors to obtain the missing information. Studies published in duplicate are included only once. Data extraction was undertaken by one reviewer (DNK) and checked for accuracy by a second (RS).

Each study was appraised using a standard checklist to assess the validity of the methods used. Data were collected on:

- Trial setting (country, and whether primary or secondary care)

- Method of randomisation

- Objective outcome, method of assessment and whether blinded or not

- Length of follow-up

- Number of patients (or limbs) randomised

- Inclusion criteria

- Exclusion criteria 
- Description of interventions and co-interventions

- Baseline characteristics of groups for important variables (e.g. first deep vein thrombosis, recurrent deep vein thrombosis)

- Definition of post-thrombotic syndrome

- Duration of follow-up

\section{Results}

- Intention to treat analysis

- Number and reason for withdrawals

- Source of funding

- Use of an a priori sample size / power calculation

It was intended to compare elastic compression stockings versus control, and other comparisons will be made if available in future. We have allowed for:

- Mechanical compression therapy vs, no intervention

- Mechanical compression therapy vs. compression stockings

- Compression stockings versus different brands of compression stockings

\section{Statistical analysis}

RCTs were analysed separately to access the efficacy of the effect estimation calculated with Mantel Haenszel test (Cochrane Software). In the absence of clinical heterogeneity, we performed a Chi-squared test for statistical heterogeneity.

\section{Description of studies}

Four trials were identified that met all the inclusion criteria. The trials of Brandjes ${ }^{1}$ and Prandoni ${ }^{2}$ consisted of 194 and 180 patients, respectively. Both compared graduated elastic compression stockings with an ankle pressure of $30-40 \mathrm{mmHg}$ versus no intervention. Patients were randomised in either group directly after the documented deep vein thrombosis. Assessment took place at least $6 /$ monthly for up to 5 years. Primary outcome was the cumulative incidence of the post-thrombotic syndrome. Both used a self developed scale for the assessment of the post-thrombotic syndrome, based on symptoms and signs in the involved leg.

The trial of Ginsberg $^{22}$ included 47 patients one year after the diagnosed deep vein thrombosis and compared the effectiveness of below knee elastic compression stockings $(20-30 \mathrm{mmHg}$ pressure at the ankle) with placebo stockings (one to two sizes too large). Their patients had no pain or swelling of the leg at the time of inclusion, but all had venous valvular insufficiency measured by plethysmography or Doppler ultrasound. Primary outcome was treatment failure defined as pain and swelling of the leg appearing during further follow up. Patients with symptomatic 
$(n=33)$ and asymptomatic $(n=12)$ deep vein thrombosis were included, while in two patients the clinical presentation was unknown.

The study of Partsch ${ }^{23}$ consisted of forty-five patients randomized into three groups. Comparison was done with inelastic compression bandages (Unna boots on the lower leg, adhesive bandages on the thigh), thigh-length compression stockings (class II), and bed rest for nine days without compression. Primary outcomes were the reduction of pain and leg circumference between baseline and day 9. while on both days the presence of pulmonary embolism and extent of deep vein thrombosis were objectively assessed by ventilation-perfusion lung scintography and duplex ultrasound scans, respectively. After nine days all patients received elastic compression stockings.

\section{Methodological quality of included studies}

True randomisation with allocation concealment (i.e. the person recruiting the patient into the trial was unaware of which group they would be recruited to) was achieved in all four trials. Study personnel were unaware of allocation at the time of outcome assessment. In the trial of Ginsberg ${ }^{22}$ the outcome was a relative scoring of current symptoms versus previous symptoms over three months intervals.

\section{RESULTS}

\section{Development of the post-thrombotic syndrome}

In the study of Brandjes ${ }^{1}$, any post-thrombotic syndrome occurred in $19(20 \%)$ of 96 patients treated with stockings and was severe in 11 patients, while those numbers were $46(47 \%)$, and 23 , respectively of 98 patients in the control group. Prandoni ${ }^{2}$ obtained similar results in his study, any post-thrombotic syndrome occurred in $22(24 \%)$ of 90 patients treated with stockings and was severe in 3 patients, while those numbers were $44(49 \%)$, and 9 , respectively of 90 patients in the control group. The risk reduction of any and severe post-thrombotic syndrome were highly statistically significant, with $\mathrm{p}$ values for both of $\mathrm{p}<0.001$. In the study of Ginsberg ${ }^{22}, 0(0 \%)$ of 24 of the active stocking group were considered treatment failures compared with $1(4.3 \%)$ of 23 treated with placebo stockings. We are awaiting data about the incidence of the post-thrombotic syndrome of the patients in the study of Partsch ${ }^{23}$. As shown in figure 1 the overall use of elastic compression stockings was associated with a highly statistically significant reduction in the incidence of any post-thrombotic syndrome with OR $0.31(95 \% \mathrm{CI} 0.20-0,48)$. Figure 2 shows the incidence of severe post-thrombotic syndrome, reduction with OR $0.39(95 \% \mathrm{Cl} 0.20-0.76)$. 
Sophu-

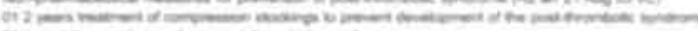

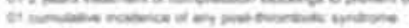

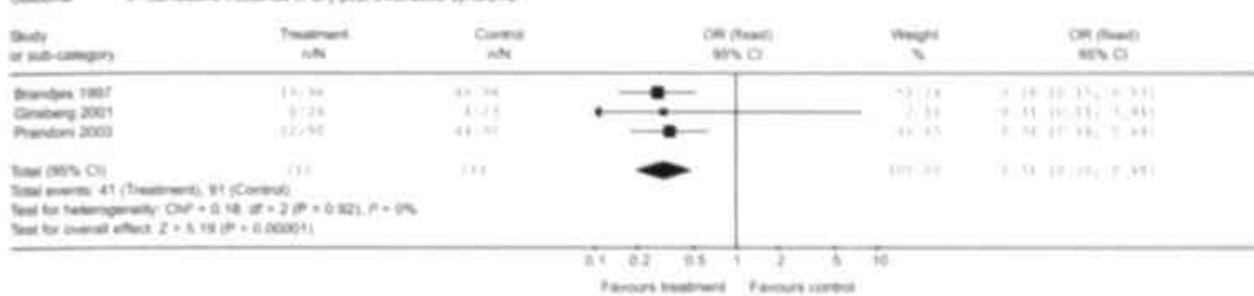

Figure 1 Cumulative incidence of any post-thrombotic syndrome after 2 years treatment of compression stockings in order to prevent development of the post-thrombotic syndrome.

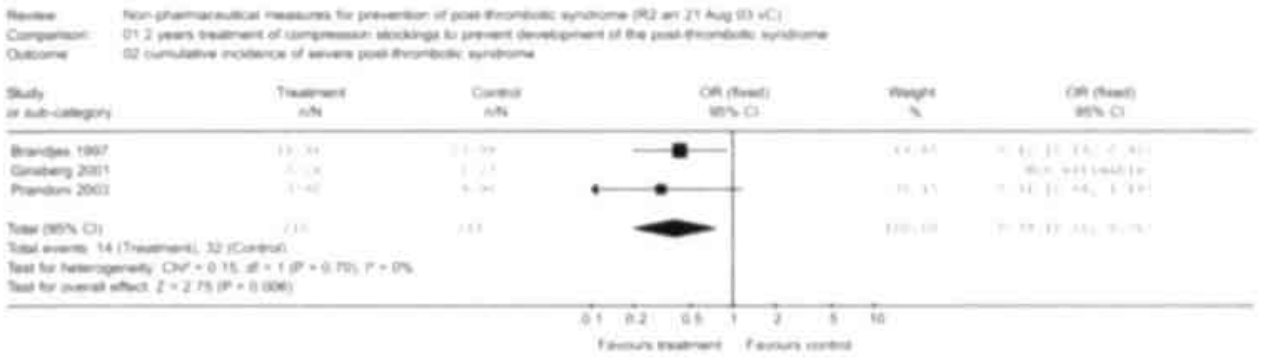

Figure 2 Cumulative incidence of severe post-thrombotic syndrome after 2 years treatment of compression stockings in order to prevent development of the post-thrombotic syndrome.

\section{Secondary outcome}

In the study of Ginsberg ${ }^{22}$, no patients developed leg ulceration and reduction of edema and pain could not be measured because exclusion from the study was based on these symptoms. No information was available in those three studies about the recurrence of deep vein thrombosis, pulmonary embolism, compliance with compression therapy, and costs.

In the article of Partsch ${ }^{23}$ only the first ten days are described. In this period pain level showed a statistically significant reduction starting after the second day in the compression groups and after 9 days in the bed rest group $(p<0.05)$. The same was found for the measurement of leg circumference. Improvement of the clinical scores was significantly better in the compression groups compared with the bed rest group $(p<0.01)$. There was no significant difference concerning the occurrence of new pulmonary emboli and regression of thrombus diameter. Progression of thrombi in the femoral vein was greater and occurred more frequently in the bed rest group than in the other two groups ( $p$ was not significant). 


\section{DISCUSSION}

The results of this systematic review show that elastic stockings reduce not only the incidence of any post-thrombotic syndrome, but also of severe post-thrombotic syndrome, with a highly statistically significant $O R$ of 0.31 and 0.39 , respectively. Only three major randomised clinical trials dedicated to the prevention of such a prevalent disorder as the post-thrombotic syndrome were found in our broad search, that included all languages as well as personal contact with other investigators involved in the clinical area. At a first glance, it seemed that the studies were conflicting, because in the study of Ginsberg ${ }^{22}$ it was concluded that most patients have no post-thrombotic syndrome one year after proximal deep-vein thrombosis and do not require elastic compression stockings. However, they included patients with asymptomatic deep vein thrombosis, who carry a low risk for the post-thrombotic syndrome. In fact, in their sub-population of patients with symptomatic deep vein thrombosis, the prevalence of post-thrombotic syndrome as assessed with a different, non-validated and probably less sensitive scale was 27 percent, and certainly not distinctly different from both other studies. Another difference worth mentioning is the use of one to two sizes too large stockings instead of no intervention. This might have diminished the contrast between the treatment groups, since even a stocking that is too large will certainly give some compression ${ }^{24}$. Indeed, it has been shown that stockings that are one or two sizes too large still exert considerable pressure in comparison to stocking without elastic threads. Moreover, the therapeutic stockings used exerted a pressure of $20-30 \mathrm{mmHg}$ at the ankle region. This is less than used in both other studies, which compared a stocking with an ankle pressure of $30-40 \mathrm{mmHg}$. In addition, in this study the stockings were only provided one year after the index thrombosis, i.e, at the moment that the majority of patients will already have developed the post-thrombotic syndrome and a preventive effect can no longer be achieved.

We analysed the data of thigh- and knee-high stockings together, because in measurements of venous pressure and foot volume no superiority of thigh high stockings was found". No serious adverse effects after initiation of the compression therapy were reported.

\section{REVIEWERS' CONCLUSIONS}

\section{Implications for practice}

There is substantial evidence that elastic compression stockings reduced the occurrence of the post-thrombotic syndrome after deep vein thrombosis. No serious adverse effects were mentioned in the studies. Hence, elastic compression stock- 
ings should be added to the treatment of deep vein thrombosis to prevent the development of the post-thrombotic syndrome.

\section{Implications for research}

It is uncertain if stockings should be prescribed directly or after compression bandaging in the acute phase (one-to-two weeks) of the deep vein thrombosis. In addition, it is still unknown how long stockings have to be worn. There is a need for the comparison of elastic compression stockings with different compression classes in the prevention of the post-thrombotic syndrome.

\section{REFERENCES}

1. Brandjes DP, Buller HR, Heijboer H, Huisnan MV, de Rujk M, Jagt H, et al. Randonuscef trial of effect of compression stockings in patients with symptomatic proximal-vein thrombosis L.ancet 1997;349:759-62

2. Prandoni P. Lensing AW. Cogo A, Cuppini S, Villalta S, Carta M, et al. The long-term clinical course of acute deep venous thrombosis. Ann Intern Med 1996;125:1-7.

3. Porter JM. Moneta GL. Reporting standards in venous disease: an update. International Consensus Commuttec on Chrome Venous Disease. J Vasc Surg 1995:21:635-45.

4. Kahn SR, Hirsch A. Shner I. Effect of postthrombotic syndrome on health-related quality of life after deep venous thrombosis. Arch Intern Med 2002:162:1144-8.

5. Haenen JH, Janssen MC. Wollersheim H, Van't Hof MA, de Rooij MJ, van Langen H, et al. The development of posthrombotic syndrome in relationshyp to venous reflux and calf muscle pump dysfunction at 2 years after the onset of deep venous thrombosis: I Vase Surg. 2002:35:1184-9.

6. Meissner MH, Zierler BK, Bergelin RO, Chandler WL, Strandness DE, Jr. Coagulation, fibrinolysis, and recanalization after acute deep venous thrombosis. J Vase Surg 2062;35:278-85.

7. Neumann HA, van Leeuwen M, van den Broek MJ, Berretty PJ. Transcutaneous oxygen tension in chronic venous insufficiency syndrome. Vasa 1984;13:213-9.

8. Guex II. Physiopathologie du syndrome post-thrombotique. Actualisation 1944. Journal des Maladies Vasculaires 1994;19:12-16.

9. Partsch H. Do we need firm compression stockings exerting high pressure? Vasa 1984:13:52-7

10. Partsch H. Rabe E. Stemmer R. Compression therapy of the extremities. I ed: Editions Phleboligiques Françaises 46, rue Saint Lambert 75015 Paris; 2001.

11. Neumann HAM. Tazelaar DJ. Compression Therapy. In: Bergan IJ, ed. Varicose veins and feleangiectasias - diagnosis and treatment.; 1993. 103-122.

12. Brakkee AJM, Kuiper IP. The influence of compressive stockings on the haemodynamics in the lower extremities. Phlebology 1988;3:147-153.

13. Neumann HAM, Veraart JCJM. The Use of Medical Elastic Compression Hosiery in Phlebology. Phlebol 1995:23-26.

14. Neumann HA personal communication:CEN classification. In: 2002.

15. Partsch H. Compression therapy of the legs. A review. J Dermatol Surg Oncol 1991:17: 799-805.

16. Partsch H. Improvement of venous pumping in chromic venous insufficiency by compresson dependant on pressure and material. VASA 1984;13:58-64. 
17. Kay TW, Martin Fl. Heel ulcers in patients with long-standing diabetes who wear antiembolism stockings. Med J Aust 1986;145:290-1.

18. Merrett ND, Hanel KC. Ischaemic complications of graduated compression stockings in the treatment of deep venous thrombosis. Postgrad Med J 1993;69:232-4.

19. Callam MJ, Ruckley CV, Dale J. Harper DR. Hazards of compression treatment of the leg: an estimate from Scottish surgeons. Br Med J (Clin Res Ed) 1987;295:1382.

20. Blattler W. Compression Therapy of Deep Vein Thrombosis. Phlebol 1995:41-46.

21. Guyatt G, Schunemann H, Cook D, Jaeschke R, Pauker S, Bucher H. Grades of recommendation for antithrombotic agents. Chest 2001;119:3S-7S.

22. Ginsberg JS, Hinh J. Julian J, Vander LandeVries M. Magier D, Mackinnon B, et al. Prevention and treatment of postphlebitic syndrome; results of a 3-part study. Arch Intern Med 2001:161:2105-9.

23. Partsch H, Blattler W. Compression and walking versus bed rest in the treatment of proximal deep venous thrombosis with low molecular weight heparin. J Vase Surg 2000;32:861-9.

24. Partsch H, Rabe E. Robert Stemmer library on compression therapy. [subbandage pressure of different stocking sizes]. In: Compresston Bulletin available at www.sigvaris.com; 2002. 


\title{
APPENDIX A
}

\section{CHARACTERISTICS OF INCLUDED STUDIES}

\author{
Study \\ Brandjes DP, Buller HR, Heijboer H. Husman MV, de Ryk M, Jagt H, et al. \\ Randomised trial of effect of compression stockings in patients with symptomatic \\ proximal-vein thrombosis. Lancet 1997:349:759-62.
}

Methods

Randomused controlled trial, observer and outcome assessor blinded In the treatment group 4 were lost to follow-up and 19 died, compared to respectively, 2 and 18 in the none-intervention group. Follow-up assessments were scheduled at three and six months, and then every six months. At each follow-up visit, the presence and severity of post-thrombotic syndrome were scored using a standardized scale.

Participants Setting the Netherlands. 109 male and 86 female, mean age 60 years.

Inclusion critera consecutive outpatients with a first episode of venogran-proven proximal decp vein thrombosis

Exclusion criteria: a life expectancy of less than 6 months; paralyses of the leg: bilateral thrombosis: leg ulcers or extensive vancosity; and current use of compression stockings

Interventions Below knee elastic compression stockings, made-to-measure (Neodurelna Varitex) with an ankle pressure of $40 \mathrm{mmHg}$ compared to no intervention

Outcomes Cumulative incidence of mild-to-moderate post-thrombotic syndrome

Study

Methods

Participants

Interventions

Outcomes

Notes
Ginsberg JS, Hirsh J, Julian J, Vander LaandeVries M, Magier D, MacKinnon B. et al. Prevention and treatment of postphlebitic syndrome: results of a 3-part study. Arch Intern Med 2001; 161:2105-9.

Randomised double blind clinical trial, observer and outcome assesor blinded.

Setting: Ontario, 26 male and 21 female, mean age 61 years

Elastic compression stocking Below knee elastic compression stockings with an ankle pressure of $20-30 \mathrm{mmHg}$ at the ankle region.

Cumulative incidence of post-thrombotic syndrome

Three part study, only data of study 2 are taken in account 
Study

Methods

Participants

Interventions

Outcomes
Partsch $\mathrm{H}$, Blattler W. Compression and walking versus bed rest in the treatment of proximal deep venous thrombosis with low molecular weight heparin. J Vasc Surg 2000:32:861-9.

Randomised double blind clinical trial, observer and assessor blinded. Of 148 consecutive patients only 45 were eligible, no drop-outs during the first 10 days.

Setting: Vienna, Austria, 45 patients, 29 male and 16 female, mean ages: 58 years. Inclusion criteria: Proximal deep vein thrombosis proven with compression ultrasound scan or phlebography in mobile patients older than 18 years. The duration of symptoms had to be less than 14 days. Exclusion criteria: compression therapy or heparin therapy already started, massive symptomatic pulmonary embolism or need for thrombolysis or thrombectomic. Ankle-brachial index lower than 0.8 or contra-indication for compression, anticoagulant or both. In the study participated 7 patients with a previous deep vein thrombosis in the same leg and 11 with a previous deep vein thrombosis in the contralateral leg.

Group A: inelastic compression bandages (Unna boots on the lower leg, adhesive bandages on the thigh), group B: thigh-length compression stockings (class II), and group $\mathrm{C}$ : bed rest for nine days without compression

Reduction of pain and leg circumference on days 0 and 9, on both days pulmonary embolsm and extend of deep vein thrombosis.

Clinical score was calculated for the following seven symptoms: pain during walking, painful foot sole, painful calf palpation, subfascial edema, increase of skin temperature, redness/cyanosis. The severity score comprised four stages: absent, mild, marked and severe
Study

Methods

Participants

Interventions

Outcomes
Prandoni P. Below-knee compression stockings for prevention of post-thrombotic syndrome in patients with proximal-vein thrombosis. In: ISTH 2003; 2003: Birmingham; 2003.

Randomised controlled trial, observer and outcome assessor blinded. In the treatment group 2 patients were lost to follow-up, 13 patients in the control group and 6 patients in the treatment group died. Follow-up assessments were scheduled at three and six months, and then every six months. At each follow-up visit, the presence and severity of post-thrombotic syndrome were scored using a standardized scale.

Setting: Italy, 180 consecutive patients with a confirmed first episode of deep vein thrombosis, 77 male and 103 female, mean age 62 years.

Exclusion criteria: a short life expectancy: bilateral thrombosis; leg ulcers or signs of chronic venous insufficiency; or a contraindication for the use of elastic compression stockings.

Below knee ready-made elastic compression stockings with an ankle pressure of $30-40 \mathrm{mmHg}$ (Flebysan, Rovigo)compared to no intervention

Cumulative incidence of post-thrombotic syndrome 


\section{APPENDIX B}

\section{CHARACTERISTICS OF EXCLUDED STUDIES}

Study

Hanley TP, Kiev J, Rice JC. Graduated compression stockings for the prevention of skin changes in CVI. Vasc Surg 1997:9

Kakkar VV, Lawrence D. Hemodynamic and clinical assessment after therapy for acute deep vein thrombosis. A prospective study. Am J Sung 1985:150:54

Prandoni P, Lensing AW, Cogo A, Cuppini S, Villalta S, Carta M, et al. The long-term clinical course of acute deep venous thrombosis. Ann Intern Med 1996;125:1-7
Reason for exclusion

No RCT

No RCT

No RCT, all patients were instructed to wear stockings for at least 2 yean. 
86 CHAPTER ? 


\section{Chapter 8}

Cochrane review

Compression therapy for treating stage I and II (Widmer) post-thrombotic syndrome 


\section{ABSTRACT}

Background Post-thrombotic syndrome (PTS) is a long-term complication of deep vein thrombosis characterized by chronic complaints, swelling, and skin changes in the affected limb. One in every three patients with deep vein thrombosis develops post-thrombotic complications within five years.

Objectives. To assess the effectiveness of compression therapy in patients with stage I and II post-thrombotic syndrome according to the classification of Widmer. Interventions of interest included elastic compression stockings and mechanical devices, compared with no intervention and with each other.

Search strategy. The reviewers searched the Cochrane Peripheral Vascular Diseases Specialised Trials Register (last searched April 2003), and the Cochrane Central Register of Controlled Trials (CENTRAL) (last searched lssue 1, 2003). In addition, journals, conference proceedings and bibliographies were hand searched. Personal contact with other investigators involved in the clinical area was sought to get information about missed or unpublished studies.

Selection criteria Trials that evaluated compression therapy for stage 1 and 11 (Widmer) post-thrombotic syndrome. Primary outcomes were leg ulceration, or deterioration of post-thrombotic syndrome. There were no restrictions on date or language. One reviewer (DNK) assessed titles and abstracts for relevance. This was verified independently by a second reviewer (MWCS).

Data collection $\&$ analysis Details of eligible studies were extracted and summarized using data extraction sheets. Data extraction was undertaken by one reviewer (DNK) and verified by a second reviewer (MHI)

Main results Only two trials were identified that addressed physical treatment of post-thrombotic syndrome. Both trials were initiated by the same group of investigators. A cross-over study lasting two months compared low and high pressure with intermittent compression units for severe post-thrombotic syndrome. This showed a beneficial effect of higher pressures. The second study, in patients with mild to moderate post-thrombotic symptoms, showed no effect of elastic compression stockings (30-40 mmHg at the ankle region) when compared to "placebo" stockings that were one to two sizes too large.

Revieures' condusions There is some evidence of a beneficial effect of intermittent pneumatic compression unts, but the study was too small and of too short a duration to draw firm conclusions. Further research is needed in order to assess whether intermittent pneumatic compression units give long term reduction of and relief from the symptoms caused by post-thrombotic syndrome, and prevent deterioration and leg ulceration. The use of elastic compression stockings to treat post-thrombotic syndrome cannot be supported on the basis of the currently available data.

\section{BACKGROUND}

Post-thrombotic syndrome (PTS) is a long-term complication of deep vein thrombosis that is characterized by chronic complaints, swelling, and skin changes in the affected limb. One in every three patients with deep vein thrombosis will develop post-thrombotic sequelae (complications resulting from a disease or condition) within five years'. Although there is no gold standard for the diagnosis of 
post-thrombotic syndrome, the presence of typical clinical features of venous insufficiency in a patient with previous deep vein thrombosis provides strong supporting evidence. Three stages of chronic venous insufficiency are recognized by Widmer ${ }^{2}$. In the first phase edema (swelling of the tissues caused by excessive fluid in the subcutaneous tissue) develops during the day and some skin changes (redness, ankle flair) occur. In the second phase edema becomes evident, lipodermatosclerosis and/or white skin atrophy occurs. (Lipodermatosclerosis is the term given to a hardening of the skin, which may gain a red/brown pigmentation, and is accompanied by wasting of the subcutaneous fat. White skin atrophy consists of small depressions of ivory-colored hard skin with stippled red spots.) In the third, and final, stage venous ulcers develop. The CEAP classification also uses a clinical classification system in their scoring system ${ }^{3}$.

In PTS, valvular incompetence (failure of the vein valves to function properly) is described as secondary because it is caused by a previous event - most frequently a deep vein thrombosis - that may have led to destruction and/or dysfunction of the deep venous valves. Objective evidence of deep venous valvular incompetence helps to confirm the diagnosis of post-thrombotic syndrome in chronic venous insufficiency.

The likelihood of PTS developing can be reduced by ensuring an adequate duration and intensity of anticoagulation for treatment of the initial deep vein thrombosis, and prescribing appropriate thromboprophylaxis after discontinuation of oral anticoagulants. Daily use of elastic compression stockings after deep vein thrombosis reduces the risk of post-thrombotic syndrome ${ }^{4}$. It also prevents worsening of established PTS ${ }^{1}$. Compression therapy ${ }^{5}$, in general, consists of circular pressure on the leg using circular bandages of any kind. Initially removable bandages or semi-permanent bandages such as adherent tape and Unna's paste boot are used, while elastic compression stockings are worn for long term treatment. In cases of severe edema, intermittent pneumatic compression can be used. Compression therapy of the legs is assumed to reduce edema, accelerate venous blood flow. and improve venous pump function ${ }^{6,7}$.

\section{OBJECTIVES}

The objective of this review was to determine the relative effectiveness of compression therapy in patients with stage $\mathrm{I}$ and II post-thrombotic syndrome according to the classification of Widmer. Interventions of interest included elastic compression stockings and mechanical devices. These were compared with eachother in the review, but will also be compared with no intervention, should appropriate trials become available in future. 


\section{CRITERIA FOR CONSIDERING STUDIES FOR THIS REVIEW}

\section{Types of studics}

Randomized controlled trials (RCTs), or controlled clinical trials (CCTs) evaluating elastic compression stockings and mechanical devices in the treatment of post-thrombotic syndrome were selected. Trials which used allocation processes that were transparent before assignment such as open list of random numbers, case record, day of the week, surname and so forth, were classified as CCTs.

\section{Types of participants}

Men and women of any age with symptoms and/or clinical changes of the legs after a previous deep vein thrombosis that had been objectively diagnosed. Methods considered acceptable for diagnosis of deep vein thrombosis included ultrasound, venography, and impedance plethysmography.

\section{Types of interventions}

The primary interventions we studied were medical elastic stockings and intermittent pneumatic compression. We allowed comparison of these with each other, e.g. different brand of stockings, but also different pressure profiles of stockings, different length of stockings, and different heights of pressure for the pneumatic compression units.

Any drug treatment or surgical interventions for post-thrombotic syndrome were required to be the same in the patient groups in the trials.

\section{Types of outcome measures}

The primary outcomes included occurrence of leg ulceration over time, and deterioration of post-thrombotic syndrome. The definitions used in each trial paper for post-thrombotic syndrome were accepted, provided they included a systematic clinical history and scoring of physical examinations (necessary because some trials only report changes in symptoms over time which provides a less valid indicator of effectiveness, as symptoms may vary).

Secondary outcomes included complications and morbidity. Adverse effects, after initiation of the compression therapy, were of particular importance, but were not mentioned in the studies reviewed. If available in forthcoming studies, common complications will be identified and compared between interventions in the stud- 
ies. These could include: discomfort, skin damage, pain, arterial leg ulceration and recurrence of thrombosis.

Additional outcomes that will be included in future, where adequate data are provided, will be patient satisfaction and quality of life (measured with generic or specific tools); economic analysis (either cost-effectiveness or cost-benefit analysis).

\section{Search strategy for identification of studies}

This review has drawn on the search strategy developed for the Cochrane Peripheral Vascular Diseases (PVD) Group as a whole. All publications that described randomized controlled trials (RCTs) and controlled clinical trials (CCTs) of compression therapy for stage I and II (Widmer) post-thrombotic syndrome were sought through electronic searches of the Cochrane Peripheral Vascular Diseases Specialised Trials Register (last searched April 2003), and the Cochrane Central Register of Controlled Trials (CENTRAL) (last searched Issue 1, 2003). Briefly, the Specialised Trials Register of the Group has been constructed from regular electronic searches of MEDLINE (1966 onwards), EMBASE (1980 onwards), and the Cochrane Central Register of Controlled Trials (CENTRAL). The full list of journals that have been hand searched, as well as the search strategies for the electronic databases, are described in the 'Search strategies for the identification of studies' section within the editorial information about the Cochrane Peripheral Vascular Diseases Group in the Cochrane Library. For details of the search strategy used to search the Cochrane Central Register of Controlled Trials (CENTRAL) database see additional tables (table 1).

In addition, we hand searched the following journals in the area of phlebology. which are not included in MEDLINE and EMBASE: Scripta Phlebologica (1993-2000), Journal of Thrombosis and Haemostasis (2003), and Conference Proceedings of the International Society of Thrombosis and Haemostasis (2001, 2002) and the International Union of Phlebology (Rome 2001). We also screened review journals in the field of phlebology including: Compression Bulletin and Scope on Phlebology.

Citations within identified studies were searched. In addition, we wrote to specialists known to be involved in phlebology and interested in post-thrombotic syndrome for details of unpublished and ongoing trials. We included in this review the relevant data provided. 
Table 1 Search strategy

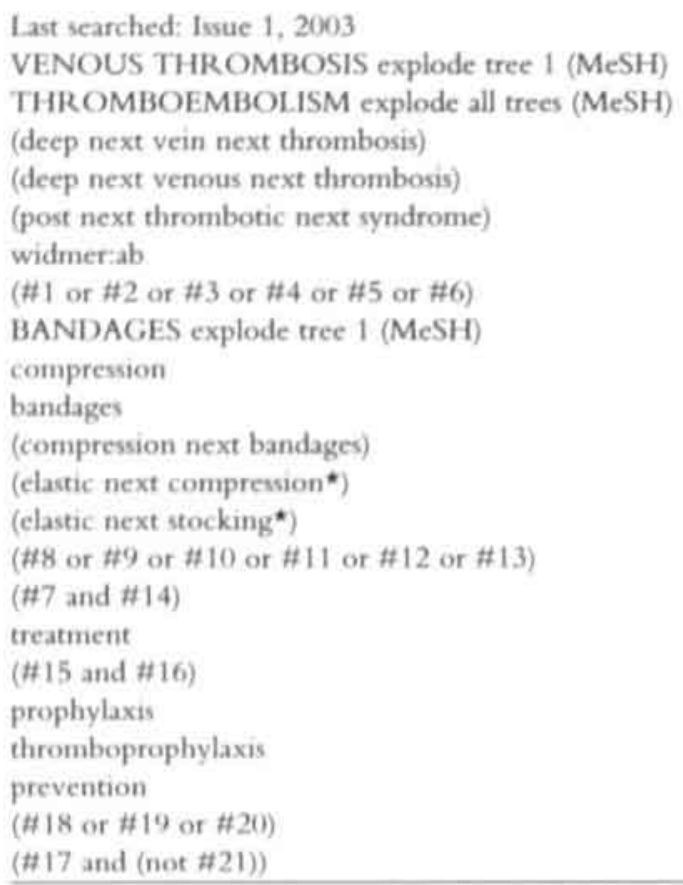

\section{METHODS OF THE REVIEW}

\section{Trial assessment}

One reviewer (DNK) assessed titles and abstracts of studies identified in terms of their relevance and design, according to the selection criteria. Full versions of articles were obtained if, from the initial assessment, they satisfied the inclusion criteria. Full papers were checked to identify those that fitted the criteria. Another reviewer (MWCS) repeated this independently, for verification. Any disagreements were resolved by discussion (MHP and HAMN).

\section{Data extraction}

Details of the studies were extracted and summarized using data extraction sheets. If data were missing from reports then attempts were made to contact the authors to obtain the missing information; no data were forthcoming. No studies were found that had been published in duplicate, however, if duplicates are identified in future they will only be included once. 
Data extraction was undertaken by one reviewer (DNK) and checked for accuracy by a second (MHP). Each study was appraised using a standard checklist to assess the validity of the methods used. Data were collected on:

- Trial setting (country, and whether primary or secondary care);

- Method of randomization;

- Objective outcome, method of assessment and whether blinded;

- Length of follow-up;

- Number of patients (or limbs) randomized;

- Inclusion criteria; exclusion criteria;

- Description of interventions and co-interventions;

- Baseline characteristics of groups for important variables (e.g. first deep vein thrombosis, recurrent deep vein thrombosis):

- definition of post-thrombotic syndrome.

\section{Results}

- Intention to treat analysis;

- Number and reason for withdrawals;

- Source of funding:

- Use of an a priori sample size/power calculation.

It was intended to compare elastic compression stockings versus control, and other comparisons will be made in future if available. We have allowed for:

- Mechanical compression therapy versus control;

- Mechanical compression therapy versus compression stockings:

- Compression stockings versus different brands of compression stockings.

\section{Statistical analysis}

The comparison of interventions as well as the format of the reported outcome made the results of these studies not suitable for the calculation of a summary statistic, so we performed a narrative overview. In future, if appropriate, heterogeneity will be explored by examining factors that may be influential such as definition of post-thrombotic syndrome used, care setting, time of follow-up, and incidence of recurrent deep vein thrombosis. In the absence of clinical heterogeneity we will test for statistical heterogeneity using the chi-squared test. If applicable, in future, RCTs and CCTs will be analyzed separately to access the efficacy of the effect estimation calculated with the Mantel Haenszel test.

\section{Description of studies}

Four trials were identified. Two were excluded ${ }^{8,9}$. The study by Kakkos ${ }^{8}$, was not designed to treat patients but rather to test the effectiveness of a new intermittent 
pneumatic compression system on 10 patients with post-thrombotic syndrome and 10 patients with varicose veins. The study by $\mathrm{Kahn}^{9}$, was designed to evaluate the effect of graduated elastic compression stockings on leg symptoms and signs during exercise in patients who had had a deep vein thrombosis one year previously. In this crossover study 40 patients were excluded, of whom 19 were diagnosed as post thrombotic syndrome.

Two trials were identified that met the inclusion criteria. These trials were both reported by Ginsberg et al. ${ }^{10,11}$. One compared the effectiveness of intermittent compression units, applying a low $(15 \mathrm{mmHg})$ or a higher therapeutic pressure (50 $\mathrm{mmHg}$ ), in a randomized cross-over design for one month ${ }^{11}$. Fifteen patients with severe post-thrombotic syndrome were included. Treatment was considered to be successful in patients who preferred the therapeutic pressure, wished to continue to use this pressure, and who demonstrated an improvement on a symptom score list. Unfortunately, changes in signs and symptoms of the post-thrombotic syndrome were not reported separately.

The other trial compared the effectiveness of elastic compression stockings (40 $\mathrm{mmHg}$ pressure at the ankle) with placebo stockings (one to two sizes too large) in , patients with, post-thrombotic svndrome defined by a svmptom list. independently of severity ${ }^{10}$. Patients were screened for post-thrombotic syndrome one year after deep vein thrombosis had been diagnosed. Follow-up was planned for two years. Patients who had symptomatic $(n=30)$ and asymptomatic $(n=3)$ deep venous thromboses were included. For two patients it was not clear if they had symptomatic clinical presentations. The primary outcome in this study was treatment failure, defined as pain and swelling that did not improve, or worsened, after the first three months; or worsening of symptoms during further follow-up; or symptoms that prevented patients from performing their daily activities for five or more days in any three-month period; or developing a leg ulcer.

\section{Methodological quality of included studies}

True randomization with allocation concealment (i.e. the person recruiting the patient into the trial is unaware to which group the patient will be assigned) was achieved in both trials. Blinded outcome assessment was achieved by cross-over design with and without therapeutic pressure in the trial with intermittent compression units ${ }^{11}$, and in the other study by comparison with placebo stockings ${ }^{10}$. Study personnel were unaware of allocation at the time of outcome assessments. In the trial with elastic compression stockings ${ }^{10}$, scoring of current symptoms was compared against scoring of previous symptoms after three months. Since the definition of failure was driven by a worsening of symptoms during a three month interval, patients with fluctuating symptoms could be classified as treatment failures, even in the presence of long-term improvement. 


\section{RESULTS}

In the study with intermittent compression units ${ }^{11}, 12$ of the 15 patients $(80 \%)$ had the perception of an important difference in favor of the therapeutic pressure levels $(95 \% \mathrm{Cl} 52 \%$ to $96 \%)$. However, after discontinuation of the study only nine patients (mean $60 \%, 95 \%$ CI 32-100\%) continued to use the compression pump successfully, at pressures between 40 and $50 \mathrm{mmHg}$ between one and four times a day. They experienced benefit six to 30 months after their enrolment in the original study. The symptom score at therapeutic pressure levels was 14.3 (SD 5.4) compared to 16.5 (SD 6.1) at placebo pressure levels. When analyzed as a crossover study (paired Student's t-test) the mean difference in scoring at the two pressure levels was -2.1 with a $95 \% \mathrm{CI}-3.6$ to $-0.7 . \mathrm{p}=0.007$.

The second study ${ }^{10}$, was conducted as a part of a larger study. The authors used a specially developed scoring system for the patient response to treatment. We evaluated only the part of the study in which they enrolled patients with symptomatic post-thrombotic syndrome. The definition used in this study was: chronic (duration of more than one month), typical (better after a night's sleep and leg elevation. worse at the end of the day and after prolonged standing or sitting), and pain and swelling of the $\operatorname{leg}(\mathrm{s})$ six months or more after a proximal deep vein thrombosis. Patients were categorised as having post-thrombotic syndrome only if they had both pain and swelling. Of the group with active stockings, $11(61.1 \%)$ of 18 treated were considered to be treatment failures, compared with $10(58.8 \%)$ of 17 treated with placebo stockings.

In this study no patients developed leg ulceration. In addition, no adverse effects after initiation of the compression therapy were mentioned. No information was available on reduction of edema, pain, recurrence of deep vein thrombosis, pulmonary embolism, compliance with compression therapy and costs.

\section{DISCUSSION}

It is unfortunate that only two randomised clinical trials dedicated to the physical treatment of such a prevalent disorder as post-thrombotic syndrome could be identified. Both trials were initiated by the same group of investigators. Our search was broad, and included all languages as well as personal contact with other investigators involved in the clinical area. Hence, it was unlikely that major trials had been missed.

As intermittent compression units ${ }^{11}$ were used for severe post-thrombotic syndrome, their effect on mild to moderate symptoms is unknown. The study lasted 
two months, which is a limited time in which to evaluate a treatment for a chronic disease such as post-thrombotic syndrome. Important additional information that would be required are the long-term effects, patient satisfaction (quality of life), and compliance with the treatment modalities. However, the beneficial effect of compression therapy is in line with the observed increased ulcer-healing rates compared with no compression ${ }^{12}$.

In the other study ${ }^{10}$, no effect was found for compression stockings for patients with mild to moderate post-thrombotic symptoms. Assessment of the post-thrombotic syndrome was done with a different, non-validated and probably sensitive scale. A blinded comparison was enabled by the use of a stocking that was one to two sizes too large. This might have influenced the results by diminishing the contrast between the treatment groups since; even a stocking that is too large will give some compression. Indeed it has been shown that stockings that are one or two sizes too large still exert considerable pressure in comparison to stockings without elastic threads ${ }^{13}$. Thus, it is possible that an effect could have been present had the comparison been done with a true placebo stocking. Additionally, we analyzed the data of thigh- and knee-high stockings together because in measurements of venous pressure and foot volume no superionty of thigh high stockings was found ${ }^{6}$.

In conclusion: there is some evidence of a beneficial effect of intermittent pneumatic compression units, but the study was too small and too short to draw firm conclusions. Further research is needed in order to assess whether intermittent pneumatic compression units give long term reduction and relief of symptoms due to post-thrombotic syndrome, as well as prevent deterioration and leg ulceration. No evidence was found for the use of elastic compression stockings to treat post-thrombotic syndrome.

\section{REVIEWERS' CONCLUSIONS}

\section{Implications for practice}

In patients with severe post-thrombotic syndrome, intermittent compression therapy is potentially effective in the treatment of post-thrombotic syndrome. No evidence was found for elastic compression stockings in the treatment of post-thrombotic syndrome.

\section{Implications for research}

There is an urgent need for more research in this field. Large randomized trials that evaluate the long term effect on the clinical course of post-thrombotic syndrome are needed. 


\section{REFERENCES}

1. Prandoni P, Lensing AW, Cogo A, Cuppini S, Villalta S, Carta M, et al. The long-term clinical course of acute deep venous thrombosis. Ann Intern Med 1996;125:1-7.

2. Widmer LK, Zemp E, Widmer MT, Schmutt HE, Brandenberg E, Voelin R, et al. Late results in deep vein thrombosis of the lower extremity. Vasa 1985;14:264-8.

3. Porter JM, Moneta GL. Reporting standards in venous disease: an update. International Consensus Committe on Chronic Venous Disease. J Vase Sung 1995;21:635-45.

4. Brandjes DP, Buller HR. Heijboer H. Huisman MV, de Rijk M, Jagt H, et al. Randomised trial of effect of compression stockings in patients with symptomatic proximal-vein thrombosis. Lancet 1997:349:759-62.

5. Partsch H. Compression therapy of the legs. A review. J Dematol Surg Oncol 1991:17: 799-805.

6. Partsch H. Do we need firm compression stockings exerting high pressure? Vas 1984:13:52-7.

7. Brakkee AJM, Kuiper JP. The influence of compressive stockings on the haemodynamics in the lower extremities. Phlebology 1988:3:147-153

8. Kakkos SK, Szendro G, Griffin M, Sabetai MM, Nicolaides AN Improved hemodynamic effectiveness and associated chinical correlations of a new intermittent pneumatic compression system in patients with chronic venous insufficiency. J Vasc Surg 2001:34:915-22.

9. Kahn SR, Azoulay L, Hirsch A, Haber M, Strulovitch C, Shrier I. Effect of graduated elastic compression stockings on leg symptoms and signs durng exercise in patients with deep venous thrombosis: a randomized cross-over tral Journal of thrombosis and haemostasis (JTH) 2003; $1: 494-499$

10. Ginsberg JS, Hirsh J, Julian J, Vander LaandeVries M, Magier D, MacKinnon B, et al. Prevention and treatment of postphlebitic syndrome: results of a 3-part study. Arch Intern Med 2001; 161:2105-9.

11. Ginsberg JS, Magier D, Mackinnon B, Gent M, Hirsh J. Intermittent compression units for severe post-phlebitic syndrome: a randomized crossover study. Cmaj 1999;160:1303-6.

12. Cullum N, Nelson EA, Fletcher AW, Sheldon TA. Compression for venous leg ulcers. Cochrane Database Syst Rev 2001:CD000265.

13. Partsch H, Rabe E. Robert Stemmer library on compression therapy. [subbandage pressure of different stocking sizes]. In: Compression Bulletin avalable at www.sigvaris.com; 2002. 


\title{
APPENDIX A
}

\section{CHARACTERISTICS OF INCLUDED STUDIES}

\author{
Study \\ Ginsberg JS, Magier D, Mackinnon B, Gent M, Hirsh J. Intermittent compression \\ units for severe post-phlebitic syndrome: a randomized crossover study. CMA] \\ Canadian Medical Association Journal 1999;160(9):1303-6.
}

Methods Randomised, cross-over design with independent blinded assessment of the outcome events, Exclusions post-randomisation: none. Losses to follow-up: none. Study durator: 2 months.

Participants Settung: Ontano teaching hospital. No. of patients $=15$. Sex: 12 women and 3 men. Age: mean age 60)

Inclusion critera documented DVT and intractable symptoms of PPS causing significant limitation of lifestyle, significant morbidity or both. as indicated by any of the following: los of job or absenteesm from work because of PPS; interference with day-to day activities; e.g hotsework, sports; frequent loss of sleep; failure of condition to improve with use of kraduated compression stockings; or patient's intolerance of, or refusal to use such stockings.

Exclusion critena DVT within the past 3 months or if they were unable to travel to the clinic.

Interventions Extremity pump twee daily (20 munutes per session) randomly assigned to use either $50 \mathrm{munH}$ g pressure or $15 \mathrm{~mm} \mathrm{H}_{\mathrm{g}}$ pressure for the first month, the other pressure was used the second month.

Outcomes Successful treatment: defined as preferring the high pressure, and continuing the use of the extremity pump and difference between the two pressures of at least slight mportance.

Study

(insberg JS, Hirsh J, Julian J. Vander LaandeVnes M, Magner 1), MacKinnon B, et al, Prevention and treatment of postphlebitic syndrome; results of a 3-part study. Archives of Internal Medicine 2001:161(17):2105-9.

Methods Randomised, double blind study, Patient and outcome assessor blinded. Exclusions post-randomisation: none described. Losses to follow-up: one in treatment group due to death. Mean follow-up: treatment group $=25.6$ months placebo group $=25,4$ months:

Participants Setting: affiliated hospital Hamilton Univenity. Ontano Canada. Evaluation was done one year after proximal DVT. PPS was defined as chronic pain and swelling as scored on a standardized questionnaire. Follow-up was done every 3 months. Exclusion critena: prevous graduated compression stockings. geographic inaccessibility and fallure to provide untormed consent. 
Interventions Comparison was done with compression stockings $(30-40 \mathrm{mmHg})$ or placebo stockings (one to rwo sizes too large). Below knee or thigh length compression stockings were administered depending on the localisation of complaints.

Outcomes Treatment falure: defined as pain and swelling that did not improve, or worsened after the fint three months, or if these symptoms worsened during further follow-up. or if a patient could not perform his daly activities for five or more days in any three-month period, or developed a leg ulcer.

DVT $=$ Deep vein thrombosis: PPS $=$ Post-phlebitic syndrome

\section{APPENDIX B}

\section{CHARACTERISTICS OF EXCLUDED STUDIES}

Study

Kahn SR, Azoulay L, Hirsch A. Haber M, Strulovitch, Shrier I. Effect of graduated elastic compression stockings on leg symptoms and signs during exercise in patients with deep venous thrombosis: a randomized cross-over trial. Journal of Thrombosis and Haemostasis 2003:1(3):494-9.

Kakkos SK, Szendro G, Griffin M, Sabetai MM, Nicolaides AN. Improved hemodynamic effectiveness and associated clinical correlations of a new intermittent pneumatic compression system in patients with chronic venous insufficiency. Journal of Vascular Surgery 2001;34(5):915-22.
Reason for exclusion

Crossover study to evaluate the effect of graduated elastic compression stockings on leg symptoms and signs during exercise in patients who had had a deep vein thrombosis one year previously. Artificial situation with treadmill exercise session, with and without stockings.

Study was not a treatment for post-thrombotic syndrome but designed to test the effectiveness of a new intermittent pneumatic compression system. 



\section{Chapter 9}

Recurrent leg ulcers in a young man with hyperhomocysteinemia, factor V Leiden and impaired fibrinolysis

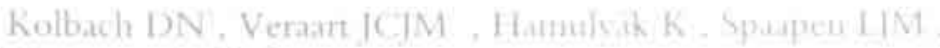

Netimann HAM

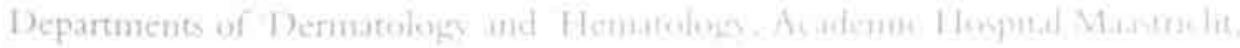

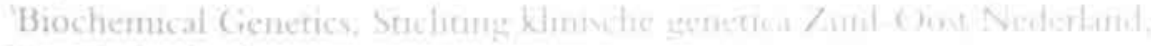
The Netherlands 


\begin{abstract}
We present a young male patient referred to our hospital with leg ulcers on both legs that had been refractory for more than 3 years to standard treatment with compression therapy. By thrombophilia screening, factor V Leiden mutation, hyperhomocysteinemia and evidence for impaired fibrinolysis were found. Treatments with folic acid in combination with long term oral anticoagulant therapy were added to non-elastic compression therapy. The leg ulcers showed slow improvement and complete healing within 3 years. During a 6 year follow-up period no new thromboembolic events occurred, nor was there recurrence of ulcerations.
\end{abstract}

This case suggests a potential synergistic pathogenic role of factor V Leiden, hyperhomocysteinemia and impaired fibrinolysis in the development of post-thrombotic syndrome and its sequelae. We postulate that increased formation of thrombi in the microcirculation of the skin, in combination with ambulatory venous hypertension due to recurrent deep vein thrombosis, might explain our observation.

\title{
BACKGROUND
}

Venous leg uleers affect 0.5 to $2 \%$ of the general population ${ }^{1.2}$. In $50 \%$ of patients with leg ulcers, a history of deep vein thrombosis (DVT) exists ${ }^{3}$. A common $(22.8 \%$ - $60 \%$ after 2 years), and often disabling, consequence of DVT is post-thrombotic syndrome (PTS), with symptoms ranging from mild edema to incapacitating swelling with pain and ulceration. PTS is strongly associated with ipsilateral recurrent DVT ${ }^{4.5}$. Several risk factors for DVT are known, including a number of inherited coagulation defects ${ }^{6-8}$. Some of these inherited defects are rare, but factor $\mathrm{V}$ Leiden and hyperhomocysteinemia are quite frequently found. Among European populations, factor $\mathrm{V}$ Leiden is the most common genetic defect causing thrombosis which is currently known. Heterozygous factor V Leiden increases the risk of thrombosis from three- to eightfold. In the Netherlands, with $\pm 4 \%$ of the population being carriers of factor $\mathrm{V}$ Leiden and having a relative risk of 8 , factor V Leiden contributes to $22 \%$ of all thrombotic events ${ }^{9}$. Mildly elevated plasma levels of homocysteine are also associated with an increased risk of venous thrombosis. In the Netherlands, basal levels exceeding $18.5 \mu \mathrm{mol} / 1$ were found in $5 \%$ of healthy individuals and were associated with a two-fold increased relative risk of venous thrombosis ${ }^{10}$. Hyperhomocysteinemia may be caused both by genetic and acquired factors, such as deficiency of vitamin B6, B12 and folic acid ${ }^{11}$.

Both factor V Leiden mutation and hyperhomocysteinemia have been proven to increase the risk for venous thromboembolism. When both factors exert their action simultaneously, these effects may interact, and the combined effect may exceed the sum of the separate effects ${ }^{12,13}$. The mechanism of interaction is not known. In $70 \%$ of carriers of the factor V Leiden mutation, the occurrence of DVT was associated with a precipitating condition, most commonly: pregnancy and surgery $^{14}$ 
In this report we present the history of a young man referred to us, who had a 3 year history of recurrent leg ulcers based on severe PTS, which followed several episodes of DVT associated with factor V Leiden, hyperhomocysteinemia and impaired fibrinolysis.

\section{CASE REPORT}

A 24 year-old male was finally referred to our hospital because of longstanding ulcerations of the lower leg. He was known to have had a history of Legg-Perthes disease when he was seven years old and three documented episodes of proximal spontaneous deep vein thrombosis of both legs. The first spontaneous thrombotic event occurred in his left leg when he was 19 years old. Documentation of DVT was made by duplex sonography. After 3 months, anticoagulant therapy was stopped. A few months later, after a trauma, he developed a DVT in his right leg. documented by duplex sonography. At the age of 21 years old, he developed a third spontaneous DVT in his left leg and anticoagulant therapy was restarted for 6 months. Soon after anticoagulant therapy was stopped, he developed a severe post-thrombotic syndrome with bilateral leg ulcers. Venography at this time showed residual thrombus in the left and right femoral vein. At the time of referral to our clinic, the ulceration had been present for more than 3 years. He was only treated with high pressure compression therapy and did not use oral anticoagulant therapy. There was no evidence for underlying acquired dsorders. The family history was negative for venous thromboembolism; his mother was known to have had unexplained recurrent abortions.

On presentation in our hospital, we saw a tall man with normal body proportions (height $197 \mathrm{~cm}$; weight $88 \mathrm{~kg}$ ). There were bilateral ulcers with some debris at the medial malleolar regions on both legs. There were signs of white atrophy and extensive pigmentation on the lower legs, including lipodermatosclerosis (photo 1). There were no venous varicosities visible. The dorsal pedis and posterior tibial pulses were palpable on both legs. Color-coded duplex sonography showed venous reflux of the superficial femoral vein and popliteal veins, the groin area revealed several superficial collaterals. Ascending venography showed remains of an old thrombus in the left and right femoral vein (photo 2); retrograde filling of the venous system in both legs. Left and right long saphenous veins showed no filling. Photoplethysmography showed a venous refill time decreased to $10 \mathrm{sec}$ (normal $25 \mathrm{sec})^{15}$. Functional investigations with air-plethysmography showed an increased venous filling index, (left leg: $8.9 \mathrm{ml} . \mathrm{sec}$ and right $14.3 \mathrm{ml} / \mathrm{sec}$; normal value $<2 \mathrm{ml} / \mathrm{sec}$ ) and diminished ejection fraction (left leg: $38.7 \%$ and right $34.5 \%$; normal value $>60 \%$ ). 


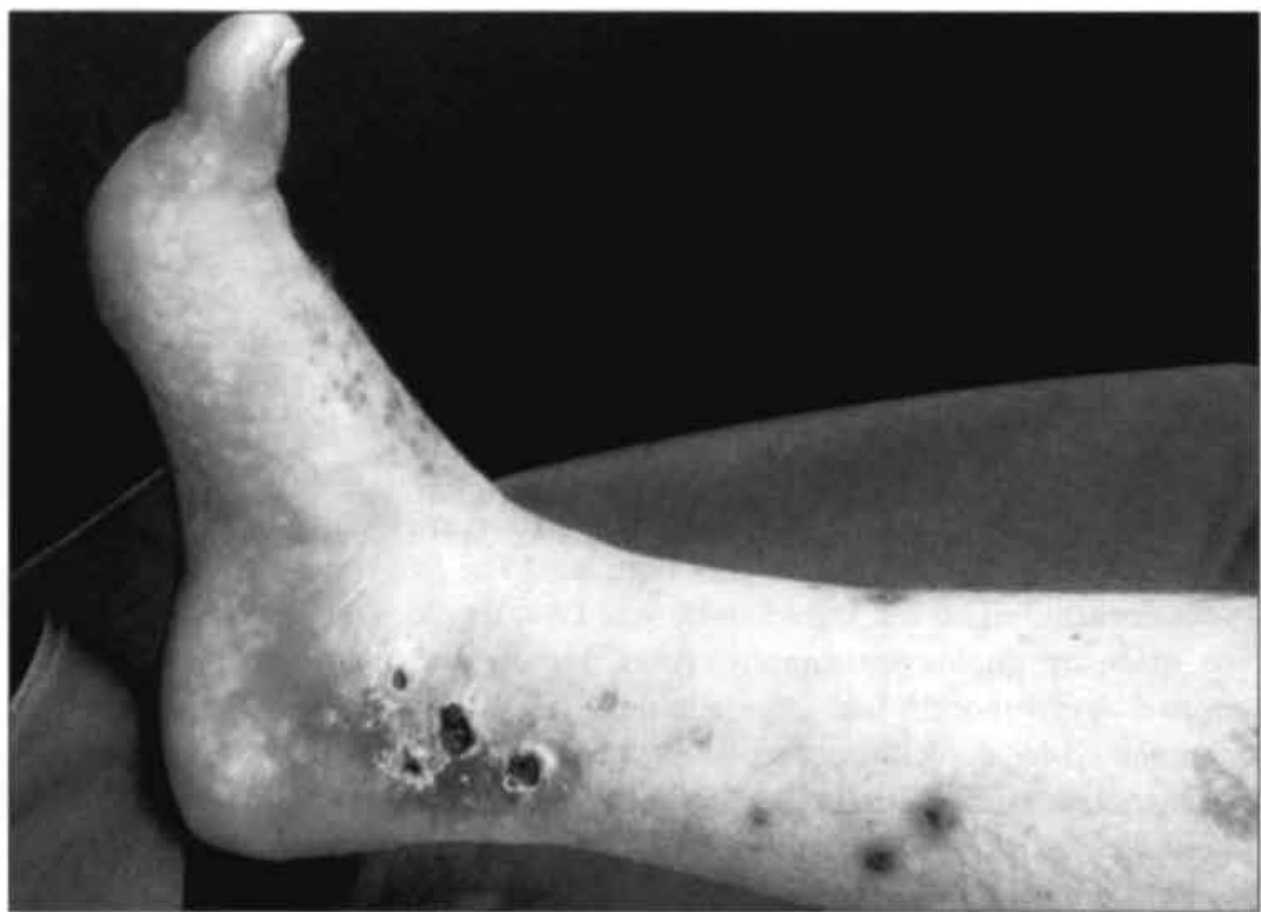

Photo 1 Skin symptoms of severe post-thrombotic syndrome with bilateral venous leg ulcers at age 23 .
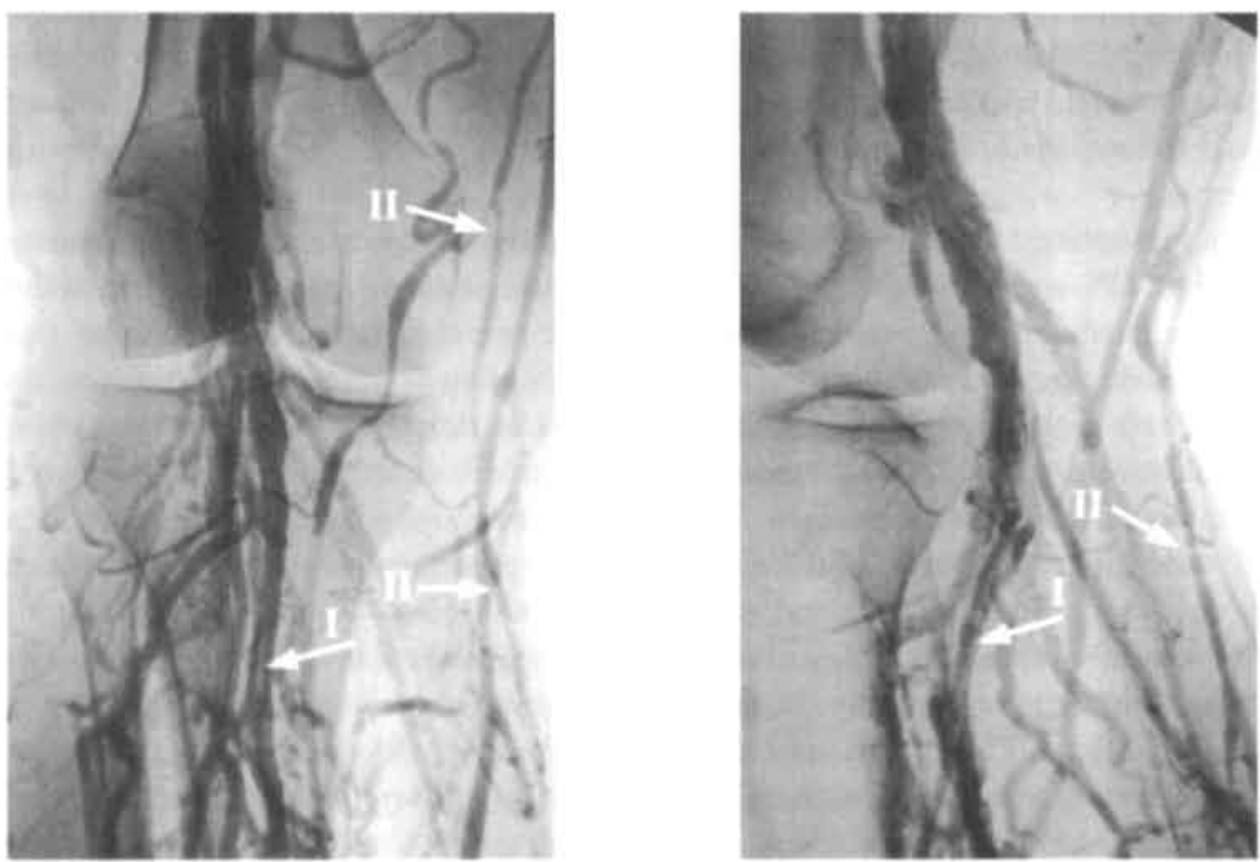

Photo 2 Ascending phlebography of the right leg. The left picture showes a frontal view and the right picture a $3 / 4$ lateral view. I: remains of an old thrombus and reconalization in the nght femoral yein. II: several superficial collaterals can be seen in the calf area. 
Extensive thrombophilia studies revealed that he was heterozygeous for the factor V Leiden mutation. In the presence of normal values for folic acid, vitamin $\mathrm{B} 6$ and vitamin $B 12$, we found an abnormal fasting homocysteine level $(20.2 \mu \mathrm{mol} /$, normal value $<18 \mu \mathrm{mol} / 1$, mean $\pm 2 \mathrm{SD}$ ) and an increased homocysteine concentration six hours after an oral intake of $100 \mathrm{mg}$ methionine/ $\mathrm{kg}$ body weight (64.4 $\mu \mathrm{mol} / 1$, normal $<56.3 \mu \mathrm{mol} / 1$, mean $\pm 2 \mathrm{SD}$ ). A control methionine loading test after 3 months and after 4 years using folic acid was normal. His basal plasminogen activator inhibitor type 1 (PAl-1) activity was slightly increased $(28 \mathrm{AU} / \mathrm{ml}$, nor$\mathrm{mal}<20 \mathrm{AU} / \mathrm{ml}$ ) on several measurements in blood sampls taken between 9 and $10 \mathrm{am}$ after an overnight fast. A venous ocelusion test was performed in order to estimate his fibrinolytic response. Upon venous occlusion no decrease of his PAI-1 activity was found, suggesting impaired fibrinolysis also to be present.

The leg ulcers were treated with local petrolatum-gauze and a firm non-elastic compression bandage. Oral anticoagulant therapy was restarted (in principle lifelong), and folic acid $5 \mathrm{mg}$ once a day added. His leg ulcers slowly improved, with complete healing after 3 years. There have been no recurrent thromboembolic events after starting treatment in our hospital.

\section{DISCUSSION}

Clinical presentation of PTS is a rare complication before the age of 30 . Our patient had already developed leg ulcers based on PTS at the age of 21 . The presence of factor $\mathrm{V}$ Leiden, hyperhomocysteinemia and impaired fibrinolysis suggests a potential synergistic role in the development of both recurrent venous thrombosis and the development of venous leg ulcers, which are difficult to treat.

In the development of venous leg ulcers, damaged deep leg veins are of major pathogenic importance. Ambulatory venous hypertension arises as the result of an incapacity of the valves of the leg veins and the associated phenomenon of venous reflux resulting in a decrease of the output of the calf muscle pump ${ }^{16}$. The more extensive and the more distal this reflux, the greater the probability that a leg ulcer will occur ${ }^{17 .}{ }^{18}$. In our patient with documented deep and superficial insufficiency, the only known effective ambulant treatment is high-pressure compression therapy ${ }^{19}$. It is of interest to note that adequate compression therapy had been given for several years in our patient without clinical improvement. While a slow, but complete healing of the ulcers obtained by restarting oral anticoagulants and introducing folic acid supply, suggests that the abnormalities found in the thrombophilia investigations might contribute to non-healing of the ulcers. 
In a previous study it was shown that compared to matched controls significantly more often the factor $\mathrm{V}$ Leiden mutation is found in patients with venous leg ulcers $(23 \% \text { compared to } 7.5 \%, \mathrm{p}=0.03)^{20}$.

In factor V Leiden mutation, microthrombi formation at the site of the leg ulceration is probably present. It has also been proposed that impaired fibrinolysis may contribute to an increased thrombotic tendency. Increased ambulatory venous pressure increases also the capillary pressure leading to leakage of capillaries with halo formation consisting of fibrin. Dilated capillaries and consequent flow decrease leads to low $\mathrm{pO}_{2}$ and white cell trapping at the level of the microcirculation. Ultimately, this leads to vessel wall damage ${ }^{21}$. Microthrombi have also been found in the skin of patients with chronic venous insufficiency ${ }^{22}$. This altered microcirculation can be the cause of skin ulceration. As the protein $\mathrm{C}$ pathway is especially important in the microcirculation of the $\mathrm{skin}^{23,24}$, oral anticoagulant therapy is therefore a treatment option. Controversial data are known on the use of aspirin $^{25}$, in that a positive effect of aspirin on the healing of leg ulcers has not been confirmed by other studies. There are no data on the use of coumarin derivatives. This case illustrates a potential clinical benefit of oral anticoagulants. Another interesting aspect of this case is the Legg Perthes disease treated at the age of seven years. In the study of Glueck et al. ${ }^{2 \hbar}$. factor V Leiden is seen in $75 \%$ of patients with Legg Perthes disease. Legg Perthes disease is also a thrombotic disorder, in which characteristic thrombotic venous occlusion of the femur leads to venous hypertension and osteonecrosis of the femur head.

The factor V Leiden mutation underlies resistance to activated protein C (APC). The activated form of coagulation factor $\mathrm{V}(\mathrm{Va})$ is an essential cofactor for thrombin generation at the site of vessel injury. In order to prevent excessive thrombin generation normal factor Va is efficiently inactivated by APC. This efficient negative feedback mechanism is disturbed in patients with factor $\mathrm{V}$ Leiden mutation, because the mutation is located on one of the major APC-cleavage sites. Thus, excessive thrombin formation takes place at the site of endothelial damage. Several mechanisms have been postulated to explain the thrombotic tendency in patients with hyperhomocysteinemia, including interference with the protein $\mathrm{C}$ pathway as well. It is unknown if the combination of factor V Leiden mutation and hereditary hyperhomocysteinemia is associated with earlier and more severe PTS. DVT at a young age, especially without the presence of environmental risk factors. is an indicator for inherited thrombophilia. Patients with chronic and/or recurrent venous leg uleers should be considered for testing of factor V Leiden and hyperhomocysteinemia. Both thrombophilia are frequently found in the caucasian population. In conclusion, we recommend screening for both thrombophilia in young people with symptomatic venous thrombosis or venous leg ulcers. 


\section{REFERENCES}

1. Callam MJ, Ruckley CV, Harper DR, Dale J Chronic ulceration of the leg extent of the problem and provision of care. Br Med J (Clin Res Ed) 1985;290: 1855-6.

2. Widmer L.K, Stathelin HB. Nissen C. A Sd. Venen-, Arterien-, Krankheiten, koronaire Herzkrankhei bei berufstatigen. In. Bern: Verlag Hans Huber, 1981, 66-82

3. Fuentein W. Was ist das wirklich Postthrombotesch Uleus cruns? Phlebologie 1994:4:150-2.

4. Prandoni P, Lensing AW, Cogo A. Cuppini S, Villalta S, Carta M, et al. The long-term clinical course of acute deep venous thrombosis. Ann Intern Med 1996;125:1-7.

5. Brandjes DP, Buller HR. Heijboer H. Hursman MV, de Rijk M, Jagt H, et al. Randoniried urai of effect of compression stockings in patients with symptonuatic proximal-vein thrombosis. Lancet 1997:349:759-62.

6. Salzmann EW, Hirsch J. The epidemiology, pathogenesis, and natural history of venous throm. bosis. In: Colman RW, Hirsch, J., Marder, V J. Salzman. E. W .. ed Hemostasis and thrombosis: bassic principles and clinical practice. 3rd ed. Philadelphia: J. B. Lippincot; 1994. 1275-96.

7. Rosendaal FR. Risk factors for venous thrombosis: prevalence, risk, and interaction. Semin Hematol 1997;34:171-87.

8. Rosendaal FR. Risk factors for venous thrombotac disease. Thromb Hacinost $19 \%, 82-610-9$

9. Rees DC, Cox M. Clegg JB. World distnbution of factor V Leiden. Lancet 1995,3 46, II 33,4

10. den Hejer M, Blom HJ. Gernts WB. Rosendal FR, Hak HL, Wijermans PW, et al Is hypeshomocysteinaemia a risk factor for tecurrent venous thrombosis? Lancet 1995,345: KK2-5.

11. Mudd SH. Levy HL., Skovby F. Disorden of transsulfaration. Chapter 35. In Senver C.R, Beaudet AL, Sly WS, eds. The Metabolic and Molecular Bases of Inhented Disease, 7th ed. McGraw-Hill, inc; 1995. 1279-97.

12. Ridker PM, Hennekens CH, Selhub J, Miletich JP, Malinow MR, Stampfer MJ. Interrelation of hyperhomocyst(e)inemia, factor V Leiden, and risk of future venous thromboenbolism Circulation 1997; $95: 1777-82$.

13. Mandel H, Brenner B, Berant M, Rosenberg N, Lanir N, Jakobs C, et al Coexistence of hereditary homocystinuria and factor V Leiden-effect on thrombosis. N Engl J Med 1996;334: 763-8.

14. Lensen RP, Bertina RM, de Ronde H, Vandenbroucke JP, Rosendaal FR. Venous thrombotic risk in family members of unselected individuals with factor $\mathrm{V}$ Leiden. Thromb Haemost 2000; $83 ; 817-21$.

15. Neumann HA, Bocrsma 1. Light reflection rheography. A non-invasuve diagnostic tool for screening for venous disease. J Dermatol Surg Oncol 1992:18:425-30.

16. Consensus paper on venous leg uleer. The Alexander House Group. J Dermatol Surg Oncol 1992:18:592-602.

17. Bassi G. [Ulcer and pre-ulcerous dermatoses in primary insufficiency of the external saphenous vein]. Phlebologie 1974:27:119-22.

18. Bjordal R. Flow and pressure studies in venous insufficiency. Acta Chir Scand Suppl 1988; 544:30-3.

19. Partsch H. Compression therapy of the legs. A review. J Dermatol Surg Oncol 1991:17: 799-805.

20. Maessen-Visch MB, Hamulyak K. Tazelaar DJ. Crombag NH, Neumann HA The prevalence of factor V Leiden mutation in patients with leg ulcers and venous insufficiency. Arch Dermitol 1999:135:41-4.

21. Neumann HAM, Tazelaar DJ. Compression Therapy, In: Bergan JJ. ed. Vancose veins and felcangiectasias - diagnosis and treatment.; 1993, 103-122.

22. Bollinger A. Leu AJ. Evidence for merovascular thrombosis obtained by intravital fluoresence videomicroscopy. Vasa 1991:20:252-5. 
23. Marciniak E. Wilson HD, Marlar RA. Neonatal purpura fulminans: a genetic disorder related to the absence of protein C in blood. Blood 1985;65:15-20.

24. Bauer KA. Coumarin-induced skin necrosis. Arch Dermatol 1993;129;766-8.

25. Ibbotson SH, Layton AM, Davies JA, Goodfield MJ. The effect of aspirin on haemostatic activity in the treatment of chronic venous leg ulceration. Br J Dermatol 1995;132:422-6.

26. Glueck CJ, Brandt G, Gruppo R, Crawford A, Roy D. Tracy T, et al. Resistance to activated protein $C$ and Legg-Perthes disease. Clin Orthop 1997:139-52. 


\section{Chapter 10}

Local endothelial function and leg symptoms in patients after deep vein thrombosis 


\section{ABSTRACT}

Background The fundamental pathophysiological disturbance in the post-thrombotic syndrome (PTS), a long term complication of deep vein thrombosis (DVT) is sustained venous, and consequently, capillary hypertension. We hypothesized this could lead to endothelial dysfunction that might be expressed in local abnormalities such as coagulation or fibrinolysis.

Methods Patients with ultrasound documented DVT were age and gender matched with controls. All subjects underwent invasive ambulant venous pressure measurement. Blood was collected from the arm and, after ten minutes standing, from the leg. Analyses were performed with paired Student'st-tests.

Results CEAP clasufication was C0-C4 among 15 patients (median time since DVT 4 years) and C0. C2 among 15 controls, while the ambulant venous pressure was $45( \pm 17)$ and $16( \pm 9)$, respectively ( $p<0.001)$. After ten minutes standing, the increase in von Willebrand Factor $(p=0.004)$ in the leg was higher in patients with previous DVT than in controls. In DVT patients with PTS systemic vWF antigen was higher in comparison to patients without PTS. Increase in fibrinogen was statistically significantly different in DVT and control group. $\mathrm{p}<0.001$ and $\mathrm{p}=0.002$. Factor VIII.c. d-dimer and PAI-1 increased also in patients with previous DVT. Mean increase in PAI-1 in DVT and control was 0.9 and 0.2 , respectively.

Condusions Increases in vWF after ten minutes standing was higher in patients with previous 1)VT than in controls. This indicates, since substantial volumes are accumulated during standing. that local endothelial dysfunction mught contribute to differences in coagulation status between patients with DVT and nomal subjects.

\section{INTRODUCTION}

The fundamental pathofysiological disturbance that can be observed in patients after a deep vein thrombosis is sustained venous hypertension, which results from valvular incompetence, outflow obstruction, calf muscle pump dysfunction, or a combination of these ${ }^{I}$. This venous hypertension is thought to lead to leg symptoms and even to venous leg ulcers, based upon alterations of the microcirculation $^{2}$. However, additional mediating pathofysiological mechanisms have been implicated in the process. Several hypotheses have been postulated, e.g. white cell trapping theory ${ }^{3}$, fibrin cuff theory ${ }^{4}$ and formation of microthrombi ${ }^{5}$. All those mechanisms might impair the microcirculation, resulting in dystrophic changes of the skin, or if severe, leading to leg ulceration.

We hypothesized that venous hypertension and consequently capillary hypertension could lead to endothelial dysfunction that might be expressed in local abnormalities of coagulation or fibrinolysis.

Hence, the purpose of this study was to evaluate in the leg a local response of coagulation and fibrinolytic parameters to a stimulus of venous hypertension in patients with a previous deep vein thrombosis, as compared to matched controls. 


\section{METHODS}

\section{Patient population}

This was a case-control study. designed to explore differences in local responses in coagulation and fibrinolytic parameters in reaction to venous hypertension in the $\mathrm{leg}$ in subjects with and without previous deep vein thrombosis (DVT). Patients with DVT were eligible if they had a lower limb DVT, more than a year prior to that and no documented ipsilateral recurrent DVT. Controls were matched for age ( \pm 3 years) and sex. Controls consisted of patients attending the outpatients department dermatology and healthy volunteers, who were without spontaneous leg complaints. Exclusion criteria were current use of anticoagulant therapy, use of aspirin or other drugs known to interfere with haemostasis. All subjects gave informed consent, and the protocol was approved by the medical ethics review committec.

\section{Experimental design}

In all patients a standardized clinical and physical examination was performed with special attention to signs and symptoms of the lower limb. A blood sample was collected from the antecubital vein (systemic circulation) after a resting period of ten minutes. Hereafter invasive venous pressure measurement was performed in the affected leg for DVT patients or the left or right leg of controls. Then, participants were asked to stand, without any movement of legs and body and without speaking for ten minutes. Directly thereafter a blood sample was collected from the leg circulation in the dorsal foot vein. This sampling was performed through the access needle of the invasive venous pressure measurement after spilling the first $2 \mathrm{ml}$.

\section{Classification of the post-thrombotic syndrome}

The clinical status of the leg was classified according to the consensus report of the American Venous Forum in 1994, also known as the CEAP classification". In this classification the clinical signs and symptoms are graded 0-6, with CEAP 0-1 representing no signs of post-thrombotic syndrome (PTS) and CEAP 2-6 representing mild to severe signs and symptoms, compatible with PTS.

\section{Ambulant venous pressure}

Invasive ambulant venous pressure measurement was performed with a 21 gauge $(0.8 \mathrm{~mm})$ butterfly needle (VYGON microflex) inserted into a vein on the dorsum of the foot ${ }^{7}$. The needle was connected through a pressure monitoring set (Edwards lifesciences) filled with physiological salt solution and an amplifier to a 
computer and printer. First, the standing venous pressure (SVP) was measured in steady state in the subject who supported himself in the standing position by holding onto a frame. Then, the subject performed a standardized exercise of 10 tiptoe movements at the rate of 1 per 1.5 seconds, synchronous with a metronome. The ambulant venous pressure (AVP) was measured at the end of the 10 tiptoe movements. Then, the subject remained still while recovery of the pressure to baseline levels was recorded. The exercise was then repeated.

\section{Biochemical analyses}

Blood for biochemical analyses was collected from the antecubital vein without venous stasis and from a dorsal foot vein as described in the experimental design. We used a Vacutainer PrecisionGlide ${ }^{\mathrm{TM}}$ connecting system $(0.8 \times 38 \mathrm{~mm})$ to collect blood. The first $2 \mathrm{ml}$ were discarded and the remaining was sampled into 4.5 $\mathrm{ml}$ Vacutainer ${ }^{*}$ tubes containing $0.129 \mathrm{M}$ sodium citrate (Becton Dickinson Europe) and serum tubes (no anticoagulant). The blood samples were processed within 30 minutes after collection. Citrated platelet poor plasma was made using two centrifugation steps: 5 minutes at $4000 \mathrm{rpm}$ at room temperature and $10 \mathrm{~min}$ utes at $11000 \mathrm{rpm}$ at $4^{\circ} \mathrm{C}$. The plasma samples were stored at $-70^{\circ} \mathrm{C}$ in aliquots of $500 \mu \mathrm{l}$ until analysis. Factor VIII:c, vWF:ag, fibrinogen, CRP, PAI-1 and d-dimer were measured in one blinded batch. Hence, the laboratory technicians were unaware of the patients' characteristics while they determined the test results. CRP was measured according to the manufacturer's specifications (Beckman-Coulter) by turbidimetry in a Beckman-Coulter LX20. Factor VIII:c activity was determined using a one stage clotting assay with factor VIII-deficient plasma (Dade-Behring. Germany) and automated activated partial thromboplastin time (APTT; Actin FS, Dade Inc, Aguada, USA). Von Willebrand antigen was determined using an ELISA assay with polyclonal rabbit anti human $\mathrm{vWf}$ antibodies (A082 (capture antibodies) and p0226 (conjugated antibodies). Dako ITK, Denmark). D-dimer was quantified with an automated quantitative assay based on the ELFA (enzyme linked fluorescent assay) technique using a VIDAS ${ }^{\mathbb{1}}$ according to the manufacturer's instructions (BioMerieux. France). Fibrinogen was measured in citrated plasma by the method described by Clauss. PAI-1 activity was determined by a commercial assay Spectrolyse ${ }^{8}$ /PL PAI (Biopool, Sweden). This assay is based on a two-stage, indirect enzymatic method as first described by Chmiclewska ${ }^{8}$ and was performed according to the manufacturer's instructions. Genetic analysis of the factor V Leiden mutation (R506Q) was performed using a commercial assay based on fluorescent resonance (Roche, Germany) on a light cycler $^{80}$ real time PCR analyser (Roche, Germany). All measurements were performed in duplicate. The final result was considered to be the mean of these measurements. Pooled normal plasma, from one hundred healthy volunteers, was used as a reference. 


\section{Statistical analyses}

Statistical analyses were performed with the software package SPSS 10.1. The independent Student's t-test was used to test for statistical significance of differences in ambulant venous pressure. The paired Student's t-test was used to test for statistical significance of differences in concentrations in systemic circulation between cases and matched controls. In addition this test was used to analyze changes in systemic and local circulation in individuals separately. The differences in systemic and local circulation were calculated and compared with paired Student's t-test between cases and controls. In addition, the differences in concentrations in patients with and without signs of post-thrombotic syndrome were analyzed with the independent sample t-test. The severity of leg symptoms (CEAP classification), differences in thrombophilia and family history were analyzed with Wilcoxon signed ranks test.

\section{RESULTS}

\section{Patient population}

A total of 30 subjects, 15 patients with prior DVT and 15 age and gender matched controls, were enrolled. Of the controls, 4 had other dermatological conditions and 11 were healthy volunteers. The demographic characteristics of the subjects, details of the episode of DVT and the CEAP classification of the clinical characteristics of the leg are given in table 1.

\section{Laboratory results in individuals and matched pairs}

The results of the comparison of differences in mean ( \pm sd) laboratory values of inflammatory, coagulation and fibrinolytic parameters between leg and arm in individuals are given in table 2 . In addition, we show the P-value for the calculated differences between arm and leg in individuals, compared between DVT and matched control. C-reactive protein (CRP) concentrations were normal in all subjects and similar in both groups. Elevated concentrations of factor VIII:c and vWF antigen were more common among DVT than among controls. In part, this is caused by the 5 patients $(33 \%)$, who were heterozygous for factor $V$ Leiden among the DVT group, compared to none in the control group. Factor VIII:c and vWF antigen in the systemic circulation were statistically significantly different in the DVT group compared to the control group, $\mathrm{p}=0.004$ and $\mathrm{p}<0.001$, respectively. When measured in the leg after ten minutes standing, factor VIII showed an increase in concentration compared to the systemic circulation in the DVT group, $179 \%$ and $189 \%$, respectively, which represented a trend $(\mathrm{p}=0.096)$. Factor VIII in the control group showed no difference after ten minutes standing. The differ- 
ence in change was $-10( \pm 43)(95 \% \mathrm{CI}-34$ to 14$)$ and was not statistically significant $(p=0.37)$ between both groups. In the leg, after ten minutes standing. vWF antigen showed an increase in concentration compared to the systemic circulation in the DVT group, which was statistically significant $(p=0.004)$, while among controls no increase could be measured $(\mathrm{p}=0.81)$. The mean difference in increase for $v$ WF between the DVT group and controls was $-10( \pm 17)(95 \% \mathrm{CI}-20$ to -1$)$ and was statistically significant $p=0.03$.

Levels of d-dimer and PAI-1 were increased in the group of DVT patients and statistically significantly different between cases and controls. After ten minutes standing no increase was observed in the leg in the d-dimer concentration in both groups. The mean difference in increase for d-dimer between the DVT group and controls was $14( \pm 109) 95 \% \mathrm{CI}-47$ to $74, \mathrm{p}=0.63$. In the leg after ten minutes standing PAI-1 showed a similar increase in concentration in both groups. While this increase represented a trend for the DVT group ( $p=0.132)$, it was statustically significant among controls $(\mathrm{p}=0.009)$. The mean difference in increase for PAI-1 between the DVT group and controls was $-0.007( \pm 2.5)(95 \%$ CI -1.5 to 1.3$)$ $p=0.91$. Fibrinogen levels measured in the leg after ten minutes standing showed a similar increase in concentration compared to the systemic circulation in both groups. This increase was statistically significant for the DVT group ( $p<0.001$ ) and among controls $(p=0.002)$. The mean difference in increase for fibrinogen between the DVT group and controls was $-0.13( \pm 0.30)(95 \% \mathrm{Cl}-0.30$ to 0.004$)$ $p=0.137$.

\section{Comparison of laboratory results in the DVT group}

Table 3 shows the results of the comparison of differences in mean ( $\pm s d$ ) laboratory values of inflammatory, coagulation and fibrinolytic parameters measured in the systemic circulation between patients with and without clinical characteristics of PTS. CRP concentration showed a trend $(p=0.054)$ toward being higher in patients with mild to severe PTS (CEAP 2-5) compared to those without signs of PTS (CEAP 0-1), means $7.1 \mathrm{mg} / \mathrm{l}( \pm 2.7)$ and $4.9 \mathrm{mg} / \mathrm{l}( \pm 1.3)$, respectively. Although in the systemic circulation factor VIII concentrations were lower in patients with mild to severe PTS than those without PTS, means $173 \%( \pm 27)$ and $183 \%( \pm 54)$, respectively, this difference is not significant $(p=0.69)$. The higher values for $\mathrm{VWF}$ antigen in the systemic circulation in patients with mild to severe PTS compared to those without PTS, means $194 \%( \pm 35)$ and $154 \%( \pm 29)$, respectively, was statistically significantly different $(p=0.031)$. Neither the Factor VIII concentration in the systemic circulation nor the increases after ten minutes standing, differed between patients with signs of mild to severe PTS (CEAP 2-5) and those without PTS (CEAP 0-1). Also, values of d-dimer were equally divided between patients with and without clinical characteristics of CEAP classification. 
Table I Patients charactenstics of DVT patients and matched controls.

Control group

p-value

\begin{tabular}{l} 
Table I Patients tharatensecof \\
\hline
\end{tabular}

\section{$52.4( \pm 11.8)$}

Mesn (tud) age in vear

Male/temale

Number of recurrent DVT (mintg)

Median period (range) in vears elaped sunce DV7

Mean it ul) anbulant venous pressure (numHg

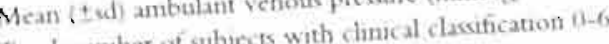

Total number of wilycek with in seten

acording to the CEAP syter

Comesmitunt divease

Fotal number of whicess with first degree relauves with DVT

Thrombophlia

$\begin{array}{ll}\text { CEAP } & 3 \\ 1 & 6 \\ 1 & 3 \\ 2 & 2 \\ 3 & - \\ 4 & 1 \\ 5 & - \\ 6 & \end{array}$

\section{$9 / 6$}

Upper limb thrombons $(n=1$

$4(1-10)$

$45( \pm 17)$
$521( \pm 120)$

$9 / 6$

Nos applicible

Not applicable

$16( \pm 0)$

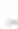

<amil

0.024

Chroni- obstructive pulmonary disease $(\mathrm{n}=1$

Chronic obatructuve pulthon

Mammacarcinoma in ${ }^{2}-1$

Fistor V Leiden in=5)

\section{9}

Hypertention $(n=1$

Notic

a 13

6042

Wurater in pattents with prot DVT compared to matched controls

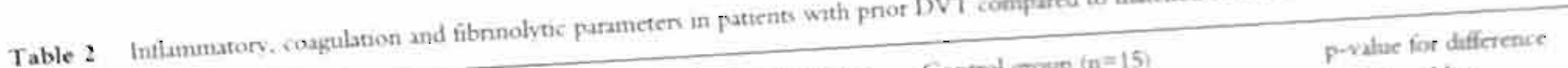

DVT parients $(n=15) \quad$ p-value for differenic Control group $(n=15)$ in arm and les.

- concentratson tor DVT patients

$\begin{array}{lll}\text { Arm } & \text { Leg } \\ \text { Mean }( \pm d) & \text { Mean }( \pm d) & - \\ 58( \pm 2.2) & - & 0190 \\ 179( \pm 44) & 189( \pm 51) & 0.0044 \\ 171( \pm 36) & 182( \pm 37) & 0.58 \\ 429( \pm 237) & 443( \pm 303) & 0132 \\ 14+( \pm 104) & 153( \pm 9.8) & 50.001 \\ 341( \pm 0.59) & 375( \pm 060) & \text { s. }\end{array}$

Arm Lrg

Mean (t)

$621+17$

$12 x+34) \quad 128( \pm 28)$

$42(+33) \quad 23( \pm 32)$

$2461=165) \quad 274( \pm 189)$

$-2(+2 x) \quad \times 1(+3 m$

$3 / 5( \pm 065) \quad 3,33( \pm 0.78$
CRP (mg t)

d-dimer (ng D)

PAl-1 actrity (AU)/ml

Fibrinogen (g/)
Factor VIII (h) in am and log?

concentratuon for

controb

$n \%$

0.81

oines

$0,0 \times n$

$6(x) 2$
Q-value for ditieterice between compared differences is arm and leg of DVT and matched controls

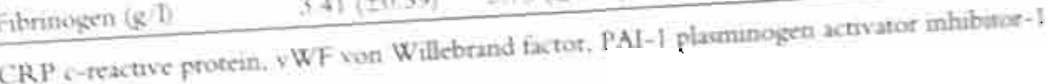


Table 3 Mean difference in the systemic circulation of the inflammatory, coagulation and fibrinolytic parametes ( \pm sd) in DVT patients with no PTS compared with mild-to-moderate PTS.

\begin{tabular}{llll}
\hline & $\begin{array}{l}\text { No PTS }(\mathrm{n}=9) \\
\text { Mean }( \pm \text { sd })\end{array}$ & $\begin{array}{l}\text { Mild-to-moderate PTS }(\mathrm{n}=6) \\
\text { Mean }( \pm \text { sd) }\end{array}$ & p-value \\
\hline CRP (mg/l) & $4.9( \pm 1.3)$ & $7.1( \pm 2.7)$ & 0.054 \\
Factor VIII (\%) & $183( \pm 54)$ & $173( \pm 27)$ & 0.69 \\
vWF antigen (\%) & $154( \pm 29)$ & $194( \pm 35)$ & 0.031 \\
d-dimer (ng/l) & $412( \pm 237)$ & $454( \pm 257)$ & 0.75 \\
PAl-1 activity (AU/ml) & $10.1( \pm 5.5)$ & $20.8( \pm 13.1)$ & 0.104 \\
Fibrinogen (k/l) & $3.17( \pm 0.54)$ & $3.73( \pm 0.54)$ & 0.082 \\
\hline
\end{tabular}

PAI-1 concentrations were higher in patients with mild to severe PTS than those without PTS, means $20.8 \mathrm{AU} / \mathrm{ml}( \pm 13.1)$ and $10.1 \mathrm{AU} / \mathrm{ml}( \pm 5.5)$, respectively, $p=0.104$. Fibrinogen concentrations were higher in patients with mild to severe PTS than those without PTS, means $3.73 \mathrm{~g} / \mathrm{l}( \pm 0.54)$ and $3.17( \pm 0.54)$, respectively, this represented only a trend $(p=0.082)$.

\section{DISCUSSION}

After ten minutes standing, the increases in vWF antigen in the leg were higher in patients with previous DVT than in controls. Also between DVT patients with clinical characteristics of PTS, concentration of $\mathrm{VWF}$ antigen increased more. This might point to a locally increased endothelial response to stress, that could contribute to the differences in coagulation status between patients with DVT and normal subjects. Although concentrations of factor VIII:c and vWF antigen are strongly related and factor VIII activity also increased more in patients with previous DVT, this difference did not reach statistical significance.

Factor VIII:c and fibrinogen are both acute phase proteins, but no arguments were found for chronic inflammation, since CRP concentration were normal in all subjects with previous DVT, and similar to the concentration in controls. This is in accordance with a prospective study (LITE study) in which also no relation between (recurrent) thrombosis and markers of inflamation was found ${ }^{9}$. We observed, again in accordance with previous studies, a large proportion of subjects with elevated factor VIII and VWF antigen among those with previous DVT ${ }^{10.11}$.

We observed in our DVT group a mean factor VIII:c of $179 \%( \pm 44)$. This is higher than could be expected based on the reported prevalence of $25 \%$ for factor VIII higher than $150 \%{ }^{12}$. In fact, 12 patients $(80 \%)$ in our group had a factor VIII higher than $150 \mathrm{IU} / \mathrm{I}$. Potentially, the higher levels of factor VIII we found, can be attributed to increased production, and/or reduced clearance of factor VIII over the 
years. Our patients were measured at a median of 4 years after the deep vein thrombosis while in most other studies patients were measured 3 months after their thrombotic event ${ }^{13}$. Such an acquired contribution to higher factor VIII is compatible with previously reported studies in which a close relation between vWF antigen and factor VIII:c activity was found, but no genetic contributions to this relationship were observed. Additionally, even in female twins, the genetic contribution to factor VIII:c and vWF antigen was estimated only at $60 \%{ }^{14-17}$

Moreover, it should be realized that the increase in volume that occurs from supine position to the standing position is substantial and has been estimated to be up to $400 \mathrm{ml}$ in patients who have had a DVT, previously compared to $100-150 \mathrm{ml}$ in normal subjects ${ }^{18}$.

It is well established that environmental factors have an influence on blood coagulation and fibrinolysis. These include exercise ${ }^{19}$ and any cause of an acute phase response. Both groups did the same exercise and after the ten minutes standing. matched controls showed less increase in the coagulation and fibrinolytic system. In previous studies increased tPA, PAI-1 level and d-dimer values were found for patients with venous insufficiency compared to controls ${ }^{20}$ and for DVT patients compared to healthy volunteers ${ }^{\prime \prime}$. This is in accordance with our results, however, after ten minutes standing no difference was found in the increase of PAI-1 and d-dimer levels between DVT and the compared control group.

One of the limitations of our study is the small group of patients. Therefore, confirmation with more DVT patients will be required. Another limitation of this study is that we didn't take a blood sample of the foot vein before the 10 minutes standing period, but assumed this would be equal to the sample of the antecubital vein. Additionally, more convincing evidence for the hypothesized mechanism could be given if both affected and non-affected legs were sampled. This is necessary to provide proof for our suggestion that venous pressure influences the endothelial system and in this way gives rise to increased vWF levels and fibrinogen. In turn the increased endothelial vWF production could lead to higher factor VIII:c levels. On the other hand, it is unlikely that any selection bias influenced the assessment of the different coagulation and fibrinolytic parameters of our DVT group. Our group showed 6 patients with moderate to severe post-thrombotic syndrome according to the CEAP classification, which is in line with clinical expectations ${ }^{21}$. Also we objectively measured the muscle pump function by a gold standard, the invasive venous pressure measurement, which showed a significant difference between both groups. The signs and symptoms of the post-thrombotic syndrome mostly develop within the first two years after the DVT ${ }^{22}$. In our study the DVT was diagnosed with a median of 4 years previously. Differences between the groups couldn't be explained by gender or age because we matched on these 
parameters. We suggest that apart from the genetic risk profile an additional effect from venous hypertension may contribute to a higher concentration of $\mathrm{vWF}$ and fibrinogen by endothelial damage.

In conclusion we believe we have elicited an acquired new mechanism, an increase of vWF antigen, leading to a pro-coagulant status in DVT patients which can additionally contribute to the clinical events of post-thrombotic syndrome.

\section{REFERENCES}

1. Criado E. Laboratory evaluation of the patient with chronic venous insufficiency (chapter 133). In: Rutherford RB, ed. Vascular surgery, 4th ed. Philadelphia: W. B. Saunders company; 1995. $1771-1785$

2. Junger M, Steins A, Hahn M, Hafner HM. Microcirculatory dysfunction in chronic venous insufficiency (CVI). Microcirculation 2000;7:53-12.

3. Coleridge Smith PD. Thomas P, Scurr JH, Dormandy JA. Causes of venous ulceration: a new hypothesis. Br Med J (Clin Res Ed) 1988;296:1726-7.

4. Browse NL, Bumand KG. The cause of venous ulceration. Lancet 1982;2:243-5.

5. Bollinger A. Leu A). Evidence for microvascular thrombosis obtained by intravital fluorescence videomicroscopy. Vasa 1991:20:252-5.

6. Porter JM. Moneta G.L. Reporting standards in venous disease: an update. International Consensus Committec on Chronic Venous Disease. J Vasc Surg 1995:21:635-45

7. Nicolaides AN, Zukowski AJ. The value of dynamic venous pressure measurements. World 1 Surg 1986;10:919-24.

8. Chmielewska J. Evidence for a rapid inhibitor tp tissue plasminogen activator in plasma. throm res $1983 ; 31: 427-36$.

9. Tsai AW, Cushman M, Rosamond WD, Heckbert SR, Tracy RP, Aleksic N, et al. Coagulation factors, inflammation markers, and venous thromboembolism: the longitudinal investigation of thromboembolism ctiology (LITE). Am J Med 2002;113:636-42.

I1). Koster T, Blann AD, Briet E, Vandenbroucke JP, Rosendaal FR. Role of clotting factor VIII in effect of von Willebrand factor on occurrence of decp-vein thrombosis. Lancet 1995:345:152-5

11. Bombeli T, Jutzi M, De Conno E. Seifert B. Fehr J. In patients with deep-vein thrombosis elevated levels of factor VIII correlate only with von Willebrand factor but not other endothelial cell-derived coagulation and fibrnolysis proteins. Blood Coagul Fibrinolysis 2002;13:577-81.

12. Kamphuisen PW. Lensen R. Houwing-Duistermat IJ. Eikenboom JC. Harvey M, Bertina RM, et al. Heritability of elevated factor VIII antigen levels in factor V Leiden families with thrombophilia. Br J Haematol 2000:109:519-22.

13. O'Donnell J. Mumford AD, Manning RA, Laffan M. Elevation of FVII1; $C$ in venous thromboembolism is persistent and independent of the acute phase response. Thromb Haemost $2000 ; 83: 10-3$

14, de Lange M, Snieder H, Ariens RA, Spector TI, Cirant PJ. The genetics of haemostasis: a twin study. Lancet 2001:357:101-5.

15. Kamphusen PW, Eikenboom JC, Rosendaal FR, Koster T, Blann AD, Vos HL, et al. High factor VIII antigen levels increase the nsk of venous thrombosis but are not associated with polymorphisms in the von Willebrand factor and factor VIII gene. Br ] Haematol 2(6)1:115:156-8. 
16. Eikenboom JC, Castaman G, Kamphusen PW, Rosendal FR, Bertina RM. The factor VIII/von Willebrand factor ratio discriminates between reduced synthesis and uscreased clearance of von Willebrand factor. Thromb Haemost 2002;87:252-7.

17. Bowen DJ. MacLean RM, Pellard S, Collins PW. High concentrations of coagulation factor VIII and thrombosis: Is the factor VIII-binding domain of von Willebrand factor implicated? Br J Haematol 2001;113:655-7.

18. Christopoulos DG, Nicolades AN, Srendro G, Irvine AT, Bull ML, Eastcont HH. Air-plethysmography and the effect of elastic compression on venots hemodynamics of the leg. I Vasc Surg 1987:5:148-59.

19. El-Sayed MS, Sale C. Jones PG, Chester M. Blood hemostasis in exercise and training. Med Sor Sports Exerc 2000:32:918-25.

20. Blomgren L, Johansson G, Siegbahn A. Bergqvist D. Coagulation and fibrinolysis in chronic venous insufficiency. Vasa 2001;30:184-7.

21. Franzeck UK, Schaich 1, Jager KA, Schneider E, Grumm J. Bollinger A. Prospective 12-year follow-up study of clinical and hemodynamic sequelae after deep vem thromboss in low-nsk patients (Zurich study). Circulation 1996;93:74-9.

22. Brandjes DP, Buller HR. Heijboer H. Husman MV, de Rijk M, Jagt H, et al Randomesd tral of effect of compression stockings in patients with symptomatic proximal-vein thrombosis Lincet 1997;349:759-62. 



\section{Chapter 11}

Severity of venous insufficiency is related to the density of microvascular deposition of PAI-1, uPA and von Willebrand factor

Departments of 1)ermateslogy, (Clumeal Eptenualogy and Medical Techology

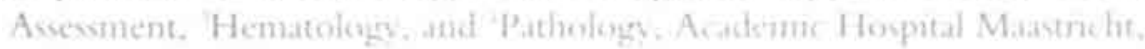

Department of Dematology, Fravius Medical ( Centre Roterdan. The Netherlands 


\section{ABSTRACT}

Backeround Impaired microcirculation in chronic venous insufficiency leads to chronic inflammation and dystrophic changes of the skin, and finally to leg ulceration. The purpose of this study was to investigate in more detail coagulation and fibrinolytic protein response of the capillaries in skin biopsies of the lower extremity.

Methods From eighteen ambulant patients with venous leg ulcer(s) $(\mathrm{n}=8)$ and controls $(\mathrm{n}=10)$ with various degrees of venous insufficiency according to the CEAP classification, we obtained 4 mm punch biopsies. Immunohistochemical staining with tissue derived plasminogen activator (tPA), urokinase derived plasminogen activator (uPA), plasminogen activator inhibitor (PAI-1) and von Willebrand Factor (vWF) was performed and analyzed with bright field microscopy.

Results. The amount of staining with vWF $(\mathrm{p}=0.04)$ and $\mathrm{UPA}(\mathrm{p}=0.02)$ showed statistically significant differences, PAI-1 $(\mathrm{p}=0.09)$ and $\mathrm{PA}(\mathrm{p}=0.50)$ showed no difference between leg ulcer and control groups. An increase of the number of capillaries with tortuous capillary loops in the papillary dermis was seen, but no statistically significant difference $(M-W$ test, $p=0.10)$ was found between the groups. Comparison between CEAP classes $0-6$ showed a statistically significant increased staining pattern of vWF $(p=0.06), u P A(p=0.02)$ and PAI-1 $(p=0.02)$, but not from tPA $(\mathrm{p}=0.30)$.

Condusion In skin biopsies of the lower extremity of patients with severe venous insufficiency increased deposition of VWF, PAI-1 and uPA were found in the capillaries. These findings point to a local imbalance in coagulation and fibrinolytic status, which might contribute to impaired microcirculation and finally to the development of venous leg ulecration.

\section{INTRODUCTION}

Although venous hypertension is a prerequisite for the development of venous leg ulcers $^{1,2}$, additional factors are considered of importance for this development, especially, impaired microcirculation which leads to chronic inflammation, dystrophic changes of the skin, and finally to leg ulceration ${ }^{3}$.

Venous hypertension is just one important point of the very complex pathophysiologic mechanism in chronic venous insufficiency; several other theories have also been published in this field i.e. fibrin cuffs, trapping of growth factors and white blood cells, disturbance of lymphatic circulation ${ }^{4-7}$

Several studies have focused on markers of coagulation and fibrinolysis in relation to chronic venous insufficiency (CV1) ${ }^{8-10}$. In progressive stages of CV1 increased systemic levels of plasminogen activator inhibitor type 1 (PAI-1) and tissue derived plasminogen activator (tPA) were found ${ }^{11}$. In skin biopsies of progressive CVI and in a group of patients with lipodermatosclerosis (C4 according to CEAP classification) elevated expression of urokinase derived plasminogen activator (uPA), but not tPA was found ${ }^{9}, 12$. In severe CVI patients (C4-6) increasing numbers of microthrombi were found in the capillaries of the papillary dermis ${ }^{13}$. It has also 
been described that venous leg ulcers treatedwith Sulodexide ${ }^{\mathrm{tt}}$, a glycosaminoglycan, heal faster and this treatment is associated with statistically significantly decreased fibrinogen levels in the systemic circulation. Factor $\mathrm{XIII}^{15,16}$ significantly accelerated healing of venous leg ulcers after topical application. Furthermore, an increased rate of ulcer healing occurred in patients receiving aspi$\operatorname{rin}^{17}$. In a recent study of our group we demonstrated a statistically significant local increase of von Willebrand factor activity after a stimulus (10 minutes standing) in patients with previous deep vein thrombosis and increased venous hypertension ${ }^{18}$. We found no evidence for chronic inflammation, as CRP levels in both groups were comparable.

The purpose of this study was to investigate in more detail coagulation and fibrinolytic protein response of the capillaries in skin biopsies of the lower limb in patients with different stages of chronic venous insufficiency by immunohistochemical evaluation of tPA, uPA. PAl and vWF.

\section{PATIENTS AND METHODS}

\section{Patient population}

We explored differences in local depositions of vWF, PAI-1, tPA and uPA in the skin of the lower extremity in subjects with varying degrees of venous insufficiency according to the CEAP classification. Subjects were recruited from patients attending the outpatient's department of dermatology and volunteers. All patients included were ambulant. Exclusion criteria were: present use of anticoagulant drugs or aspirin, arterial insufficiency, diabetes mellitus, malignancy, major surgery in the three previous month and/or active infections evaluated by clinical status. Diagnosis of deep vein thrombosis was documented in the past with venography or duplex ultrasound. The protocol was approved by the medical ethics review committee. All subjects were informed about the purpose and consequences of this study, and gave their informed consent.

\section{Experimental design}

In all patients a standardized clinical and physical examination was performed with special attention to signs and symptoms of venous insufficiency of the leg. A punch biopsy with a diameter of $4 \mathrm{~mm}$ was taken at the median side of the ankle region or one centimeter outside the border of the ulcer. All punch biopsies were taken under local anesthesia with $1 \%$ lidocaine. The biopsies were fixed in $10 \%$ phosphate-buffered formalin. processed by routine histological procedures and embedded in paraffin for further processing. Paraffin section $(+\mu m)$ were stained with 
hematoxylin and eosin and used for histochemical evaluation of pathologic changes in the epidermis, dermal capillaries, and the presence of capillary loops.

\section{Classification of the venous insufficiency}

The clinical status of the leg was classified according to the consensus report of the American Venous Forum in 1994, also known as the CEAP classification ${ }^{19}$. In this classification the clinical signs and symptoms are graded $0-6$. In the $\mathrm{C}$ classes we compared the results of $\mathrm{C} 5-6$ (leg ulcer group) with $\mathrm{C} 0-4$ (the control group). The control group consisted of patients without a history of venous leg ulcers.

\section{Immunohistochemical staining}

Paraffin sections $(4 \mu \mathrm{m})$ were mounted on superfrost microscope slides (Menxel-Gläser: Braunschweig. Germany). The sections were dewaxed and rehydrated, the sections underwent a microwave pretreatment with citric acid for 20 minutes for the PAI-1, tPA and uPA staining. The skin biopsy tissue sections were incubated with $10 \%$ normal calf serum for 10 minutes and then incubated for 2 hours with primary antibodies (murine Anti-Human PAI-1 (AB 380): goat Anti-Human tPA (AB387)(American Diagnostica, Greenwich, CT) or rabbit Anti-Human uPA, (I)AKO, Glostrup, Denmark). The immunostaining was done in accordance to the protocol as described by Ferrier et al. (20). For the vWF staining, sections were pretreated with pepsin ( $1 \mathrm{mg} / \mathrm{ml}$ in $0.01 \mathrm{~N} \mathrm{HCl}$ ) for 30 minutes room temperature. Then the sections were incubated for 30 minutes with the VWF antibody (DAKO). After the first antibody step, the sections were washed and incubated with biotinylated secondary antibodies for 30 minutes. Subsequently, the sections were incubated with alkaline phosphatase-conjugated $\mathrm{ABC}$. incubation (DAKO) for 45 minutes and Vector Red substrate kit (DAKO) to localize the specific binding of the antibodies. Sections were counterstained with Mayers' hematoxylin (Merck; Darmstadt Germany) and mounted (Imsol mounting medium; Klinipath, Duiven, the Netherlands).

\section{Classification of the immunostaining signal}

The immunostaining signal was evaluated using bright field microscopy. Signal strength was assessed using a score system with a five point scale: $(-)$, no detectable specific signal: $( \pm)$. signal occasional in vascular structures; $(+)$, specific signal in limited amount of vascular structures: $(++)$ specific signal in moderate amount of vascular structures: $(+++)$. specific signal in all vascular structures, extending from the capillaries into the surrounding matrix. All specimens were evaluated blindly. To check the reproducibility, the slides were examined by two independent observers, in case of disagreement another observer adjudicated. 


\section{Counting of capillaries}

The pattern of vascularisation was assessed on vWF stained tissue sections using bright field microscopy. All capillary loops in the papillary dermis of the skin were counted over the whole length of the biopsy. The numbers of counted capillary loops were normalized by epidermal length of the evaluated histological section.

\section{Statistical analyses}

Statistical analyses were performed with the software package SPSS 11.5. The degrees of staining (ordinal scale) between control and leg ulcer group were compared with chi-square test for trend, while comparison for the CEAP categories were calculated with Somer's D, a bidirectional test for trend ${ }^{21}$ The difference in number of capillaries seen in the skin biopsies of control and the leg ulcer group were analyzed with the Mann-Whitney $U$ test, because of small groups exact significances were calculated. The independent sample $t$-test was used to calculate differences in age and history of deep vein thrombosis for the control and leg uleer group.

\section{RESULTS}

\section{Patient characteristics.}

Eighteen subjects were included in this study; their demographic characteristics are presented in table 1. Nine women and nine men with a mean age of $56 \pm 14$ years were included. To evaluate the microvascular changes in more detail, we divided the varying degrees of venous insufficiency into two major groups, namely leg ulcer and controls. Eight patients were known with present $(n=6)$ or prior $(n=2)$ leg ulcer (mean age $62 \pm 16$ years) and 10 patients had various degrees of venous insufficiency and no history of leg ulcers (mean age: $52 \pm 11$ years). In the control group 3 patients had no venous insufficiency $(\mathrm{C} 0)$, no $\mathrm{C} 1$ was classified, classification in $\mathrm{C} 2, \mathrm{C} 3$ and $\mathrm{C} 4$ was found in 2,2 and 3 patients, respectively.. The difference in age was not statistically significant between the leg uleer and the control group $(p=0.153)$.

Staining results obtained in various degrees of venous insufficiency

Results of the staining signal are presented in table 1. Analysis of difference in the amount of signal from VWF, UPA and PAI-1 between CEAP classes (C)-6) showed statistically significant increases in staining with more severe chronic venous insufficiency, $p=0,06, p=0,005$ and $p=0.02$, respectively. The staining with 
Table 1 Demographic characteristics of the patients in the control and leg ulcer group and the results of immunostaining of the skin biopsies of the lower extremity with PAI-1, uPA, tPA and vWF.

\begin{tabular}{|c|c|c|c|c|c|c|c|}
\hline CEAP & Age & $\begin{array}{l}\text { Documented } \\
\text { DVT }\end{array}$ & $\begin{array}{l}\text { Blood } \\
\text { vessels }\end{array}$ & VWF & uPA & PAI-1 & tPA \\
\hline
\end{tabular}

Control group

$\begin{array}{llllllll}\text { C0 } & 49 & \text { no } & 80 & ++ & - & - & - \\ \mathrm{C} 0 & 30 & \text { yes } & 25 & + & \mathrm{NA} & - & + \\ \mathrm{C} 0 & 36 & \text { no } & 35 & + & - & - & - \\ \mathrm{C} 2 & 51 & \text { no } & 56 & ++ & - & - & - \\ \mathrm{C} 2 & 53 & \text { yes } & 24 & + & \mathrm{NA} & - & (+) \\ \mathrm{C} 3 & 62 & \text { no } & 71 & + & (+) & (+) & (+) \\ \mathrm{C} 3 & 54 & \text { no } & 68 & +++ & (+) & - & (+) \\ \mathrm{C} 4 & 66 & \text { yes } & 19 & + & + & - & - \\ \mathrm{C} 4 & 53 & \text { yes } & 75 & + & - & (+) & (+) \\ \mathrm{C} 4 & 63 & \text { yes } & 19 & (+) & - & - & (+)\end{array}$

Leg ulcer proup

$\begin{array}{lllrllll}\text { C5 } & 60 & \text { no } & 5 & (+) & (+) & - & - \\ \text { C5 } & 43 & \text { yes } & 81 & ++ & + & (+) & (+) \\ \text { C6 } & 76 & \text { no } & 59 & ++ & ++ & (+) & (+) \\ \text { C6 } & 82 & \text { no } & 108 & +++ & - & - & - \\ \text { C6 } & 60 & \text { yes } & 110 & +++ & ++ & + & + \\ \text { C6 } & 79 & \text { no } & 89 & +++ & (+) & - & - \\ \text { C6 } & 37 & \text { yes } & 120 & +++ & ++ & + & ++ \\ \text { C6 } & 60 & \text { no } & 42 & ++ & ++ & (+) & ++\end{array}$

p-values of comparison

between control and

leg ulecr group

$0.15 * 0.62 *$

$0.07 *$

$0,04 * \star$

$0.02 *$

$0,09 * \star \star *$

$0.50 * * *$

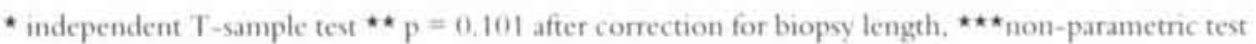
(Mann Whitney $U$ test) $N A=$ not avalable

tPA showed no association $(\mathrm{p}=0.30)$ with more severe chronic venous insufficiency.

\section{Staining results compared for leg ulcer}

In addition, we also analyzed for difference between leg ulcer and control groups. In photo 1 a-d the different staining results with uPA, tPA, PAI-1 and VWF in a patient from the leg ulcer group are given. The amount of staining with vWF, and uPA showed a statistically significantly difference between both groups, $\mathrm{p}=0.04$ and $p=0.02$, respectively. The amount of staining signal of PAl-1 showed a trend to significant difference, $\mathrm{p}=0.09$. The staining with tPA showed no difference $(p=0.50)$ between both groups. 

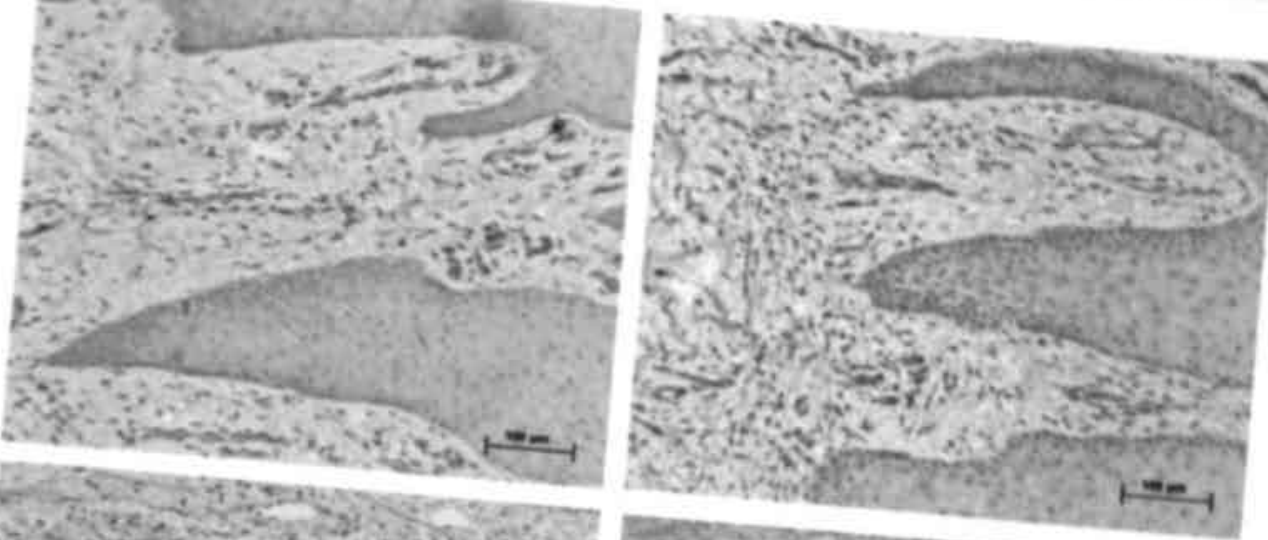

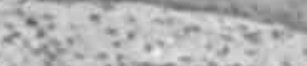

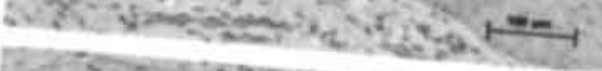

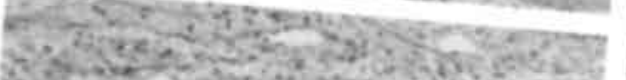

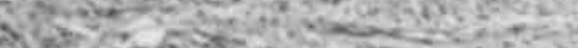

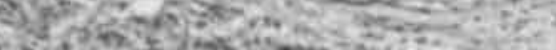

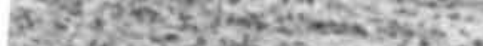

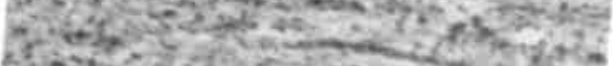

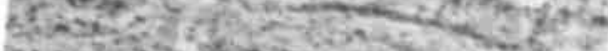

Fis.

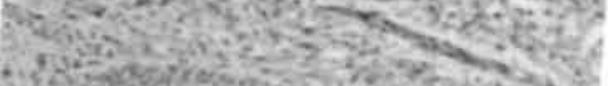

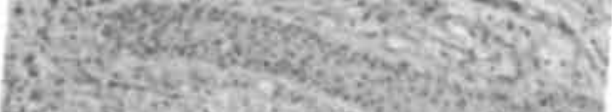

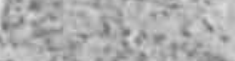

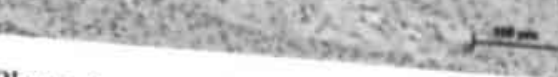

Photo 1

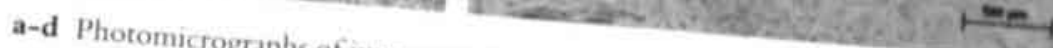

side the border of the leg of immunostained tissue sections of a biopsy tak

D: vWF.

Photo 2

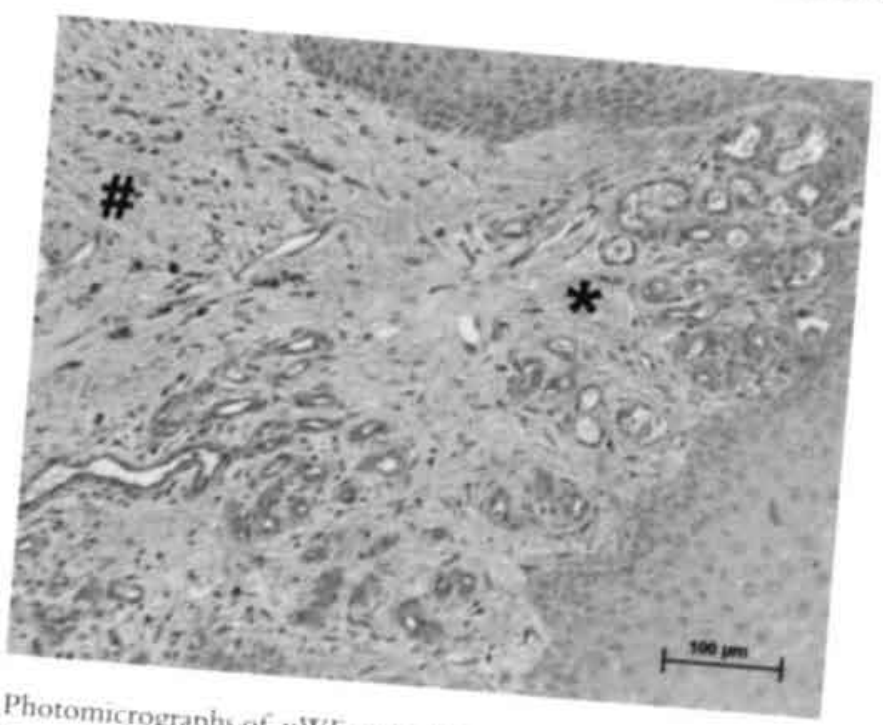

border of the leg ul $\mathrm{vWF}$

\#: area with leg ulcer.

$100 \mathrm{\mu m}$.

biopy taken I cm outside the 


\section{Vascular patterm}

In the severe chronic venous insufficiency group vWF staining revealed a pattern of staining in the capillary with extension into the surrounding matrix. Photo 2 shows a picture of staining results with $v W F$ in one of the patients of the venous leg ulcer group. In patients with leg ulcer or prior leg ulcer a strong increase of the number of capillaries with tortuous capillary loops in the papillary dermis was seen as compared to control patients (CO-4), where a more regular pattern of vascularisation was seen. Moreover in progressive venous insufficiency microscopically a pattern of areas with only a few or no capillaries (photo 2 \#) and tortuous capillaries were seen (photo $2 \star$ ). The number of vessels in the leg ulcer group compared to controls showed a trend toward statistically significant increase $(\mathrm{M}-\mathrm{W}$ test, $\mathrm{p}=$ $0.10)$.

\section{DISCUSSION}

In skin biopsies of the lower extremity of patients with venous insufficiency, intensity of depositions of vWF, PAI-1 and UPA in the capillary wall of the capillaries in the papillary dermis was elevated with increasing severity of the venous insufficiency. In a previous study we suggested that venous pressure influences the endothelial system and in this way gives rise to increased VWF levels ${ }^{18}$. While uPA was statistically significant increased, we observed no difference of tPA staining between groups. This is in line with the uPA and tPA staining results of Herouy et al. in patients with venous leg ulcers ${ }^{22}$. Evidence from transgenic and knockout mouse studies suggests that $\mathrm{UPA}$ and $\mathrm{PA}$ can form plasmin from its inactive precursor plasminogen and that either activator can compensate for the other ${ }^{23}$. In another mouse study it was found that the uPA supplied sufficient fibrinolytic potential to clear fibrin deposits and support wound healing without the benefit of uPA or tPA ${ }^{24}$. In mice with a disrupted plasminogen gene, dermal wound healing was associated with impaired keratinocyte migration, but an intact inflammatory response $\mathrm{s}^{25}$.

The positive association of the severity of chronic venous insufficiency with the immunostaining results of $\mathrm{PAI}-1$ and $\mathrm{vWF}$, both of which are released by endothelial cells, points to possible endothelial perturbation in patients prone to leg ulcers. We suggest that apart from the genetic risk profile of venous thromboembolism leading to macro and microthrombi, an additional effect, probably from venous hypertension leads to endothelial damage of the microcirculation. This may contribute to a higher concentration of VWF, UPA and PAI-1 and can lead to micro-thrombi and initially insufficient fibrinolytic response in the microcirculation of the skin. Increase of VWF leads to hypercoagulation in the microcirculation. Evidence for this can be found in an immunohistochemical study. where the amount of microthrombi in capillaries of the skin at the median 
ankle was highly statistically significantly increased $(p<0,001)$ in patients with severe chronic venous insufficiency ${ }^{13}$. In line with these findings and in intravital fluorescence videomicroscopy as well, microthrombi were found in skin capillaries of the lower extremity ${ }^{26}$.

Another intriguing phenomenon is the strong increase in the numbers of capillaries with tortuous capillary loops in patients with severe chronic venous insufficiency. We suppose this increased amount of capillaries is not due to active proliferation but to an elongation and tortuous deformation of single capillaries. Goal of our study was to investigate in more detail coagulation and fibrinolytic protein response of the capillaries. So, we haven't done research of the above mentioned problem. Future research is needed to look more in detail which part of capillary formation is due to elongation and which part is due to proliferation. Possibly, changes of the capillaries could be either influenced by the viscosity of the blood or by high shear stress forces. Studies of cultured endothelial cells have shown that shear stress forces elongate and align cells in the direction of flow. The shear stress forces at the capillary wall is related directly to flow velocity and inversely to capillary diameter: thus high shear stresses occur when blood flows rapidly in narrow capillaries $^{27}$. At present nothing is known about the relationship between high shear stress forces and the increased expression of uPA, PAI-1 and vWF at the capillary wall in the skin.

The small group of patients used is one of the limitations of our study. Our study population was small and heterogeneous, possibly an additional explanation might be the presence of congenital or acquired thrombophilia. In patients with venous leg ulcer higher proportion of thrombophilia was found, which might indicate a higher risk of (previous) venous thromboembolism ${ }^{28-30}$. Another limitation is the age difference; acquired alterations in haemostatic parameters can be the result of both thrombotic events and aging. Indeed, aging is associated with an increased risk of leg ulceration, which may be due to physiological alterations of the haemostatic system or the capillary wall. On the other hand, our leg ulcer group was not statistically significantly older than the control group. Also, it is unlikely that any selection bias influenced the assessment of the different coagulation and fibrinolytic parameters of chronic venous insufficiency. In a former study of our group, age and gender matched patients with a history of deep vein thrombosis were demonstrated to have increased PAI-1 and $\mathrm{vWF}$ levels ${ }^{18}$.

In conclusion, in skin biopsies of the lower extremities of patients with severe venous insufficiency, increased deposits of vWF, PAI-1 and uPA were found in the capillaries. This points to a local imbalance in coagulation and fibrinolytic status, which might contribute to impaired microcirculation and finally to the development of venous leg ulceration. 


\section{REFERENCES}

1. Nicolaides AN, Zukowski AJ. The value of dynamic venous pressure measurements. World J Surg 1986;10:919-24.

2. Payne SP, London NJ, Newland CJ. Thrush AJ, Barrie WW, Bell PR. Ambulatory venous pressure: correlation with skin condition and role in identifying surgically correctible disease. Eur J Vasc Endovasc Surg 1996;11:195-200.

3. Dormandy A. Pathophysiology of venous leg ulceration. Int J Microcire Clin Exp 1997;17 Suppl 1:2-5.

4. Bumand KG. The aetiology of venous ulceration. Acta Chir Scand Suppl 1988;544:21-4.

5. Coleridge Smith PD. Thomas P, Scurr JH, Dormandy JA. Causes of venous ulceration: a new hypothesis. Br Med J (Clin Res Ed) 1988;296:1726-7.

6. Falanga V, Eaglstein WH. The "trap" hypothesis of venous ulceration. Lancet 1993;341: $1006-8$.

7. Gschwandtner ME, Ehringer H. Microcirculation in chronic venous insufficiency. Vase Med 2001:6:169-79.

8. Margolis DJ. Kruithof EK. Barnard M. Howe K. Lazarus GS. Fibrinolytic abnomalities in two different cutaneous manifestations of venous disease. J Am Acad Dermatol 1996:34:204-8.

9. Herouy Y. Aizpurua J. Stetter C, Dichmann S. Idzko M, Hofmann C, et al. The role of the urokinase-type plasminogen activator (UPA) and its receptor (CD87) in lipodermatosclerosis. J Cutan Pathol 2001:28:291-7.

10. Brakman M, Faber WR, Kerckhaert JA, Krajjenhagen RJ, Hart HC. Immunotluorescence studies of atrophie blanche with antibodies against fibrinogen, fibrin, plasminogen activator inhibi-

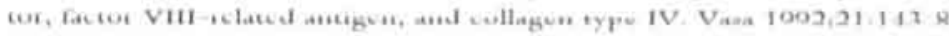

11. Blomgren L, Johansson G. Siegbahn A, Bergqvist D. Coagulation and fibrinolysis in chronic venous insufficiency. Vasa 2001;30:184-7.

12. Peschen M, Roges AA. Chen WY, Vanscheidt W. Modulation of urokinase-type and tissue-type plasminogen activator occurs at an early stage of progressing stages of chronic venous insufficiency. Acta Derm Venereol 2000;80:162-6.

13. Peschen M, Zeiske D, Laff H, Weiss JM. Schopf E, Vanscheidt W. Clinical histochemical and immunohistochemical investigation of the capillary basal membrane in chronic venous insufficiency. Acta Derm Venereol 1996;76:433-6.

14. Coccheri S, Scondotto G, Agnelli G. Aloisi D, Palazzini E. Zamboni V. Randomised, double blind, multicentre, placebo controlled study of sulodexide in the treatment of venous leg ulcers. Thromb Hacmost 2002;87:947-52.

15. Herouy Y, Hellstem MO, Vanscheidt W. Schopf E, Norgauer J. Factor XIII-mediated inhibiton of fibrinolysis and venous leg uleers. Lancet 2000;355:1970-1.

16. Peschen M, Thumm C, Weyl A, Weiss JM, Kurz H, Augustin M, et al. Possible role of coagulaton factor XIII in the pathogenesis of venous leg ulcers. Vasa 1998;27:89-93.

17. Ibbotson SH, Layton AM. Davies JA. Goodfield MJ. The effect of aspirin on haemostatic activity in the treatment of chronic venous leg ulceration. Br J Dermatol 1995:132:422-6.

18. Kolbach DN, van Oerle R. Hamulyák K. Neumann HAM. Prins MH. Local endothelial function and leg symptoms in patients after deep vein thrombosis. In: Joumal of Thrombosis and Haemostasis 2003;1: in press

19. Porter JM. Moneta GL. Reporting standards in venous disease: an update. International Consensus Commuttec on Chronic Venous Disease. J Vase Surg 1995:21:635-45.

20. Ferner C.M, van Geloof WL. de Witte HH, Kramer MD, Ruiter DJ, van Mujen GN. Eprtopes of components of the plasnunogen activation system are re-exposed in formalin-fixed paraffin sections by different retrieval techniques. J Histochem Cytochem 1998;46:469-76.

21. Gibbons J Nonparametric Measures of Association; 1993 
22. Herouy Y. Trefzer D. Hellstern MO, Stark GB, Vanscheidt W, Schopf E, et al. Plasminogen activation in venous leg ulcers. Br J Dermatol 2000;143:930-6.

23. Bugge TH, Flick MJ. Danton MJ. Daugherty CC. Romer J, Dano K, et al. Urokinase-type plasminogen activator is effective in fibrin clearance in the absence of its receptor or tissue-type plasminogen activator. Proc Natl Acad Sci U S A 1996:93:5899-904.

24. Carmeliet P. Collen D. Targeted gene manipulation and transfer of the plasminogen and coagulation systems in mice. Fibrinolysis 1996;10:195-213.

25. Romer J, Bugge TH, Pyke C, Lund LR, Flick MJ, Degen JL, et al. Impaired wound healing in mice with a disrupted plasminogen gene. Nat Med 1996;2:287-92.

26. Bollinger A, Leu AJ. Evidence for microvascular thrombosis obtained by intravital fluorescence videomicroscopy. Vasa 1991;20:252-5.

27. Lowe GD. Rheological influences on thrombosis. Baillieres Best Pract Res Clin Haematol 1999; 12:435-49.

28. Maessen-Visch MB, Hamulyak K, Tazelaar DJ, Crombag NH, Neumann HA. The prevalence of factor V Leiden mutation in patients with leg ulcen and venous insufficiency. Arch Dermatol $1999 ; 135: 41-4$.

29. Hafner J, Kuhne A, Schar B, Bombeli T, Hauser M, Luthi R, et al. Factor V Leiden mutation in postthrombotic and non-postthrombotic venous ulcers. Arch Dermatol 2001:137:599-603.

30. Mackenzie RK, Ludlam CA, Ruckley CV, Allan PL, Burns P, Bradbury AW. The prevalence of thrombophilia in patients with chronic venous leg ulceration. J Vasc Surg 2002;35:718-22. 

Chapter 12

Epilogue and future research 


\section{CLINICAL ASPECTS}

\section{Impact of the post-thrombotic syndrome on daily life}

The occurrence of the post-thrombotic syndrome may dramatically affect the long-term quality of life $\mathrm{e}^{\mathrm{J}}$ and places strain on health care resources. There is a great need for furnishing information to both health care professionals and patients in the area of post-thrombotic syndrome.

\section{Diagnosis of the post-thrombotic syndrome}

The definition of post-thrombotic syndrome is still under debate. Our first step was to evaluate definitions of the post-thrombotic syndrome. We discussed the well-known definitions and presented a pictorial guide for the clinical characteristics. The next step will be to evaluate the usefulness of the definition of Prandoni in daily practice. We expect this definition is a good tool for classification of chronic venous insufficiency as well. Validation of the definition of Prandoni for clinical severity of chronic venous insufficiency has not yet been done and will be necessary. Ideally, a clinical assessment should be accompanied by an objective test that establishes the presence of the post-thrombotic syndrome. The underlying pathophysiological feature of the post-thrombotic syndrome is ambulatory venous hypertension. We have shown that experts in the field give different interpretations of invasive ambulant venous pressure measurement. Hence, a first step would be to establish clear guidelines for the performance and interpretation of this test. Only after that, can non-invasive tools be developed and validated with the optimised invasive venous pressure measurement.

\section{Treatment and prevention with therapeutic elastic stockings}

Elastic therapeutic compression stockings prescribed shortly after the diagnosis of deep vein thrombosis successfully reduced the development of a post-thrombotic syndrome by approximately $50 \%{ }^{2}$. As shown in chapter 7 , the overall use of elastic compression stockings led to a significant reduction, OR $0.31(95 \% \mathrm{Cl} \quad 0.20-0.48)$ in the occurrence of the post-thrombotic syndrome. Although these data are available, still not all physicians incorporate the routine prescription of elastic stockings in their treatment of venous thromboembolism.

In daily practice, patients with deep vein thrombosis should be instructed to wear compression stockings. However, there is a huge diversity in treatment among physicians. In a survey among general practitioners concerning the general management of deep vein thrombosis, compression therapy was not mentioned ${ }^{3}$. Among dermatologists, in the initial, acute phase after deep vein thrombosis, treat- 
ment consists mostly of compression bandages and in the maintenance phase elastic compression stockings are applied ${ }^{+}$. Ambulant therapy for deep vein thrombosis gives a faster resolution of pain and swelling. The risk of pulmonary embolism is not significantly increased by this approach. ${ }^{5}$. As soon as the leg circumference has reduced, several steps should be taken: prescription of stockings specifying brand and classes; instructions about how to put on the stockings and about mobilization at home and what exercises are advised. Furthermore, it is generally known that a substantial proportion of patients do not get stockings prescribed or do not wear their stockings very regularly since the wearing of compression stockings can be troublesome in daily life due to discomfort, warmth, transpiration and adverse cosmetic appearance. This was confirmed in our survey of dermatologists: $47 \%$ of the respondents estimated that the compliance is $30-70 \%, 41 \%$ estimated the compliance $<30 \%$ and $12 \%$ more than $70 \%$. Additionally, after a certain period of time, the stockings will be frayed and worn and the prescription of new stockings will be necessary. However, in the Netherlands, the prescription of new stockings is mainly not based on signs of wear, but occurs after standard periods, which are contracted for in the insurance policy. Due to the diversity of treatment, there seems to be room for improvement. There is little evidence concerning how fast after the deep vein thrombosis stockings should be applied. In daily practice, it is a difficult business to decide which stocking should be prescribed for the individual patient. Every brand has its own different characteristics in hysteresis, slope or stiffness factor, pressure exerted at the ankle region, knitting of the stocking (round- or flat-knitted), and quality of material (silk, cotton, lycra, rubber).

\section{PATHOPHYSIOLOGY}

\section{Macrocirculatory changes}

The underlying pathophysiological feature of the post-thrombotic syndrome is ambulatory venous hypertension, this is for a large part created, in addition to persistent venous obstruction and impaired microcirculation, by valvular destruction in the thrombosed venous segments ${ }^{6}$. Differences in the extent of thrombus resolution leave a variable degree of vein damage, which results in ambulatory venous hypertension. Despite these consequences, prevention of the post-thrombotic syndrome often receives little attention. Only a limited number of studies have been performed to identify risk factors for the post-thrombotic syndrome. The development of ipsilateral recurrent deep vein thrombosis was strongly associated with the risk for the post-thrombotic syndrome (hazard ratio $6.4 ; 95 \%$ CI $3-13$ ) 7 . This finding was confirmed by a study of Van Dongen et al. who also found an increased risk (OR 8.5; 95\% CI 3-29) for patients with an ipsilateral recurrent event ${ }^{8}$. This finding is consistent with the notion that the post-thrombotic syndrome is a conse- 
quence of venous damage and obstruction. Additionally, Van Dongen et al. observed that patients who spent a large amount of their time at less than the therapeutic range of vitamin $\mathrm{K}$ anticoagulant therapy had an almost three time higher risk for the post-thrombotic syndrome. One of the causes of this period of under-treatment could, be non-compliance of the patient with the vitamin $\mathrm{K}$ anticoagulant treatment, which could be a lead for further research for the prevention of the post-thrombotic syndrome. However, several studies about the relationship between compliance and therapeutic quality could not show statistically significant differences. Another antithrombotic therapy, thrombolytic therapy, offers the promise of dissolving the thrombus within the deep venous system, restoring patency and preserving valve function, which would lead to the prevention of the post-thrombotic syndrome ${ }^{9}$. Indeed, long-term follow-up of patients who had participated in a randomized trial on comparing thrombolytic with conventional anticoagulant management suggested that venous valve function can be maintained and the incidence of the post-thrombotic syndrome be reduced with thrombolytic therapy ${ }^{10}$. Unfortunately, thrombolytic therapy carries a three time higher risk for bleeding complications compared to conventional anticoagulant therapy. Moreover, in a decision analysis, " the potential beneficial effect of thrombolytic therapy to prevent the post-thrombotic syndrome did not outweigh the effects of complications of this therapy.

\section{Microcirculatory changes}

Knowledge about the local pathophysiological changes in the different stages of leg symptoms after deep vein thrombosis is lacking. Although the precise microcirculatory events leading to venous ulceration have not been determined, there is general agreement that persistent elevation of ambulatory venous pressure is the driving force leading to the microcirculatory changes associated with venous ulceration. Alterations in cutaneous microcirculatory physiology accompany the formation of a venous ulcer $^{12}$. Pericapillary fibrin deposition, alterations in fibrinolysis and/or plasminogen activation, and microcirculatory leukocyte trapping (with associated cutaneous capillary and lymphatic destruction) all appear to interact in a complex and incompletely defined manner to produce local conditions conducive to ulcer formation.

\section{Innovative treatment of the post-thrombotic syndrome}

Several treatment modalities are used to speed up the healing of leg ulcers, such as topical application of Sulodexide ${ }^{13}$, a glycosaminoglycan and Factor XIII (antifibrinolytic) ${ }^{14,15}$. Furthermore, an increased rate of ulcer healing occurred in patients receiving aspirin ${ }^{16}$. Moreover, with the introduction of new drugs (direct thrombin inhibitors) with a more predictable pharmacokinetic and pharmody- 
namic profile, or a wider therapeutic range, the quality of long-term anticoagulant treatment will improve.

These new treatment modalities not only can be used in treatment of deep vein thrombosis but also in chronic venous insufficiency. Markers of coagulation and fibrinolysis in the microcirculation might be a key to evaluating the potental usefulness of these new drugs in the treatment of the post-thrombotic syndrome.

\section{REFERENCES}

1. Kahn SR, Hirsch A, Shrier I. Effect of postthrombotic syndrome on health-related quality of life after deep venous thrombosis. Arch Intern Med 2002;162:1144-8.

2. Brandjes DP, Buller HR, Heijboer H. Huisman MV, de Rijk M, Jagt H, et al. Randonised trial of effect of compression stockings in patients with symptomatic proximal-vein thrombosis. Lancet 1997:349:759-62.

3. van der Velde EF, Kraajenhagen RA, van Weert HC. Turkstra F. Buller HR. Survey of the management of deep vein thrombosis in general practice in the Netherlands. Neth I Med 2000;57:135-41.

4. Kolbach DN, Hamulyak K. Neumann HA. Prins MH. Therapy of acute deep vein thrombosis and prevention of the post-thrombotic syndrome: A survey among dermatologists in the Netherlands. Phlebologie 2003

5. Partsch $\mathrm{H}$, Blattler $\mathrm{W}$. Compression and walking versus bed rest in the treatment of proximal deep venous thrombosis with low molecular weight heparin. J Vase Surg 2000;32;861-9

6. van Bemmelen PS, Bedford G, Beach K, Strandness DE, Jr. Functional status of the deep venous system after an episode of deep venous thrombosis. Ann Vasc Surg 1990;4:455-9.

7. Prandoni P, Lensing AW. Prins MR. Long-term outcomes after deep venous thrombosis of the lower extremities. Vasc Med 1998:3:57-60.

8. Van Dongen CJ. Prandoni P. Frulla M, Marchion A, Prins MH. Hutten BA. Relation between quality of anticoagulant treatment and the development of a post-thrombotic syndrome, submitted 2003

9. Meissner MH, Manzo RA, Bergelin RO, Markel A, Strandness DE, Jr. Deep venous insufficiency: the relationship between lysis and subsequent reflux. J Vase Surg 1993;18:596-605; discussion 606-8.

10. Schweizer J, Kirch W, Koch R, Elix H, Helliner G, Forkmann L, et al. Short-and long-term results after thrombolytic treatment of deep venous thrombosis. J Am Coll Cardiol 2000:36:1336-43.

11. O'Meara J, 3rd, McNutt RA, Evans AT, Moore SW, Downs SM. A decision analysis of streptokinase plus heparin as compared with heparin alone for deep-vein thrombosis. N Engl J Med 1994:330:1864-9.

12. Gschwandtner ME. Ehringer H. Microcirculation in chronic venous insufficiency. Vase Med 2001:6:169-79.

13. Coecheri S. Scondotto G. Agnelli G. Aloisi D. Palazzini E. Zamboni V. Randomised, double blind, multicentre, placebo controlled study of sulodexide in the treatment of venous leg ulcers. Thromb Haemost 2002:87-947-52

14. Peschen M. Thimm C. Weyl A. Weiss JM, Kurz H, Augustin M, et al. Possible role of coagulation factor XIII in the pathogenesis of venous leg uleer. Vasa 1998;27:89-93. 
15. Herouy Y, Hellstern MO, Vanscheidt W, Schopf E, Norgauer J. Factor XIII-mediated inhibition of fibrinolysis and venous leg ulcers. Lancet 2000;355:1970-1.

16. Ibbotson SH, Layton AM, Davies JA, Goodfield MJ. The effect of aspirin on haemostatic activity in the treatment of chronic venous leg ulceration. Br J Dermatol 1995;132:422-6. 


\section{Summary}

Chapter 1 constitutes a short introduction to the post-thrombotic syndrome (PTS). From a dermatologist's viewpoint this syndrome seemed so simple at a first glance. However, its complexity is highlighted by describing studies dedicated to the diagnosis, prevention and treatment as well as the pathophysiological mechanisms of this syndrome.

\section{PART ONE}

The first part of this thesis deals with the diagnosis of leg symptoms after deep vein thrombosis. Chapter 2 shows a pictorial guide to careful physical examination of the skin of the lower extremity. Those pictures can be used to interpret the signs described in the various definitions of the post-thrombotic syndrome. Chapter 3 describes the interobserver variation between 3 experts by reading Ambulatory Venous Pressure (AVP) from graphs of intravenous pressure measurements. For each observer the association between the presence of post-thrombotic syndrome and the level of AVP readings was statistically significant $(p<0.001)$. Median AVP readings by the 3 experts for all graphs were $51.4,43.0$ and 32.2 , showing systematic differences in the way AVP was estimated. The random interobserver variation was expressed as the standard deviation of the differences in readings by a pair of experts; these standard deviations were 13,10 and $10 \mathrm{mmHg}$, respectively. Even though AVP readings from the 3 experts in this study seemed as correct as those reported in the literature, there is proof of large systematic and random errors in estimating AVP from intravenous pressure measurement graphs. It is likely that other phlebologists would show at least similarly large measurement error. In order to improve the situation, clear reading instructions should be devised, based on consensus between experts in the field of intravenous pressure measurements. Chapter 4 presents the various definitions of PTS that are used and their relationships with invasive venous pressure measurement. In total 124 patients were enrolled of whom both legs underwent a physical examination. Evaluated were the definition of Widmer, the CEAP classification, the Venous Clinical Severity (VCS) score also without compression therapy and the definitions according to Prandoni and Brandjes. Comparison of none, mild-to-moderate and severe scoring was done in 76 legs with invasive ambulant venous pressure measurement. In the DVT legs, $10(7 \%)$ to $29(21 \%)$ were defined as severe PTS, compared to 0 to 4 $(4 \%)$ in the control legs. Mild-to-moderate PTS in the DVT legs ranged from $23 \%$ $-49 \%$, compared to $13 \%-34 \%$ in the control legs. Overall the presence of any PTS in the DVT legs varied from $30 \%$ (VCS without compression) to $6.6 \%$ 
(Brandjes). The scoring systems of Brandjes and VCS showed a tendency towards more legs to be defined as severe PTS. Absolute frequencies of PTS in DVT legs were highest for the classifications according to Widmer, Prandoni and Brandjes. Differences in proportions of any PTS calculated between DVT and control legs varied from $18 \%$ to $39 \%$, while odds ratios varied between 2.2 and 5.2 for the different definitions. The CEAP classification and definition of Brandjes show a moderate relation to Widmer, $\kappa 0.53$ and $\kappa 0.52$, respectively. The VCS shows in all comparisons a poor correlation $(\kappa 0.22-0.41)$. Prandoni has a moderate correlation with most definitions ( $\kappa 0.40-0.44)$. Although all clinical definitions of PTS were highly statistically significantly associated with the gold standard, invasively determined ambulant venous pressure, their ability to discriminate between DVT and control legs as well as the observed prevalence of PTS differed substantially. The definition that combines good discriminatory power with a plausible correlation to the gold standard was the definition of PTS according to Prandoni. Since this definition has known measurement properties, it seems to be the definition of choice for future studies, especially if criteria for the grading of individual elements of the scorings system were to be made explicit.

\section{PART TWO}

The second part of this thesis describes prevention and treatment of the post-thrombotic syndrome. Chapter 5 summarizes the result of a postal questionnaire sent to all of the dermatologists in the Netherlands about the use of compression therapy in the management of deep vein thrombosis. The overall response rate was $81 \%$. Availability of a treatment protocol was indicated by $60 \%$. In the acute phase, treatment was mostly (91\%) initiated by internists, in $70 \%$ of these cases, compression therapy was given by the dermatologist. A clear association $(p<0.001)$ was found between the use of diagnostic procedures by the dermatologist and the prescription of compression therapy. Home treatment protocols were available in $50 \%$; dermatologists were involved in only half of these protocols. The majority of the dermatologists preferred early mobilization, $54 \%$ prescribed class III flat knitted elastic compression stockings for treatment. Our survey indicated that in the Netherlands deep vein thrombosis generally is treated by internists. Compression therapy is still not fully incorporated as a treatment to prevent post-thrombotic syndrome. Involvement of dermatologists in the actual management as well as the development of standardised treatment protocols is limited. Chapter 6 deals with a retrospective study to which extent in the past, bed rest in the care of deep vein thrombosis and pulmonary embolism was given compared to the current situation. To gain better insight into factors underlying the bed rest advice. appropriateness of the patient's hospital stay was assessed by the Dutch Appropriateness Evaluation Protocol. Only $27.1 \%$ of the treatment for deep vein thrombosis was found to be 
appropriate in a hospital setting and related to specific hospital care. The inappropriate stay was mostly related to delays in hospital and discharge procedures. Of the patients with pulmonary embolism, $50.2 \%$ needed hospital stay. This proportion was statistically significantly higher than in deep vein thrombosis patients $(p<$ 0.001 ). The extent of the deep vein thrombosis was not related to the length of bed rest prescribed or mortality. The Dutch Appropriateness Evaluation Protocol was sensitive to identify inappropriate hospital stay in the past within venous thromboembolism patients. Chapter 7 presents a systematic review of the relative effectiveness of, and the rate of complications in using non-pharmaceutical interventions in patients with deep vein thrombosis for prevention of the post-thrombotic syndrome. Three randomised controlled trials on the development of the post-thrombotic syndrome were identified. Two studies compared elastic compression stockings with a pressure of $30-40 \mathrm{mmHg}$ at the ankle with no intervention applied directly after the deep vein thrombosis. The other small study compared elastic compression stockings (pressure $20-30 \mathrm{mmHg}$ ) with one to two sizes too large stockings in patients one year after the deep vein thrombosis. The overall use of elastic compression stockings was associated with a highly statistically significant reduction in the incidence of any post-thrombotic syndrome with an OR of $0.31(95 \% \mathrm{Cl} 0.20-0.48)$. Also the incidence of severe PTS was reduced with OR 0.39 (95\% CI 0.20-0.76). In another randomized controlled trial regarding the first nine days after deep vein thrombosis, no difference in pulmonary embolism and extent of thrombus in the femoral vein was found. A statistically significant reduction $(\mathrm{P}<0.05)$ of pain, swelling and clinical scores was found, favoring the compression group. There is substantial evidence that elastic compression stockings reduced the occurrence of the post-thrombotic syndrome after deep vein thrombosis. No serious adverse effects were mentioned in the studies. Hence, elastic compression stockings should be added to the treatment of deep vein thrombosis in order to prevent the development of the post-thrombotic syndrome. Chapter 8 presents a systematic review to assess the effectiveness of compression therapy in patients with stage I and II post-thrombotic syndrome according to the classification of Widmer. Interventions of interest included elastic compression stockings and mechanical devices, compared with no intervention and with each other. Only two trials were identified that addressed physical treatment of post-thrombotic syndrome. Both trials were initiated by the same group of investigators. A cross-over study lasting two months compared low and high pressure with intermittent compression units for severe post-thrombotic syndrome. This showed a beneficial effect of higher pressures. The second study, in patients with mild to moderate post-thrombotic complaints, showed no effect of elastic compression stockings $(30-40 \mathrm{mmHg}$ at the ankle region) when compared to 'placebo' stockings that were one to two sizes too large. We concluded that there is some evidence of a beneficial effect of intermittent pneumatic compression units, but the study was too small and of too short a duration to draw firm conclusions, Further 
research is needed in order to assess whether intermittent pneumatic compression units give long term reduction and relief of the symptoms caused by post-thrombotic syndrome, and prevent deterioration and leg ulceration. The use of elastic compression stockings to treat post-thrombotic syndrome cannot be supported on the basis of currently available data.

\section{PART THREE}

The third part of this thesis is dedicated to pathophysiological mechanisms of the post-thrombotic syndrome. Chapter 9 reports on a young male patient with venous leg ulcers on both legs that had been refractory for more than 3 years to standard treatment with compression therapy. By thrombophilia screening, factor V Leiden mutation, hyperhomocysteinemia and evidence for impaired fibrinolysis were found. Treatment with folic acid in combination with long term oral anticoagulant therapy were added to non-elastic compression therapy. This combination eventually led to healing of the leg ulcers. During a 6 years follow-up period, no new thromboembolic events occurred, nor was there recurrence of ulcerations. Chapter 10 describes some local aspects of coagulation and fibrinolysis. After ten minutes standing, the increase in vWF:ag $(p=0.004)$ in the leg was higher in patients with previous DVT compared to age and gender matched controls. In DVT patients with PTS systemic vWF antigen was higher in comparison to patients without PTS. Increase in fibrinogen was statistically significantly different in DVT and control groups, $\mathrm{p}<0.001$ and $\mathrm{p}=0.002$, respectively. Factor VIII:c, d-dimer and PAI-I also increased in patients with previous DVT. The mean increase in PAI-1 in DVT and control group was 0.9 and 0.2 , respectively. The higher increase of $\mathrm{vWF}$ in the DVT group indicates, since substantial volumes are accumulated during standing, that local endothelial dysfunction might contribute to differences in coagulation status between patients with DVT and control subjects. Chapter 11 presents, in more detail, coagulation and fibrinolytic protein response of the capillaries in skin biopsies of the lower extremity in patients with and without venous insufficiency. The amount of staining with vWF $(p=0.04)$ and $\mathrm{uPA}(\mathrm{p}=0.02)$ showed statistically significantly differences, PAI-1 $(\mathrm{p}=0.09)$ and $\mathrm{PA}(\mathrm{p}=0.50)$ showed no difference between leg ulcer and control groups. An increase of the number of capillaries with tortuous capillary loops in the papillary dermis was seen, but no statistically significant difference $(M-W$ test, $p=0.10$ ) was found between the groups. Comparison between CEAP classifications showed a statistically significant increased staining pattern of $v W F(p=0.06), u P A(p=0.02)$ and PAI-1 $(p=0.02)$, but not from tPA $(p=0.30)$. We concluded that in skin biopsies of the lower extremities of patients with severe venous insufficiency increased deposition of VWF, PAI-1 and uPA were found in the capillaries. These findings point to a local imbalance in coagulation and fibrinolytic status, which 
might contribute to impaired microcirculation and finally to the development of venous leg ulceration. Chapter 12 gives a general overview of the clinical aspects and the pathophysiology of the post-thrombotic syndrome. The new insights gained with this thesis and the problems still not solved are briefly discussed. Finally, the innovative treatment possibilities with several drugs are described. 


\section{Samenvatting}

In hoofdstuk 1 wordt een korte inleiding over het post-trombotisch syndroom gegeven. Het post-trombotisch syndroom bestaat uit chronische klachten en symptomen na een doorgemaakte diep veneuze trombose. Dermatologisch bezien leek het aanvankelijk een duidelijk probleem. Er zijn echter nog veel onduidelijkheden over de diagnose, de preventie, de behandeling en de pathofysiologische aspecten.

\section{DEEL EEN}

In het eerste deel staat de diagnose van beenklachten na een diep veneuze trombose centraal. Hoofdstuk 2 geeft een beschrijving van de huidafwijkingen die voorkomen in de verschillende definities voor het post-trombotisch syndroom. In hoofdstuk 3 beschrijven we de verschillen tussen drie experts in het aflezen van de ambulant veneuze druk (AVP) uit grafieken, verkregen bij intraveneuze drukmeting. De associatie tussen de diagnose post-trombotisch syndroom en de waarde van de AVP was statistisch significant $(p<0,001)$. Mediane AVP waarden voor de drie experts van alle grafieken waren respectievelijk 51,$4 ; 43,0 \mathrm{en} 32,2 \mathrm{mmHg}$. Dit toont systematische verschillen aan in de beoordeling van AVP. De toevallige fout tussen de verschillende beoordelingen van de drie experts, werd uitgedrukt als de standaard deviatie van de verschillen tussen de afleeswaarden bij een combinatie van twee experts, deze waarden voor de standaarddeviaties waren $13,10 \mathrm{en} 10$ $\mathrm{mmHg}$. Hoewel het aflezen van de AVP door de drie experts even correct lijkt als de afleeswaarden beschreven in de literatuur, is er bewijs voor grote systematische en toevallige fouten in het beoordelen van de AVP. Het lijkt aannemelijk dat andere flebologen een minstens even grote beoordelingsfout zouden kunnen maken. Om deze situatie te verbeteren is het ontwikkelen van duidelijke afleesinstructies voor AVP in grafieken gewenst. Hoofdstuk 4 vermeldt de verschillende klinische definities voor het post-trombotisch syndroom en hun relatie tot de AVP. Bij 124 patienten met een voorafgaande diep veneuze trombose werden beide benen beoordeeld met de volgende definities: de classificaties van Widmer, CEAP, de Venous Clinical Severity score (met en zonder compressietherapie), definities volgens Brandjes en Prandoni. Vergelijking van geen, mild-tot-matig en ernstig post-trombotisch syndroom met de gemeten AVP waarde werd voor 76 benen gedaan. Van de trombosebenen werd $10(7 \%)$ tot $29(21 \%)$ gedefinieerd als ernstig PTS, vergeleken met 0 tot $4(4 \%)$ in de controle benen. Mild-tot-matig ernstig PTS in de trombosebenen verschilde van $23 \%-49 \%$, vergeleken met 
$13 \%-34 \%$ in de controle benen. De prevalentie van PTS in de trombosebenen varieerde van $30 \%$ (VCS zonder therapie) tot $66 \%$ (Brandjes). De scores met de definitic van Brandjes en VCS toonden een tendens tot ernstig PTS. Absolute frequenties van PTS in trombosebenen waren het hoogst voor de classificatie van Widmer, Prandoni en Brandjes. Verschil in aantal PTS berekend tussen tromboseen controlebenen varieerde van $18 \%$ tot $39 \%$, (odds ratios $2,2-5,2$ ) voor de verschillende definities. The CEAP classificatie en definitie van Brandjes toonden een gemiddelde relatie tot Widmer $(\kappa 0,53$ en $\kappa 0,52)$. De VCS toonde in alle vergelijkingen een matige correlatie $(\kappa 0,22-0,41)$. Prandoni had een gemiddelde correlatie met de meeste definities $(\kappa 0,40-0,44)$. Hoewel de klinische definities van PTS een statistisch significante associatie tonen met de gouden standaard (AVP), zijn de verschillen die door de definities tussen trombose- en controlebenen worden aangebracht en de prevalentie van PTS substantieel verschillend. De definitie van Prandoni gaf een duidelijk verschil in wel/niet PTS met een adequate correlatie tot de gouden standaard. Deze definitie is gevalideerd en lijkt hiermee een goede leidraad voor toekomstige studies. Het is zeer belangrijk om de gradering van de verschillende elementen van de definitie duidelijk te omschrijven.

\section{DEEL TWEE}

In het tweede deel worden preventie en behandeling van PTS beschreven. Hoofdstuk 5 geeft de resultaten weer van een schriftelijke enquête onder alle dermatologen in Nederland over het beleid rondom diep veneuze trombose en de plaats van compressietherapie. We hadden een respons van $81 \%$ van de dermatologen. De aanwezigheid van een behandelingsprotocol voor DVT werd aangegeven door $60 \%$. De behandeling in de acute situatie werd in $91 \%$ gedaan door internisten, in $70 \%$ van deze situaties werd compressietherapie gegeven door de dermatoloog. Indien de dermatoloog zelf diagnostisch onderzoek verrichtte bleek dit statistisch significant $(p<0,001)$ gecorreleerd met het voorschrijven van compressietherapie. Een protocol voor thuisbehandeling was in $50 \%$ aanwezig, slechts bij de helft hiervan was de dermatoloog betrokken. De meeste dermatologen geven de voorkeur aan vrocge mobilisatie, $54 \%$ schrijft klasse III kousen voor. Deze enquète liet zien dat internisten in Nederland de hoofdbehandelaars waren. De dermatoloog werd onvoldoende betrokken in de actuele therapie als ook in de ontwikkeling van protocollen voor behandeling. Compressietherapie als preventie voor de ontwikkeling van PTS was onvoldoende opgenomen in de behandeling van DVT. Hoofdstuk 6 is een retrospectieve studie waarmee terecht verblijf in het ziekenhuis voor zowel DVT als longembolie werden beoordeeld met het Appropriateness Evaluation Protocol (AEP), aangepast aan de Nederlandse situatie. AEP toonde aan dat in slechts $27.1 \%$ van de DVT er een noodzaak was voor verblijf in het ziekenhuis. Het onterechte verblijf werd voornamelijk veroorzaakt door vertraging in zieken- 
huis- en ontslagprocedures. De longembolie patiènten blijken in 50,2\% terecht in het ziekenhuis te verblijven. Dit verschil was statistisch significant hoger $(\mathrm{p}<$ $0,001)$. De hoogte van de trombose was noch aan de duur van bedrust noch aan de mortaliteit gerelateerd. De aangepaste AEP was sensitief voor het identificeren van onterecht verblijf. Hoofdstuk 7 is een systematische review naar de relatieve effectiviteit en de mate van complicaties van met medicamenteuze behandelingen bij patiënten met DVT, ter preventie van het ontstaan van PTS. Drie gerandomiseerde gecontroleerde studies naar de ontwikkeling van het PTS werden gevonden. In twee studies werd geen interventie vergeleken met het gebruik van elastische therapeutische kousen $(30-40 \mathrm{mmHg}$ enkeldruk) direct na de DVT. De andere kleinere studie vergeleek bij patiènten 1 jaar na de DVT. elastisch therapeutische kousen (20-30mmHg enkeldruk) met 1-2 maten te grote kousen. In de analyse bleek dat het gebruik van elastisch therapeutische kousen statisch significant geassocieerd was met de incidentie van PTS met een OR $0,31 \quad(95 \%$ CI $0,20-0,48)$. Ook de incidentie van ernstig PTS verminderde met OR 0.39 (95\% $\mathrm{Cl} 0,20-0,76)$. In een andere gerandomiseerde gecontroleerde studie die de eerste 9 dagen na DVT beoordeelde, werd geen verschil in de incidentie van longembolie en uitbreiding van de trombusmassa in de vena femoralis gevonden. In deze studie werd in de compressietherapie groep een statisch significante vermindering (p $<0,05)$ van de pijn, zwelling en klinische verschijnselen gevonden. Wij concludeerden dat er voldoende bewijs is dat het dragen van elastisch therapeutische kousen gedurende 2 jaar na een DVT de incidentie van het PTS vermindert. Hoofdstuk 8 is een systematische review naar de effectiviteit van compressietherapic in patiënten met een stadium I of II PTS volgens de criteria van Widmer. In de vergelijking werden elastisch therapeutische kousen en mechanische compressiemachnes vergeleken met geen interventie en met elkaar. Slechts twee studies van dezelfde onderzoeksgroep voldeden aan de criteria. In een cross-over studie werd een intermitterende compressiemachine met een lage (15 mm Hg) en hoge (60) $\mathrm{mm} \mathrm{Hg}$ ) druk vergeleken bij patiënten met een ernstig PTS. Er was een verbetering in de behandeling met de hoge druk. De andere studie vergeleek elastische kousen (30-40mm Hg enkeldruk) met placebokousen in patiënten met mild-tot matig ernstig PTS. We concludeerden dat er enig bewijs is van het effect van een intermitterende compressiemachine, maar dat de studie te klein was en slechts 2 maanden duurde. Het gebruik van elastisch therapeutische kousen voor de behandeling van PTS kan met de huidige beschikbare gegevens niet worden onderbouwd.

\section{DEEL DRIE}

Het derde deel is gewijd aan pathofysiologische aspecten van het PTS. Hoofdstuk 9 geeft een beschrijving van een jongeman, die ondanks adequate compressiethe- 
rapie een zeer matige genezingstendens van ulcera cruris (open benen) vertoonde. Bij trombofilie onderzoek werd factor V Leiden, hyperhomocysteïnemie en een verhoogde fibrinolytische respons gevonden. $\mathrm{Na}$ toevoegen van foliumzuur en orale antistolling aan zijn behandeling, genazen de ulcera. Hoofdstuk 10 geeft een beschrijving van lokale aspecten van coagulatie en fibrinolyse. Na 10 minuten staan blijkt het verschil in stijging voor vWF:ag $(p=0,004)$ hoger in DVT patiënten vergeleken met controles van dezelfde leeftijd en geslacht. $\mathrm{Bij}$ degenen met PTS van de DVT groep, was de hoogte van het vWF in de circulatie hoger. Verhoogd fibrinogeen was statistisch significant verschillend in de DVT en de controle groep, $\mathrm{p}<0,001$ en $\mathrm{p}=0,002$. Factor VIII:c, d-dimeren en PAI-1 waren ook hoger in de DVT groep. De gemiddelde verhoging in PAI-1 in de DVT en de controle groep was 0,9 en 0,2 . Gezien het veneuze volume dat zich in het been bevindt gedurende staan, is er een forse stijging van vWF in de DVT groep. Endotheel disfunctie kan hierdoor een mogelijke bijdrage leveren in de verschillen in coagulatie tussen DVT en controle personen. Hoofdstuk 11 is een histopathologische studie waarbij coagulatie en fibrinolytische reacties op het niveau van de capillairen werd bekeken in huidbiopten van het onderbeen van patiënten met en zonder veneuze insufficiëntic. De mate van aankleuren met vWF $(p=0,04)$ en uPA $(p=0,02)$ toonde statistisch significante verschillen. PAI-1 $(p=0,09)$ en tPA $(p=0,50)$ waren niet verschillend in de ulcus en controle groep. Er was een verhoogd aantal capillairen met kronkelende uitlopers in de papillaire dermis zichtbaar, maar niet statistisch significant verschillend $(M-W$ test, $p=0,10)$ tussen de groepen. Vergelijking tussen de verschillende CEAP klassen toonde een statistisch significant verhoogd aankleuringspatroon voor $\mathrm{vWF}(\mathrm{p}=0,06), \mathrm{uPA}(\mathrm{p}=0,02)$ en PAI-1 $(p=0,02)$, maar niet voor tPA $(p=0,30)$. We concludeerden dat bij patiënten met chronisch veneuze insufficientie in de microcirculatie van de huid ter hoogte van de enkel, vWF, PAI-1 en uPA in verhoogde mate tot expressie komen. Deze bevindingen kunnen wijzen op een lokale verstoring van de balans tussen coagulatie en fibrinolyse, wat kan leiden tot veranderingen in de microcirculatie en tenslotte tot een ulcus cruris. Hoofdstuk 12 is een overzicht van de klinische aspecten en de pathofysiologie van het post-trombotisch syndroom. Nieuwe inzichten verkregen door dit proefschrift en de nog op te lossen problemen worden kort besproken. Tenslotte wordt nog een korte introductie van mogelijke medicamenteuze behandeling gegeven. 


\section{Dankwoord}

Bij het tot stand komen van een proefschrift zijn heel veel mensen direct en indirect betrokken. Het persoonlijk bedanken van iedereen, die een steentje aan mijn proefschrift heeft bijgedragen, is welhaast onmogelijk. Het waren er velen. Ik ga proberen om zoveel mogelijk mensen te noemen. Allereerst natuurlijk alle patienten en proefpersonen die hebben deelgenomen aan mijn studies. Het contact met $u$. jullie was geweldig leuk, de bereidheid om mee te werken was fantastisch. Het post-trombotisch syndroom is een probleem waar nog veel onderzock naar gedaan moet worden. Door jullie bereidheid om vragenformulieren in te vullen en de vele metingen te laten verrichten is er weer een klein deel van de puzzel ingevuld.

Bij mijn promotie heeft mijn promotor prof.dr. M.H. Prins de belangrijkste rol gespeeld, beste Martin, het werken met jou is heel stimulerend, je hebt een geweldige kennis op het gebied van de epidemiologie en de veneuze tromboembolie in het bijzonder. De wyze waarop je mijn ideeen op dit gebied ondersteunde heeft mij doen groeien in dit wetenschappelijk onderzoek. De nauwkeurigheid en snelheid waarmee je mijn artikelen corrigeerde zijn onvoorstelbaar. Het voortzetten van onze samenwerking verheugt mij dan ook zeer.

Prof.dr. H.A.M. Neumann, beste Martino, je geloofde in mij, was vanaf onze eerste kennismaking bereid om in mij te investeren. Mijn wens om te promoveren heb ik in de lange periode tot aan het afronden van mijn opleiding als dermatoloog uiteindelijk toch gerealiseerd. Jouw visie op het post-trombotisch syndroom en je ideeën over microcirculatie liggen ten grondslag aan dit proefschrift. Dank voor het vertrouwen in de goede afloop.

Mijn co-promotor dr. K. Hamulyák, beste Karly, al die jaren gaf je mij adviezen en corrigeerde mijn artikelen, jouw vertrouwen heeft me gesteund.

For prof.dr. H. Partsch: Dear Hugo, Thank you so much for taking part in my committee. I would like to gratefully acknowledge your invaluable assistance because you are the expert on the post-thrombotic syndrome. You began as one of the first research-workers in the field of phlebology: you have continued to do research on ambulant compression therapy for many years; and moreover, you understand the importance of the statistical analysis of data. I am very pleased to have had your help as expert and co-author of chapter 3. In my forthcoming projects, I will take your suggestions into account with respect to the definition of 
how to read AVP measurements. I'm thankful that our cooperation in research will carry on.

Prof.dr P.M. Steijlen, beste Peter, bedankt voor je begrip en de ruimte die je me gelaten hebt om te promoveren. Dat jij de voorzitter van mijn beoordelingscommissie bent, stel ik erg op prijs.

Prof.dr. H. Buller, bedankt voor uw bereidheid om in mijn beoordelingscommissie zitting te nemen. Dat u daarna ook nog op het symposium spreekt vind ik geweldig.

Prof.dr. H. ten Cate, beste Hugo, in de laatste fase van mijn onderzoek ben je in Maastricht gekomen, waar je als lid van de beoordelingscommissie je visie over mijn proefschrift hebt gegeven. Hopelijk zullen we in de toekomst samen verder werken aan onderzoek op het gebied van het post-trombotisch syndroom. De eerste stap is het symposium.

Dr. E.M.J. de Boer, beste Edith, jij hebt mijn enthousiasme voor de dermatologie gewekt. Ik vind het dan ook heel bijzonder dat je in mijn corona zitting hebt.

Prof.dr. J.H. Kuiper, bedankt voor uw snelle en accurate manier van samenwerken in hoofdstuk 3.

Pieter Leffers, het was erg leerzaam en aangenaam om met je van gedachten te wisselen, bedankt voor je hulp.

René van Oerle, dankzij jou heb ik een beter begrip van de stolling. Je hebt me fantastisch geholpen. De bloedafnames bij de invasieve drukmeting waren samen met jou veel gemakkelijker te doen.

Bert Panis, onze kennismaking was heel bijzonder. Je was er als de kippen bij toen je hoorde dat ik gebruik maakte van DAEP criteria voor mijn onderzoek. We besloten samen verder te gaan, waarna je opnieuw alle statussen doorkeek, waardoor het echt jouw onderzoek werd. Toen je ook nog dezelfde promotor bleek te hebben, werd ons contact nog intensiever.

Jacques Cleutjens, na enige omzwervingen van mijn biopten kwam ik bij jou terecht met mijn vraagstelling. Het zoeken van de juiste antilichamen kostte tijd, die we gezamenlijk in het laboratorium doorbrachten. Daarna samen met Coby de finale proeven. Bed.ankt voor jullie hulp. Graag doe ik bij volgende studies weer een beroep op jullie. 
Lidwine Tick, de Mega-PTS studie bracht ons samen. Een gedeelte van de metingen voor mijn dwarsdoorsnede onderzoek heb je samen met mij, Ria Sandbrink en Daniel Oser gedaan. Helaas door alle problemen rondom de validatie en het faillissement van Domed zijn deze resultaten nog niet verwerkt. Toch bedankt voor je hulp en steun bij mijn onderzoek.

Ria Sandbrink, mijn paranimf, je bent geweldig. Jouw aanbod om mij te helpen heb ik direct omarmd. Je onuitputtelijke kennis van excel en andere computersoftware heeft mij heel veel tijd bespaard. Jouw visie als bedrijfsarts op de problemen na diep veneuze trombose leidde ertoe dat mijn onderzoek ons onderzoek werd. Het is mij dan ook een groot genoegen om je straks bij jouw promotie te mogen helpen. Ik hoop dat we nog lang vriendinnen blijven.

Caroline Vos, mijn paranimf, we zijn een geweldig team bij het organiseren van allerlei activiteiten. Het zoveelste symposium regelen is dan ook geen probleem. Het maken van een website? Och, dat kan Ali wel doen. Bedankt voor jullie vriendschap en de samenwerking op vele fronten.

Eddie Vanderweijer, een betere buurman en vriend kan ik mij niet wensen. De vele evenementen die je organiseerde (skivakantie, champagneweekend, gewoon gezellige dingen) waren voor mij altijd weer welkome momenten van ontspanning tijdens de afgelopen hectische periode. Je bent een van de belangrijkste mensen uit mijn vriendenkring. Ik stel het dan ook erg op prijs dat je de organisatie van het feest op je genomen hebt. In feite ben jij ook een van mijn paranimfen.

Sylvia Schins en Marianne van Gemert, jullie hulp bij de dataverwerking was heel efficiènt en heeft me veel tijd bespaard. Bedankt.

Mark Dresen, als student maakte je voor mij een DVT database. Door de jaren heen heb je mij geholpen bij allerlei hardware en software problemen. Ik hoop dat onze vriendschap nog lang zal duren.

Appie Derks en Geertjan van Zonneveld, samen met jullie werken aan de foto's was een feest voor mij. Ik ben trots op het eindresultaat. Dank voor jullie onaflatende inzet.

Sherrie Saive: Dear Sherrie, thank you very much for your help. I enjoyed our conversations about all kinds of problems, not just those as a dermatologist and research-worker, but also as a mother, a wife and a woman.

Het doen van onderzoek leidt tot vele vragen, organiseren van allerlei afspraken, verzenden van vele brieven en altijd weer opnicuw zoeken naar oplossingen. 
Oplossen van al deze problemen was alleen maar mogelijk dankzij de hulp van Petra, Annelies, Ingrid, Nicole, Els, Kim, Lilian Kreusch, Irene van Hoof en Wil Lokkerbol. Jullie zijn goud waard.

Anita, Marie-Paulle, Irene, Germaine, Marlene, Paulette, Frits, Janneke, Nelleke, Brigitte, Mieke, Pascalle, Patricia, Anouk, Gerda, Anke, Fiona, en Frida wil ik heel hartelijk bedanken voor de hulp bij mijn onderzoek en het organiseren van de patiëntenstroom op de polikliniek.

Staf dermatologie en arts-assistenten, Joep, Gertruud, Anja, Judith, Monique, Charles, Pierre, Kees-Peter, Françoise, Adriënne, Carmen, Patricia, Nicole, Jeroen, Yolande, Saskia, Daniëlle en José, bedankt voor de tijd en ruimte die jullie mij voor het onderzoek hebben gegeven.

Het contact, de belangstelling en de financiële ondersteuning van vele medewerkers van de farmaceutische industrie heb ik zeer gewaardeerd. Twee mensen wil ik in het bijzonder noemen: Pascal Herveille je hulp bij de metingen was heel erg welkom. Dan Marc Ditmarsch, jij hebt echt indruk op me gemaakt. Nadat je me een half uur kende was je al bereid om twee huidbiopten af te staan voor mijn onderzoek. Ja, je benen zal ik blijven bewonderen.

Ook de hulp en het begrip van mijn vrienden, mijn familie en schoonfamilie voor de enorme hoeveelheid werk die promoveren met zich meebrengt zijn hartverwarmend. De bereidheid om Klaas en Adriaan op te vangen was er altijd en ik kan iedereen daar niet genoeg voor bedanken. In het bijzonder wil ik mijn schoonmoeder, Ankie en Adriaan, Ron en Marga, en niet te vergeten Miets bedanken. Pa en Moeke, dat jullie trots op me zijn weet ik zeker.

Tenslotte, maar zeker niet in de laatste plaats wil ik de niet aflatende steun van Peter noemen, zijn begrip voor mijn wens om te promoveren en de ruimte die hij, samen met Klaas en Adriaan, voor mij creëerde was grenzeloos. Ik houd van jullie. 


\section{Curriculum Vitae}

Dinanda Nicolina Kolbach was born on 10th January, $196+$ in Rijswijk (NBr), in the Netherlands. She attended secondary school at the "Oude Hoven" in Gorinchem from 1976 to 1983 . In 1983 she started her medical education at the Free University in Amsterdam, where she obtained her medical degree in June 1990.

Following that, she worked in a number of different centres in order to gain practical experience and to share her knowledge by teaching. She worked from July 1990 till April 1991 at the research laboratory of the Department of Dermatology of the Free University in Amsterdam and during the same period taught Surgery. Anatomy and Physiology at a nurse's training course in Bussum. From May 1991 till May 1992 and during the summer period of 1993, she worked as a resident Dermatologist in Velsen as well as in the Medical Centre Alkmaar. From May 1992 till January 1994 she was a resident in Internal Medicine at the "Onze Lieve Vrouwe Gasthuis" in Amsterdam.

These experiences developed her interest in research, and she became involved in a number of research projects in different services with a view to writing a thesis. From September 1993 till January 1994 she participated in a research project on the pathology of AIDS related Kaposi Sarcoma with the Veneral Diseases Department of the Erasmus Medical Centre in Rotterdam under the supervision of Prof.dr. E. Stolz, head of the department. From 1994 till 1996, she became affiliated as research-clinician at the Municipal Health Service in Amsterdam, of which Prof.dr. R. Coutinho is head of Department, with the mission of studying the prevalence, incidence and risk factors for HIV infection on a group of homosexual men and in addition, studying the natural course of HIV infection.

Finally in September 1996, she started as a scientific researcher on the subject of the post-thrombotic syndrome at the Department of Dermatology in the Maastricht Academic Hospital. From March 1998 till February 2003 she was trained in Dermatology and Phlebology, by the head of the Department, Professor Martino Neumann. She was likewise trained as a Clinical Epidemiologist by Professor Martin Prins at the Department of Clinical Epidemiology and Medical Technology Assessment, at the University of Maastricht. After her registration as dermatologist, she began writing her thesis, concentrating her work on patients diagnosed with deep vein thrombosis, who were, for the most part, undergoing treatment at the Hematology and Dermatology Department of the Maastricht Academic Hos- 
pital. During this time, she continued working in several Dermatology Departments as a Dermatologist, i.e.: the Viecurie Medical Centre in Venlo, the Kraaiennest in Amsterdam, the Catharina Hospital in Eindhoven and the Walcheren Hospital in Vlissingen.

Additional activities have included holding the position of secretary of the Royal Dutch Medical Association (KNMG) in Amsterdam from 1990 till 1995 and from 1996 till 2003 of the KNMG in Maastricht. Since 1996, she has been a member of the executive committee of the "Kamer Dienstverband, Orde van Medisch Specialisten".

More information about the author of this thesis and her research work can be found on www.ptsinfo.nl.

She is married to Peter de Feiter, surgeon-intensivist, and has two children, Klaas and Adriaan, with whom she resides in Eijsden, Limburg. 


\section{List of publications}

\section{INTERNATIONAL JOURNAL REFERENCES}

Kolbach DN, Nieboer C. Fumaric acid therapy in psoriasis: results and side effects of two years of treatment. J Am Acad Dermatol 1992;27:769-771.

Kolbach DN, Jonkman M, Remme JJ. Jong de MCJM, Pas H, Meer van der JB. Bullous pemphigoid succesfully controlled by oral treatment with Tetracycline and Niacinamide. Br J Dermatol 1995;133:88-90.

Wolthers KC, Otto SA, Lens SMA, Kolbach DN. Lier RAW. Miedema F, Meyaard L. Increased expression of CD80, CD86 and CD70 on T cells from HIV infected individuals upon activation in vitro: regulation by CD4+ T cells. Eur J Immunol 1996;26:1700-06.

Groot DWAA, Kolbach DN, Prenger K, Neumann HAM. Compression therapy of the legs after harvesting the long saphenous vein for coronary artery bypass graft surgery. Scripta phlebologica. 1999:7:30-33.

Kolbach DN, Veraart JCJM. Spaapen LJM. Neumann HAM. Trombose: denk ook aan hyperhomocysteinemie. Scripta Phlebologica 1998;6:5-7.

Kolbach DN, Kockaert MA. Veneuze malformatie. Scripta Phlebologica 2000; 8:36-38.

Kolbach DN, van Neer PAFA. Varicosis manuum, case report. Scripta Phlebologica 1999;7:38-39.

Jacobs JA, Kolbach DN, Vermeulen AH, Smeets $\mathrm{MH}$, Neumann HAM. Tinea incognito due to Trichophyton rubrum after local steroid therapy. Clin Infect Dis 2001, 33 (12) E142-4.

Kolbach DN, Veraart JCJM, Hamulyák K, Spaapen LJM, and Neumann HAM. Recurrent leg ulcers in a young man with hyperhomocysteinemia, factor $\mathrm{V}$ Leiden and impaired fibrinolysis. Acta Dermatol Venerol (Scand), 2002;81:52-54. 
Kolbach DN, Hamulyák K, Prins MH, Neumann HAM. Therapy of acute deep vein thrombosis and prevention of post-thrombotic syndrome: a survey among dermatologists in the Netherlands. Phlebologie 2003;32:45-9.

Kolbach DN, Sandbrink MWC, Hamulyák K, Neumann HAM, Prins MH. Non-pharmaceutical measures for prevention of post-thrombotic syndrome. (review) Cochrane Collaborative Review Group on Peripheral Vascular Diseases. In: The Cochrane Library, issue 3, 2003. Oxford Update Software.

Kolbach DN, Sandbrink MWC Neumann HAM, Prins MH. Compression therapy for treating stage I and II (Widmer) post-thrombotic syndrome. (review) Cochrane Collaborative Review Group on Peripheral Vascular Diseases. In: The Cochrane Library, issue 3, 2003. Oxford Update Software.

Kolbach DN, Oerle R van, Hamulyák K, Neumann HAM, Prins MH. Endothelial function and leg symptoms after deep vein thrombosis. Journal of Thrombosis and Haemostasis 2003:1: in press.

Kolbach DN, Hamulyák K, Prins MH, Neumann HAM, Cleutjens JPM. Severity of venous insufficiency is related to the density of microvascular deposition of PAI-1, uPA and von Willebrand factor. VASA 2004, in press.

Kolbach DN, Prins MH. Rutosides in the prevention of the post-thrombotic syndrome. (title) Cochrane Collaborative Review Group on Peripheral Vascular Diseases. In: The Cochrane Library, issue 3, 2003. Oxford Update Software.

Kolbach DN, Prins MH. Rutosides in the treatment of the post-thrombotic syndrome, (title) Cochrane Collaborative Review Group on Peripheral Vascular Diseases. In: The Cochrane Library, issue 3, 2003. Oxford Update Software.

Panis LJGG, Kolbach DN, Hamulyák K, Prins MH. Identifying inappropriate hospital stay in patients with venous thromboembolism. Submitted for publication.

Kolbach DN, Neumann HAM, Prins MH. Definitions of the post-thrombotic syndrome: a comparison with invasive venous pressure measurement. Submitted for publication.

Kolbach DN, Leffers P. Neumann HAM, Kuiper JP. Partsch H, Prins MH. Interobserver variation in reading ambulant venous pressure from invasive venous pressure curves. The need for clear guidelines. Submitted for publication. 


\section{NATIONAL JOURNAL REFERENCES}

Kolbach DN. Fumaarzuur en vitamine D3 als behandelingsmogelijkheden bij psoriasis. Nieuwsbrief Psoriasisvereniging Noord-Holland: 1991.

Kolbach DN. Traumatische arterio-veneuze malformatie. Ned T Dermatol Venereol 1998;8:131.

Kolbach DN, Boer J. Jonge patiënt met chronisch recidiverende ulcera crurum: hyperhomocysteinemie en heterozygoot factor V Leiden. Ned T Dermatol Venereol 1998;8:125-6.

Kolbach DN, Vos MC. Verdwenen leden. Ingezonden brief Medisch Contact 2000;55:1223.

Kolbach DN en Neumann HAM. Diagnose in beeld (38). Contactallergie voor colofonium. Ned Tijdschr Geneeskd 2001;145:955.

Kolbach DN en Neumann HAM. Diagnose in beeld (96). Een jongen met 'wasbordnagels'. Ned Tijdschr Geneeskd 2002;146:1321.

Kolbach DN. Diagnostiek en beleid ter voorkoming van het post-trombotisch syndroom. Ned Tijdschr Derm Venereol 2002;12:171-173.

Kolbach DN. De verschillende stadia van incontinentia pigmenti. Ned Tujdschr Derm Venereol 2002;12:155-6.

Kolbach DN. Klinische aspecten van het post-trombotisch syndroom. Tromnibus 2003:31: 25-28.

Sandbrink MWC, Kolbach DN. Diep veneuze trombose en de bedrijsarts, Submitted for publication.

\section{ABSTRACTS}

Kolbach DN, Nieboer C. Fumaric acid therapy in psoriasis, long term retrospective study on the effect of fumaricacid combination therapy and dimethylfumaric acid monotherapy. Br J Dermatol 1990;123:534-35.

Kolbach DN Long-term survivors of HIV-1 infection: impact of different case definitions. Abstractboek Onderzoekschool infectic \& immuniteit 1995 
Kolbach DNLong-term survivors of HIV-1 infection: impact of different case definitions (WEON). IEA regional meeting Perspectives on epidemiology in Europe 1995.

Kolbach DN, Boer J. Jonge patiēnt met chronisch recidiverende ulcera crurum: hyperhomocysteinemie en heterozygotie voor factor V Leiden. Ned Tijdschr Geneesk 1998;142:2706-07.

Kolbach DN. Prospectief gerandomiseerde studie naar compressietherapie bij diep veneuze trombose in het acute stadium. Programmaboek $9 \mathrm{e}$ vergadering NWO-werkgroep Huid 4-5 febr 1999.

Kolbach DN, Veraart JCJM, Boer J. Spaapen LJM, Hamulyák K, Neumann HAM. Severe post-thrombotic syndrome in a young patient with Hyperhomocysteinemia and Factor V Leiden. Neth J Med 1998:52:S26.

Kolbach DN. Hyperhomocysteinemia and Factor V Leiden associated with severe post-thrombotic syndrome in a young patient. Thromb Haemost 1998;397 suppl 2: 28 .

Kolbach DN, Veraart JCJM. Hamulyák K, Spaapen LJM, Neumann HAM. Recurrent leg ulcers based on severe post-thrombotic syndrome in a young patient with hyperhomocysteinemia, factor V Leiden and impaired fibrinolysis. International Angiology:2001:20 suppl.1 to no 2:369.

Kolbach DN, Neumann HAM. Survey of the prevention of post-thrombotic syndrome among dermatologists in the Netherlands. Phlebologie 2002;31:a29-30.

Kolbach DN, Oerle R van, Hamulyák K, Neumann HAM, Prins MH, Local changes in coagulation and fibrinolysis in patients with a previous deep venous thrombosis. Journal of Thrombosis and Haemostasis 2003; 1 Supplement 1 July: abstract number 496.

Kolbach DN, Prins MH. Definitions of the post-thrombotic syndrome: a comparison with invasive venous pressure measurement. Journal of Thrombosis and Haemostasis 2003: 1 Supplement 1 July: abstract number 3014.

Kolbach DN, Oerle R van, Hamulyák K, Neumann HAM, Prins MH. Local endothelial function and leg symptoms in patients after deep vein thrombosis. UIP worldeongress 2003, San Diego: abstract 0005. 
Kolbach DN, Prins $\mathrm{MH}$. The inter-observer variability of invasive pressure measurement in the dorsal foot vein. UIP worldcongress 2003, San Diego: abstract 0148 .

Kolbach DN, Prins MH. Definitions of the post-thrombotic syndrome: a comparison with invasive venous pressure measurement. UIP worldcongress 2003, San Diego; abstract 0004 .

Kolbach DN, Prins $\mathrm{MH}$. Elastic compression stockings in the prevention of the post-thrombotic syndrome after deep vein thrombosis: a meta-analysis. UIP worldcongress 2003, San Diego; abstract 0147.

Kolbach DN, Prins MH. Treating stage I and II (Widmer) post-thrombotic syndrome with compression therapy; evidence based? UIP worldcongress 2003, San Diego; abstract 0182. 
